\title{
EVALUATION OF SOME NUMERICAL TECHNIQUES FOR DETERMINING PALEOTEMPERATURES FROM PLANKTONIC FORAMINIFERAL ASSEMBLAGES
}

\author{
José M. GONZÁLEZ-DONOSO and Dolores LINARES \\ Departamento de Geología. Facultad de Ciencias, Universidad. 29071 Málaga. Spain.
}

González-Donoso, J.M. and Linares, D. 1998. Evaluation of some numerical techniques for determining paleotemperatures from planktonic foraminiferal assemblages. Revista Española de Paleontología, 13 (1), 107 129. ISSN 0213-6937.

\begin{abstract}
This study evaluates the results of various numerical techniques intended to estimate environmental variables from the composition of associations of organisms in sediment samples. An analysis is made of various transfer functions (species regression technique, 13 variants; weighted average technique, 8 variants; principal component regression technique, 270 variants; discriminant analysis technique, one procedure) and of the modern analog technique (11 variants). The initial point is the calibration data set composed of the associations of planktonic foraminifera contained in 605 core-top samples from the North Atlantic and the Mediterranean, together with the corresponding sea surface winter temperatures. To compare the results of the various techniques, the calibration data set is randomly divided into two subsets of 450 and 155 samples, respectively. The former is used as the provisional calibration data set; this is used to estimate the winter temperatures of the subset of 155 samples (the analog set) and of another set, formed of 27 samples from the South Atlantic and the Indian Ocean (no-analog set). After evaluating the errors of the estimate of the different techniques, the best ones are selected. The provisional calibration data set is randomly divided into three new sets of 150 samples, each of which is estimated by the techniques selected in the first experiment, with the remaining 455 samples being used as the provisional calibration data set. The evaluation of the errors of the estimate of the four experiments together leads us to the conclusion that, among the transfer functions, the best for the analog set is a principal component regression technique based on an R-mode analysis of the correlation matrix, with retention of the first 9 non rotated principal components; for the paleoecological equation, the nonlinear equation of the second degree is used. For the no-analog set, the best technique is the one using the variance - covariance matrix, the first 6 non rotated principal components and a linear equation. Of the modern analog techniques, the best ones use the squared chord distance as the dissimilarity coefficient and the inverse distance squared weighting function (for the analog set) or the chord similarity measure weighting function (for the no-analog set). On comparing the results of the two groups of techniques, the modern analog technique is seen to be superior.
\end{abstract}

Keywords: Modern analogs, transfer functions, species regression, weighted average, principal component regression, discriminant analysis, planktonic foraminifera, environmental variables.

\section{RESUMEN}

En este estudio se evalúan los resultados de varias técnicas numéricas destinadas a estimar los valores de variables ambientales a partir de la composición de las asociaciones de organismos contenidas en muestras sedimentarias. Se han analizado los resultados de funciones de transferencia ( 13 variantes de la técnica de la regresión de especies, 8 variantes de la técnica de la media ponderada, 270 variantes de la técnica de la regresión de componentes principales y un procedimiento de la técnica del análisis discriminante) y de técnicas basadas en la detección de análogos modernos (11 variantes). El punto de partida es un conjunto de datos de calibración formado por las abundancias relativas de 26 especies de foraminíferos planctónicos en las asociaciones de foraminíferos planctónicos contenidas en muestras de 605 cimas de sondeos procedentes del Atlántico $\mathrm{N}$ y del Mediterráneo, y las correspondientes temperaturas invernales de las aguas superficiales. Para comparar los resultados de las distintas técnicas se dividió aleatoriamente el conjunto de calibración en dos subconjuntos de 450 y 155 muestras, respectivamente. El primero se utilizó como conjunto de calibración provisional para estimar las temperaturas invernales del subconjunto de 155 muestras (para simular un conjunto análogo) y de otro conjunto de 27 muestras procedentes del Atlántico S y del Índico (como conjunto no análogo). Tras evaluar los errores de la estimación correspondientes a las diferentes técnicas, se seleccionaron las mejores. A 
continuación, se dividió aleatoriamente el conjunto de calibración provisional en tres nuevos subconjuntos, y se estimaron las temperaturas invernales de cada uno de ellos con las técnicas seleccionadas en el experimento anterior, utilizando como conjunto de calibración las 455 muestras restantes. La evaluación de los errores de las estimaciones de los cuatro experimentos reunidos nos lleva a la conclusión de que la mejor función de transferencia es, para el caso de un conjunto análogo, la técnica de componentes principales basada en el modo R de la matriz de correlaciones, con retención de los nueve primeros componentes principales no rotados, y, como ecuación paleoecológica, la de segundo grado. En el caso del conjunto no análogo, la mejor función de transferencia se basa también en un modo R, pero de la matriz de varianzas y covarianzas, con retención de los seis primeros componentes principales no rotados y una ecuación lineal. En cuanto a las técnicas de los análogos modernos, los mejores resultados se logran utilizando, como coeficiente de disimilaridad, la distancia de la cuerda al cuadrado, y, como función de ponderación, la inversa de la distancia al cuadrado para un conjunto análogo, y la medida de similaridad de la cuerda, para un conjunto no análogo. Tras comparar los resultados de ambos grupos de técnicas, las de análogos modernos parecen ser mejores.

Palabras clave: Análogos modernos, funciones de transferencia, regresión de especies, media ponderada, regresión de componentes principales, análisis discriminante, foraminíferos planctónicos, variables ambientales.

\section{INTRODUCTION}

Since the late 1960 s, various numerical techniques have been suggested to estimate the values of environmental variables in the past, based on the relation between the composition of assemblages of contemporary organisms and the values of the environmental variables within a set of observations, the calibration data set (Berger, 1969; Imbrie and Kipp, 1971; Hecht, 1973; Williams and Johnson, 1975; Berger and Gardner, 1975; Hutson, 1977, 1980). Although all the techniques examined in this study were designed to calculate the values of oceanographic variables (particularly sea surface temperatures) based on the composition of the assemblages of planktonic foraminifera, they can be applied to other organisms and/or other environments.

Numerical techniques of this type can be divided into two groups.

a) Transfer function techniques (including species regression, weighted average regression, principal component regression and discriminant analysis) start with the calculation, from the calibration data set, of the parameters of an empirical equation to estimate the values of the environmental variable, which is derived from the percentage composition of the assemblages, in their initial state, or after being submitted to different transformations. The subsequent step, after the transformation of the percentage composition of the fossil assemblage, if required by the technique employed, is the application of this equation to infer the corresponding value of the environmental variable.

b) Modern analog techniques, based on a direct transfer, assign to the fossil sample the average (weighted or unweighted) of the values of the environmental variable within the subset of samples of the calibration data set that are, in faunal terms, most similar (or least dissimilar) and are, therefore, conceptually simplest.

The inevitable question arises: which is the better technique? There are conflicting conclusions from researchers who have compared the results of two or more methods. Hutson (1977) prefers weighted regression, while Prell (1985) and Pflaumann et al., (1996) favour modern analog techniques; Le (1992), however, is inclined towards principal component regression. This paper evaluates the results of the above techniques, using a calibration data set covering the North Atlantic and the Mediterranean. These techniques are applied to two sample sets, one of (partial) analog conditions and another of no-analog conditions.

\section{BASIC PROBLEMS AND ANTECEDENTS}

\section{ASSUMPTIONS IMPLICIT IN THE TECHNIQUES}

To apply any of these techniques, a series of general assumptions must be made about the relations within the calibration data set and about those between the latter and the fossil assemblage (Imbrie and Kipp, 1971; Imbrie et al., 1973; Hutson, 1977; Imbrie and Webb, 1981; Prell, 1985; Thunnell, 1979; Dowsett and Poore, 1990; Le, 1992; Maslin et al., 1995). In the case of the modern analog technique, the general assumption is that the more similar two samples are in faunal composition the closer are the respective values of the environmental variable in the habitat of the biocoenoses from which they proceed. In the case of the transfer function techniques, the first and most general assumption is that the composition of the assemblages of the sediment surface is systematically related to the physical nature of the medium lived in by the organisms that produce them (Imbrie and Kipp, 1971). But the question is not straightforward and is further complicated when the all-embracing term "physical nature of the medium" must be substituted by "environmental variable":

- Firstly, one must suppose that the environmental variable is (or is linearly related to) a variable that is ecologically important to the group of organisms. In principle, this assumption poses no great problem for the case here studied: sea surface temperatures and planktonic foraminifera.

- Secondly, the composition of the assemblage is expressed in terms of the relative abundances of its 
elements. However, the relative abundance of an element within an assemblage depends on its absolute abundance and on the absolute abundances of the other elements, irrespective of whether there is any kind of biological relation with them. Ideally, the start point would be the relation between the absolute abundance of each element and the values of the environmental variable in the calibration data set. Obviously, however, this is not possible as the absolute abundance of an element within a sample depends on three factors that may be totally unrelated: the rate of production of the element by the biocoenoses, the rate of sedimentation of the other components of the sediment (organic and inorganic) and taphonomic alteration. Consequently, calibration must be performed on relative abundance and not with biocoenoses but with taphocoenoses.

- Thirdly, the composition of the assemblage depends on not just one, but a set of environmental and taphonomic variables. This problem may be resolved by transforming the data for assemblages into single-variable values that may be assumed to act as the independent variable of an equation -whether linear or otherwiseestimating the environmental variable (e.g., in the weighted average regression technique) or into contributions to each assemblage by a series of orthogonal components -theoretical assemblages- the number of which must be greater than that of the environmental variables assumed to have influenced the composition of the real assemblage (principal component regression technique, Imbrie and Kipp, 1971; Imbrie et al., 1973).

Additionally, the application of any numerical technique (transfer function or modern analog technique) requires two more assumptions to be fulfilled:

- Fourthly, that the fossil assemblage is located within the hypervolume occupied by the calibration data set in the hyperspace whose axes are the elements of the assemblages (i.e., to use the terminology of Hutson, 1977, that the fossil assemblage is a biological analog). This assumption is very difficult to test, except in the case where the relative abundance of a species within a fossil assemblage exceeds the maximum value measured in the calibration data set. When this is not so, there exists the risk of the transfer function producing anomalous results due, for example, to an extrapolation resulting in the overestimating or underestimating of the values of the environmental variable. Of the transfer functions, only the weighted average regression technique avoids this problem (Hutson, 1977); the modern analog technique, because of its methodology, will also be unaffected by it.

- Fifthly, that the elements (normally species) of the fossil assemblage are also part of the assemblages of the calibration data set. This assumption is a taxonomic hypothesis; the failure of this might derive from phenomena of homeomorphy. This leads to another question: is it possible to apply one of these numerical techniques if the fossil assemblage contains species that are currently absent, whether by extinction, or by phyletic evolution, or if the calibration data set contains species

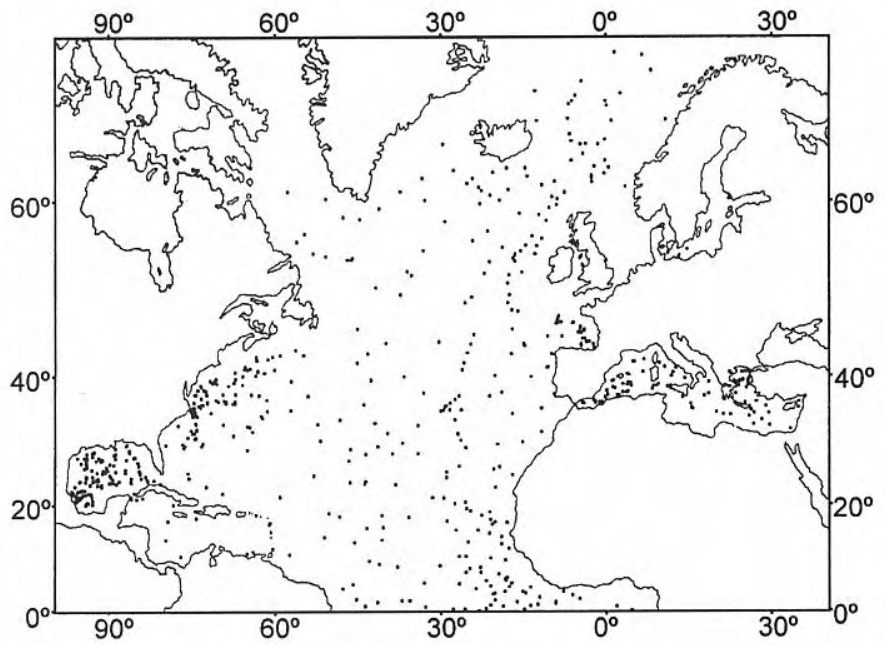

Figure 1. Calibration data set. Locations of North Atlantic and Mediterranean core-top samples.

that are more recent than the fossil assemblage? The only solution lies in accepting the hypothesis that the fossil species are the ecological equivalents of their modern descendants and in ignoring the contemporary species without supposed equivalents in the fossil assemblage and vice versa (Thunnell, 1979; Dowsett and Poore, 1990; Dowsett, 1991).

Finally, two more assumptions must be accepted. These are difficult, if not impossible, to prove affirmatively, though in the course of research there may appear evidence to refute them.

- Sixthly, that the environment lived in by the organisms of the fossil sample has modern analogs within the calibration data set.

- Seventhly, that the ecological response of the various elements of the fossil assemblage was similar to that shown by their present-day representatives or equivalents.

If there exist reasons to doubt the validity of any of the above assumptions, there will obviously be a reduction in the confidence for the estimate obtained with the numerical technique.

\section{PROCEDURES TO EVALUATE THE ESTIMATES}

Various criteria have been proposed to evaluate the quality of the results but, unfortunately, none is definitive and, indeed, the validity of some of them is open to question:

a) The first is exclusive to the modern analog technique. The estimated value of the environmental variable is an average of the values of this variable in the subset of most similar samples. The dispersion statistics of these values may thus be indicative of the confidence about the estimate. For example, the lower the range of values, the more accurate must the estimated value be (Hutson, 1980). This aspect is discussed further below.

b) Another criterion consists in evaluating the errors of the values estimated by the transfer function when this is applied to the calibration data set from which it derives by a series of statistics and indices: standard error of 
estimate, multiple correlation coefficient (both, normally, adjusted to take into account the degrees of freedom lost), maximum error of the estimate, number of errors of the estimate (expressed in absolute values) exceeding a given limit value, distribution of the errors of the estimate with respect to the observed values (to determine whether there is an accumulation of errors in particular regions of the range of values of the environmental variable), geographical distribution of the errors of the estimate in the area covered by the calibration data set, etc. This criterion has been used on many occasions (Imbrie and Kipp, 1971; Imbrie et al., 1973; Kipp, 1976, and, in general, all those authors who have employed techniques that include a regression). Obviously, if a technique produces unsatisfactory results according to this criterion it must be discarded, but the obtention of a good result is no guarantee that this would be repeated when applied to a different set, even in the case where this is obtained from analogous conditions (see below). In the case of the modern analog technique, there is no equivalent criterion. When the value of an environmental variable is estimated for any sample from the calibration data set, this automatically becomes a sample that is excluded from the set in question. Thus, the evaluation of the errors of the estimate deriving from this technique when applied to the calibration data set should be considered according to the following criterion.

c) Another possible evaluation criterion consists of applying the transfer technique to contemporary samples that are not included in the calibration data set. A set of samples obtained from the geographical area covered by the calibration data set might be a good test of the technique in approximately analog conditions, providing the sampling density in the area of the calibration data set is suitable (though, of course, some samples may be biologically or environmentally no-analog). However, the transfer techniques may also be tested in no-analog conditions with a set of samples obtained from another geographical area (e.g., Berger and Gardner, 1975, applied a transfer function calculated with a calibration data set from the North Atlantic to a set of samples from the South Pacific, and Kipp, 1976, derived a transfer function from the North Atlantic and applied it to the South Atlantic). In such cases, apart from the possibility that the set might contain biological or environmental noanalog, the ecological response of the species may be different (Cifelli, 1971). It is also possible to resort to a set obtained from another taphonomic environment (Hutson, 1977, 1978, used a transfer function derived from a set of samples with low dissolution, applied to a set of samples with high dissolution) or from another ecological environment.

We shall now consider criteria based on the analysis of estimates from fossil samples:

d) In certain cases, the technique provides values that are clearly meaningless and it can then be immediately discarded. An example of this is the $76^{\circ} \mathrm{C}$ obtained for a sample from the Norwegian Sea (Hutson, 1977). However, in most cases the possible error is not so obvious. e) Another possibility is to compare the estimates provided by different methodologies. If, using the same calibration data set, different techniques are applied to a fossil sample and clearly different estimates are obtained, it is fair to suspect no-analog conditions (Hutson, 1977). Of course, this in itself provides no indication of which technique is the best. When similar estimates are obtained, while the relative suitability of the techniques is still not clarified, at least a certain confidence may be placed in the validity of the result. Nevertheless, as will be made clear below, even this is not guaranteed.

f) Alternatively, one could choose to estimate the environmental variable by using different groups of organisms (CLIMAP, 1976; Molfino et al., 1982), but the lack of agreement between the estimates does not indicate, either, the optimum technique to employ.

g) Finally, the estimated value of the environmental value could be compared with that indicated by tests that are not based on the composition of assemblages of organisms (e.g., oxygen isotopes, Imbrie et al., 1973), taking into account the same reservations as expressed above.

All these tests could be described as external (Sachs et al., 1977); internal tests, however, can also be used:

h) In the case of the techniques that include Q-mode factor analysis, it might be useful to examine the values of the communalities, though there are conflicting opinions on this. The communality of a sample is a measure of the proportion of the original information (biological, in this case) conserved in the principal components. Communality, therefore, measures the success of Q-mode factor analysis in describing the composition of a sample. According to Imbrie and Kipp (1971), low communality values could be associated with anomalies in the composition due to differential dissolution, stratigraphic mixing or to local ecological phenomena. Hutson (1977) suggested such values might indicate a no-analog condition, though the contrary is not necessarily true. On the other hand, Le (1992) concluded that low communality does not necessarily indicate a noanalog condition. The main problem, however, lies in the relation between communalities and errors of the estimate. Hutson (1977), applying a transfer function calibrated with a low dissolution set to a high dissolution one, found a clear negative correlation between communalities and errors of the estimate. Nevertheless, Le (1992) found no such relation within his data calibration set. This question is further considered below.

i) For the case of $\mathrm{R}$ mode analyses, the $\mathrm{T}^{2}$ values of the test for outliers (Rohlf, 1993) could be used, with the same qualifications as expressed above.

j) With regard to the modern analog technique, the biological no-analog samples are detected by their low values of similarity coefficients or high values of taxonomic distances. Nevertheless, there is no clear relation between the magnitude of the errors of the estimate and the values of the similarity or dissimilarity coefficients (see below). 


\section{MATERIALS AND METHODS}

\section{CALIBRATION DATA SET}

This research was undertaken with the aim of developing a series of procedures to calculate the values of the environmental values of the surface of the Alborán Sea during the Quaternary. Given the geographical position of the Alborán Sea, in the westernmost part of the Mediterranean and the presumably important environmental variations in the Quaternary, we thought it logical to start from a broad calibration data set, covering the North Atlantic and the Mediterranean. In addition, working with such a geographically wide-ranging calibration data set reduces the possibility of the sample to be estimated coming from no-analog conditions.

Numerous articles contain quantitative data on the assemblages of planktonic foraminifera in the study area. From these, we selected those following taxonomic schemes equivalent to that of Kipp (1976), given its acceptance among the authors who have worked with transfer function techniques and, also, the great number of core top samples included in his study. Unfortunately, but inevitably, this meant not being able to include the data from several interesting studies. Furthermore, and despite their possible ecological interest, it was necessary to group the members of three pairs of morphotypes, as they were not separated by all the authors: pink and white Globigerinoides ruber, G. trilobus $(=G$. sacculifer) with and without saclike final chamber, and rightcoiling Neogloboquadrina pachyderma and "P-D intergrade". The 26 species and morphotypes used are listed in Table 1. Finally, we maintained the lists contained in Gardner and Hays (1976), Kellogg (1976), Kipp (1976), Balsam and Flessa (1978) and Pujol (1980). We also added the lists of Thunnell (1978), Brunner (1979) and Loubere (1981), which were not included in their respective publications, but were very kindly made available by their authors.

The data on the environmental variable (it was decided to use the sea surface winter temperature) were obtained from the maps produced by Gorshkov (1978). As these maps only extend up to latitude $71^{\circ} \mathrm{N}$, it was necessary to eliminate 16 samples located further to the north.

Finally, the calibration data set was composed of a relative abundance matrix of 605 samples (geographic location in Fig. 1) with 26 species (and morphotypes) and a temperature vector of 605 observations.

It should be noted that the calibration data set includes samples dissolved to various degrees. This, in principle, might be advantageous; the transfer function could provide accurate estimates under a large range of dissolution conditions (Kipp, 1976; Hutson, 1978; Hutson and Prell, 1980; Thompson, 1981). However, Miao et al. (1994), using a transfer function (developed by Thompson, 1981), based on a wide range of dissolution samples, showed that increases in dissolution result in cooler sea surface temperature estimates. There exist several possibilities to reduce the impact of this problem:

a) To calibrate high- and low-dissolution transfer functions (see Hutson, 1978).

b) To create a calibration data set using samples with larger mesh sizes, assuming that planktonic foraminifera in coarse size fraction are more resistant to dissolution (Thompson, 1976; Hutson, 1978).

c) To attempt to reconstruct the original composition of the associations of samples altered by dissolution (Le and Thunell, 1996).

None of these solutions has been employed in this study; the wide range of dissolution conditions within the calibration data set has been retained, in order to observe the behaviour of the transfer function in the case of samples affected by selective dissolution. As regards the modern analog technique, given the way in which it estimates paleotemperatures, this should work equally well with samples with either high or low degrees of dissolution, always providing there are analogous samples in the calibration set.

\section{TECHNIQUES EMPLOYED AND ITS VARIANTS}

Below, we shall employ the terms used by Hutson (1977) in a revision of those described until then, with the appropriate additions.

\section{Species regression technique}

To apply this technique, described by Hutson (1977), it is only necessary to apply a multiple regression to calculate the constant and the coefficients of the equation estimating the values of the environmental variable (dependent variable) from the relative abundance of the species (independent variables). By applying such an equation to the relative abundance of the species in the fossil assemblage, we directly obtain the estimated value of the environmental variable. If a linear equation is fitted, the number of coefficients to calculate is not excessive (26 in our case). But if we attempt to work with a nonlinear equation of the second degree, the number of independent variables becomes so great (as the squares and cross-products of the original variables must be added) that normal computation methods are insufficient (in our case, we were not able to perform the regression of the 377 variables of the cross product matrix).

This study tested, as well as the original version (Tab. 3, SPR), some modifications to the technique:

a) Transformation of the relative abundances so that each vector sample has a length of 1 (Tab. 3, SPRVL1).

b) Logit transformation of the relative abundances: logarithm of the relative abundance divided by one minus the logarithm of the relative abundance, with prior substitution of the zero values by quantities lower than the least non-zero relative abundance in the calibration data set. Substitutions were tested with values of 0.0001 , $0.0002, \ldots \ldots .0 .0009$ (Tab. 3, SPRLOGIT1.....SPRLOGIT9). By means of these transformations, the relative abundances were converted into negative and positive values.

c) Reduction of the number of variables to a more manageable quantity (18), eliminating those making the lowest contribution to the reduction of the residuals. To achieve this, a stepwise regression was used: the species eliminated were Globigerina calida, Globigerinoides conglobatus, Neogloboquadrina dutertrei, Globigerinita glutinata, Globorotalia inflata, Pulleniatina obliquiloculata, left-coiling Globorotalia truncatulinoides and Orbulina 
universa. Clearly, such a solution might seem somewhat drastic, as it eliminates species that are important constituents in some assemblages (especially $N$. dutertrei and $G$. inflata ) but with this procedure it is possible to test an equation of the second degree. The table 3 gives the results of the linear and quadratic equations, after the elimination of the eight species and the recalculation of the relative abundances (Tab. 3, SPR18LIN and SPR18QUAD).

\section{Weighted average technique}

This technique, in Berger and Gardner's version (1975), has been used by Hutson (1977), Birks et al. (1990) and Le (1992). It comprises two steps: firstly, provisional values are estimated for the environmental variable of the calibration data set samples. This is performed by calculating the average of the optimum values of the environmental variable for the species present in each sample, weighted with the relative abundance of the species in question. Secondly, a linear equation is fitted, taking the values obtained in the previous estimate as those of the independent variable; for the values of the dependent variable, those of the environmental variable in the calibration data set are used. To estimate the value of the variable for the fossil sample, an initial result is obtained from the first-step, which is subsequently corrected with the coefficient and the constant of the second-step equation.

The method used to obtain the optimum values of the environmental variable for each species is somewhat imprecise in Berger and Gardner's study (1975). Here, we decided upon the mean of the values of the variable in the calibration data set, weighted with the relative abundances of the species (Birks et al. 1990) (Tab. 3, WAOPT). As regards the regression, a study of the plot with the values of the first estimate of the variable and of the observed values led us to suspect that the linear equation would not provide optimum results. Therefore, the nonlinear equation of the second degree and a potential equation with intercept $\left(y=a+b x^{c}\right)($ Tab. 3 , rows WAOPTLIN, WAOPTQUAD, WAOPTPOT) were also fitted.

As the tolerance (maximum likelihood estimate of weighted standard deviation) of the optimum value varied to a considerable extent (from $\pm 2.71{ }^{\circ} \mathrm{C}$ for Sphaeroidinella dehiscens and $\pm 6.58{ }^{\circ} \mathrm{C}$ for Globigerinita glutinata), we also applied the relevant formula provided by Birks et al. (1990) (see, too, Le, 1992) (Tab. 3, WATOL). The results were also adjusted with the three equations quoted in the above paragraph (Tab. 3, rows WATOLLIN, WATOLQUAD, WATOLPOT).

\section{Principal component regression technique}

This has been described and discussed in detail by Imbrie and Kipp (1971, while the mathematical aspects, as regards principal component analysis, were studied in depth by Klovan and Imbrie (1971). It has subsequently been used by many authors, both applied to planktonic foraminifera (e.g., Imbrie et al., 1973; Kipp, 1976; Gardner and Hays, 1976; Hutson, 1977; 1978; Molina-Cruz and Thiede, 1978; Thunnell, 1979; Pujol, 1980; Molfino et al., 1982; Dowsett and Poore, 1990; Le, 1992; Pflaumann et al., 1996) and to other groups of organisms.
The technique basically consists of fitting the nonlinear equation of the second degree that estimates the environmental variable from the first $\mathbf{m}$ principal component loadings (rotated by means of the varimax criterion) of the cosine-theta matrix of the samples. Several of these operations may be substituted by other alternative ones, some of which are examined in this study (Tabs. 2 and 4).

a) Association matrix. Imbrie and Kipp's method is based on the Q-mode analysis of the cosine-theta matrix. Alternatively, other types of similarity coefficients between objects can be analysed, or R-mode can be used, analysing the correlation matrix or the variance-covariance matrix between the variables. In such cases, the regression is applied to the principal component scores. Both R-modes, together with the Q-mode of the cosine-theta matrix, have been examined in this study, using three groups of tests: COS, COR and VCV.

b) Rotation. There are various procedures to perform the rotation of the eigenvector matrix. In this study, in addition to the varimax criterion, rotations applying the equamax and quartimax criteria were tested. Unrotated matrices were also studied. When we carried out, for example, varimax rotation of the first $\mathbf{m}$ principal components, there is a change in the principal component loadings (Q-mode) or the principal component scores (R-mode). The coefficients of the paleoecological equations derived from the regression of the rotated and non-rotated matrices are, thus, also different. But the estimated values with both equations are identical (apart from rounding errors). Varimax rotation produces principal components that are easier to interpret, but neither increases nor decreases the errors of the estimate. If the first $\mathbf{p}$ principal components are rotated and from those, the first $\mathbf{m}$ are taken $(\mathrm{p}>\mathrm{m})$, the paleoecological equation corresponding to the matrix rotated in this way produces different estimates. Testing all the possibilities arising from the above case would lead to an impractical number of tests. In this study, we decided to rotate all the principal vectors $(\mathrm{p}=\mathrm{n}, 26)$. Consequently, the principal components of each association matrix were tested in four ways: non-rotated (NR) and rotated with the equamax, quartimax and varimax criteria (EX, QX and VX), except in the case of the cosinetheta matrix rotated by the equamax criterion, as it was not possible to achieve convergence in 300 iterations.

c) Number of principal components. Imbrie and Kipp decided upon 5 principal components, basing their choice on the geographical distribution of the planktonic foraminifera. The number of principal components used in later studies has usually been five, six (e.g., Kipp, 1976) or seven (e.g., Hutson and Prell, 1980), also for biogeographical reasons. Le (1992) compared the results when using six, eight or ten principal components, and concluded it was not sufficient to consider only the biogeographical provinces to determine the number of principal components; he therefore recommended using a number of principal components that would avoid low communalities in the samples to be estimated. Initially, we applied a stepwise regression procedure in order to estimate the number of principal components which can be removed, but we got odd results (see also the section on species regression technique). For example, when we applied the procedure to the 26 components of the variance- 
covariance matrix, six of them were eliminated, but not the last six, but the numbers $12,13,18,19,22$ y 26 . This is not a surprise due to the problems of the stepwise regression procedure (see, for example, SYSTAT, pp. 168-169). Finally, we decided to test transfer functions with 1, 2, 3, 4, $5,6,7,8,9,12,15$, and 18 principal components. In those cases where better results were obtained with 9 than with 8 or 12 , the functions of 10 and 11 principal components were added. In this way, each of the procedures defined in the above sections (COSNR, COSQX, COSVX, CORNR, COREX, CORQX, CORVX, VCVNR, VCVEX, VCVQX, and VCVVX) produces 12 or 14 transfer functions (COSNR1, COSNR2,.....COSNR18, etc.).

d) Regression. Although most authors following Imbrie and Kipp's method have used the nonlinear equation of the second degree, the linear equation has also been employed; for example, it was preferred by Hutson (1977). Both possibilities have been investigated in this study: COSNR1LIN, COSNR1QUAD, COSNR2LIN, COSNR2QUAD, etc. In total, 270 variants of Imbrie and Kipp's method were tested (Tabs. 2 and 4).

\section{Discriminant analysis technique}

Although the initial results are promising, it has not yet been possible to satisfactorily develop this technique. In fact, as will be seen below, it would be necessary to have a much wider calibration data set to achieve acceptable results.

If the samples of the calibration data set are classified into a series of groups, using any procedure, numerical or otherwise, a subsequent discriminant analysis (included in many statistical packages: SPSS, SYSTAT, NTSYS, etc.) will provide classification functions enabling us to identify the group to which each sample of the calibration data set belongs and to identify the group in which other samples, not belonging to this set, should be included.

To apply this technique, all the samples of the calibration data set corresponding to a certain value interval of the environmental variable are grouped together. In our study, we chose intervals of $0.5^{\circ} \mathrm{C}$; as there was only a small number of samples of the calibration data set with winter temperatures below $2{ }^{\circ} \mathrm{C}$, we decided to combine them into a single group. Thus, 54 groups were established: $<2{ }^{\circ} \mathrm{C}, 2{ }^{\circ} \mathrm{C}$ to $2.5^{\circ} \mathrm{C}, 2.5$ ${ }^{\circ} \mathrm{C}$ to $3{ }^{\circ} \mathrm{C} . .28^{\circ} \mathrm{C}$ to $28.5^{\circ} \mathrm{C}$. Even so, some groups consisted of just three samples, a quantity which is clearly insufficient. The results are listed in Tab. 3, row DISC.

\section{Modern analog technique}

This technique, described by Hutson in 1980, can be summarized in the following three successive steps:

a) Calculate the faunal similarity of the fossil assemblage with each of the assemblages of the calibration data set. Hutson used the cosine of the vector angle between the modern and the downcore sample as the similarity coefficient.

b) Create a subset with the ten most similar samples.

c) Calculate the average of the values of the environmental variable in the subset, weighted with the corresponding values of the similarity coefficient.

Obviously, each of these stages may be modified. The cosine of the vector angle has also been used by Pflaumann

\begin{tabular}{|c|c|c|c|}
\hline Species and morphotypes & MxRA & TOP & TOL \\
\hline Globigerina bulloides d'Orbigny & 0.450 & 13.2 & 4.5 \\
\hline Globigerina calida Parker & 0.092 & 20.8 & 3.6 \\
\hline Globigerinoides conglobatus (Brady) & 0.100 & 21.2 & 4.5 \\
\hline Globorotalia crassaformis (Galloway and Wissler) & 0.073 & 23.2 & 3.6 \\
\hline $\begin{array}{l}\text { Globorotalia cultrata (d'Orbigny) } \\
\quad=\text { G. menardii }\end{array}$ & 0.309 & 23.1 & 3.6 \\
\hline Sphaeroidinella dehiscens (Parker and Jones) & 0.091 & 26.0 & 2.7 \\
\hline Beella digitata (Brady) & 0.040 & 20.0 & 4.9 \\
\hline Neogloboquadrina dutertrei (d'Orbigny) & 0.542 & 21.1 & 5.7 \\
\hline Globigerina falconensis Blow & 0.197 & 18.2 & 3.9 \\
\hline Globigerinita glutinata (Egger) & 0.357 & 17.2 & 6.6 \\
\hline Globorotalia hirsuta (d'Orbigny) & 0.093 & 17.4 & 3.5 \\
\hline Globorotalia inflata (d'Orbigny) & 0.432 & 14.3 & 4.2 \\
\hline Pulleniatina obliquiloculata (Parker and Jones) & 0.256 & 22.4 & 3.7 \\
\hline Neogloboquadrina pachyderma (Ehrenberg) & & & \\
\hline $\begin{array}{l}\text { Neogloboquadrina pachyderma (Ehrenberg) } \\
\text { (left-coiling) }\end{array}$ & 0.984 & 5.0 & 3.4 \\
\hline Turborotalita quinqueloba (Natland) & 0.348 & 8.3 & 4.5 \\
\hline Globoturborotalita rubescens Hofker & 0.145 & 20.3 & 4.7 \\
\hline $\begin{array}{l}\text { Globigerinoides ruber (d'Orbigny) } \\
\text { (pink and white) }\end{array}$ & 0.817 & 21.0 & 4.0 \\
\hline Globorotalia scitula (Brady) & 0.093 & 16.5 & 5.3 \\
\hline Globigerinella siphonifera (d'Orbigny) & 0.141 & 21.4 & 4.0 \\
\hline Globoturborotalita tenella (Parker) & 0.114 & 21.0 & 3.6 \\
\hline Globigerinoides trilobus (Reuss) = G. sacculifer & & & \\
\hline (with and without saclike final chamber) & 0.513 & 23.2 & 3.8 \\
\hline $\begin{array}{l}\text { Globorotalia truncatulinoides (d'Orbigny) } \\
\text { (rigth-coiling) }\end{array}$ & & & \\
\hline (rigth-coiling) & 0.138 & 20.7 & 3.4 \\
\hline Globorotalia truncatulinoides (d'Orbigny) & & & \\
\hline & 0.470 & 23.2 & 3.8 \\
\hline Globorotalia tumida (Brady) & 0.840 & 25.7 & 3.0 \\
\hline Orbulina universa d'Orbigny & 0.184 & 19.0 & 5.3 \\
\hline
\end{tabular}

Abbreviations: MxRA: maximum relative abundance; TOP: optimum winter temperature; TOL: tolerance.

Table 1. Species and morphotypes.

et al., 1996. Prell (1985) and Le (1992) chose a dissimilarity coefficient, the squared chord distance. In this study, both coefficients have been used, in addition to the Euclidean distance, the average Manhattan distance (city block) and the squared $\chi^{2}$ distance (MATCOS, MATSCH2, MATEUC, MATMANH, MATCHI2, respectively) (see Overpeck et al., 1985, for other possibilities).

The number of analogs to be included in the subset is doubtless the aspect of the technique that is most liable to modification, either by choosing a fixed number of analogs or by assigning to the subset all the contemporary samples presenting a similarity above a certain minimum value or a dissimilarity below a maximum value. In this study, a fixed number of analogs, ten as in the original work, was decided upon.

With respect to the weighting method, Pflaumann et al., 1996, included the geographical distance between the modern sample and the downcore sample. Clearly, this might reduce the size of the error of the estimate if each sample of the calibration data set is estimated with the other samples from the set. But taking into account that environmental changes lead to faunal migrations, it seems more suitable not to introduce geographical distance into the estimate of the downcore sample. Only if a calibration data set including samples from more than one hemisphere or ocean were used (i.e., changes in the ecological responses of the species) would the use of geographical weighting be justified. In this study, therefore, the original 


\begin{tabular}{rrrccc}
\hline & N & RNA & RA & SENA & SEA \\
\hline $\mathrm{C}$ & 1 & 0.698 & 0.697 & 4.888 & 4.893 \\
$\mathrm{O}$ & 2 & 0.794 & 0.793 & 4.154 & 4.163 \\
$\mathrm{~S}$ & 3 & 0.875 & 0.874 & 3.306 & 3.318 \\
$\mathrm{~N}$ & 4 & 0.934 & 0.933 & 2.446 & 2.457 \\
$\mathrm{R}$ & 5 & 0.940 & 0.940 & 2.324 & 2.337 \\
$\mathrm{~L}$ & 6 & 0.940 & 0.940 & 2.323 & 2.339 \\
$\mathrm{I}$ & 5 & 0.941 & 0.940 & 2.319 & 2.337 \\
$\mathrm{~N}$ & 8 & 0.941 & 0.940 & 2.317 & 2.338 \\
& 9 & 0.947 & 0.946 & 2.192 & 2.214 \\
& 12 & 0.950 & 0.948 & 2.142 & 2.171 \\
& 15 & 0.950 & 0.948 & 2.129 & 2.166 \\
& 18 & 0.954 & 0.952 & 2.042 & 2.085 \\
$\mathrm{C}$ & 1 & 0.698 & 0.697 & 4.888 & 4.899 \\
$\mathrm{O}$ & 2 & 0.910 & 0.909 & 2.825 & 2.840 \\
$\mathrm{~S}$ & 3 & 0.938 & 0.936 & 2.372 & 2.397 \\
$\mathrm{~N}$ & 4 & 0.962 & 0.961 & 1.853 & 1.882 \\
$\mathrm{R}$ & 5 & 0.966 & 0.964 & 1.778 & 1.819 \\
$\mathrm{Q}$ & 6 & 0.968 & 0.966 & 1.704 & 1.758 \\
$\mathrm{U}$ & 7 & 0.970 & 0.967 & 1.659 & 1.728 \\
$\mathrm{~A}$ & 8 & 0.973 & 0.970 & 1.581 & 1.665 \\
$\mathrm{D}$ & 9 & 0.976 & 0.973 & 1.475 & 1.573 \\
& 12 & 0.981 & 0.977 & 1.313 & 1.469 \\
& 15 & 0.985 & 0.979 & 1.164 & 1.392 \\
& 18 & 0.989 & 0.981 & 1.020 & 1.340
\end{tabular}

\begin{tabular}{rrrccc} 
& N & RNA & RA & SENA & SEA \\
\hline $\mathrm{C}$ & 1 & 0.897 & 0.897 & 3.017 & 3.020 \\
$\mathrm{O}$ & 2 & 0.900 & 0.899 & 2.980 & 2.987 \\
$\mathrm{R}$ & 3 & 0.933 & 0.933 & 2.450 & 2.458 \\
$\mathrm{~N}$ & 4 & 0.934 & 0.933 & 2.447 & 2.458 \\
$\mathrm{R}$ & 5 & 0.948 & 0.948 & 2.167 & 2.179 \\
$\mathrm{~L}$ & 6 & 0.948 & 0.948 & 2.165 & 2.180 \\
$\mathrm{i}$ & 7 & 0.953 & 0.952 & 2.076 & 2.092 \\
$\mathrm{~N}$ & 8 & 0.955 & 0.954 & 2.034 & 2.053 \\
& 9 & 0.955 & 0.954 & 2.032 & 2.053 \\
& 12 & 0.960 & 0.959 & 1.915 & 1.942 \\
& 15 & 0.961 & 0.960 & 1.884 & 1.916 \\
& 18 & 0.962 & 0.961 & 1.856 & 1.895
\end{tabular}

\begin{tabular}{rrrccc} 
& N & RNA & RA & SENA & SEA \\
\hline $\mathrm{V}$ & 1 & 0.812 & 0.811 & 3.989 & 3.993 \\
$\mathrm{C}$ & 2 & 0.836 & 0.835 & 3.751 & 3.760 \\
$\mathrm{~V}$ & 3 & 0.917 & 0.917 & 2.722 & 2.731 \\
$\mathrm{~N}$ & 4 & 0.951 & 0.950 & 2.115 & 2.125 \\
$\mathrm{R}$ & 5 & 0.952 & 0.951 & 2.096 & 2.108 \\
$\mathrm{~L}$ & 6 & 0.952 & 0.951 & 2.087 & 2.101 \\
$\mathrm{i}$ & 7 & 0.953 & 0.952 & 2.078 & 2.095 \\
$\mathrm{~N}$ & 8 & 0.954 & 0.953 & 2.042 & 2.060 \\
& 9 & 0.954 & 0.954 & 2.037 & 2.057 \\
& 12 & 0.959 & 0.958 & 1.938 & 1.964 \\
& 15 & 0.961 & 0.959 & 1.895 & 1.927 \\
& 18 & 0.963 & 0.961 & 1.847 & 1.885
\end{tabular}

$\begin{array}{rrrrrr}C & 1 & 0.898 & 0.897 & 3.011 & 3.018 \\ \mathrm{O} & 2 & 0.940 & 0.939 & 2.328 & 2.341 \\ \mathrm{R} & 3 & 0.950 & 0.949 & 2.125 & 2.147 \\ \mathrm{~N} & 4 & 0.956 & 0.955 & 2.001 & 2.033 \\ \mathrm{R} & 5 & 0.964 & 0.963 & 1.808 & 1.850 \\ \mathrm{Q} & 6 & 0.968 & 0.966 & 1.718 & 1.772 \\ \mathrm{U} & 7 & 0.971 & 0.968 & 1.633 & 1.701 \\ \mathrm{~A} & 8 & 0.975 & 0.972 & 1.523 & 1.604 \\ \mathrm{D} & 9 & 0.976 & 0.973 & 1.484 & 1.582 \\ & 10 & 0.978 & 0.974 & 1.421 & 1.536 \\ & 11 & 0.981 & 0.977 & 1.338 & 1.470 \\ & 12 & 0.981 & 0.976 & 1.323 & 1.480 \\ & 15 & 0.985 & 0.979 & 1.173 & 1.403 \\ & 18 & 0.989 & 0.981 & 1.020 & 1.340\end{array}$

$\begin{array}{rrrrrr}\text { V } & 1 & 0.824 & 0.823 & 3.866 & 3.874 \\ C & 2 & 0.904 & 0.903 & 2.915 & 2.932 \\ \text { V } & 3 & 0.947 & 0.946 & 2.189 & 2.211 \\ N & 4 & 0.961 & 0.959 & 1.899 & 1.930 \\ \text { R } & 5 & 0.967 & 0.965 & 1.740 & 1.780 \\ Q & 6 & 0.969 & 0.967 & 1.676 & 1.728 \\ U & 7 & 0.972 & 0.970 & 1.601 & 1.667 \\ A & 8 & 0.976 & 0.973 & 1.495 & 1.575 \\ \text { D } & 9 & 0.977 & 0.973 & 1.470 & 1.567 \\ & 12 & 0.981 & 0.976 & 1.329 & 1.486 \\ & 15 & 0.987 & 0.981 & 1.112 & 1.330 \\ & 18 & 0.989 & 0.982 & 0.990 & 1.301\end{array}$

$\begin{array}{rrrrrr}\mathrm{C} & 1 & 0.755 & 0.754 & 4.479 & 4.484 \\ \mathrm{O} & 2 & 0.770 & 0.769 & 4.358 & 4.368 \\ \mathrm{~S} & 3 & 0.890 & 0.889 & 3.113 & 3.123 \\ \mathrm{Q} & 4 & 0.904 & 0.903 & 2.921 & 2.934 \\ \mathrm{X} & 5 & 0.922 & 0.921 & 2.648 & 2.663 \\ \mathrm{~L} & 6 & 0.941 & 0.941 & 2.304 & 2.319 \\ \mathrm{I} & 7 & 0.944 & 0.943 & 2.255 & 2.273 \\ \mathrm{~N} & 8 & 0.944 & 0.943 & 2.253 & 2.274 \\ & 9 & 0.944 & 0.943 & 2.253 & 2.276 \\ & 12 & 0.949 & 0.948 & 2.149 & 2.178 \\ & 15 & 0.951 & 0.949 & 2.113 & 2.149 \\ & 18 & 0.954 & 0.952 & 2.054 & 2.096 \\ \mathrm{C} & 1 & 0.769 & 0.767 & 4.368 & 4.378 \\ \mathrm{O} & 2 & 0.875 & 0.873 & 3.309 & 3.328 \\ \mathrm{~S} & 3 & 0.934 & 0.932 & 2.442 & 2.467 \\ \mathrm{Q} & 4 & 0.952 & 0.950 & 2.099 & 2.133 \\ \mathrm{X} & 5 & 0.954 & 0.952 & 2.050 & 2.097 \\ \mathrm{Q} & 6 & 0.966 & 0.963 & 1.776 & 1.832 \\ \mathrm{U} & 7 & 0.971 & 0.969 & 1.632 & 1.700 \\ \mathrm{~A} & 8 & 0.973 & 0.970 & 1.585 & 1.669 \\ \mathrm{D} & 9 & 0.975 & 0.972 & 1.514 & 1.614 \\ & 12 & 0.981 & 0.976 & 1.324 & 1.480 \\ & 15 & 0.985 & 0.979 & 1.176 & 1.406 \\ & 18 & 0.989 & 0.981 & 1.000 & 1.314\end{array}$

$\begin{array}{rrrrrr}\mathrm{C} & 1 & 0.760 & 0.760 & 4.434 & 4.439 \\ \mathrm{O} & 2 & 0.818 & 0.817 & 3.932 & 3.941 \\ \mathrm{R} & 3 & 0.818 & 0.817 & 3.924 & 3.937 \\ \mathrm{Q} & 4 & 0.884 & 0.883 & 3.194 & 3.209 \\ \mathrm{X} & 5 & 0.910 & 0.909 & 2.835 & 2.851 \\ \mathrm{~L} & 6 & 0.912 & 0.911 & 2.794 & 2.813 \\ \mathrm{I} & 7 & 0.948 & 0.948 & 2.166 & 2.183 \\ \mathrm{~N} & 8 & 0.958 & 0.957 & 1.963 & 1.980 \\ & 9 & 0.958 & 0.957 & 1.951 & 1.971 \\ & 12 & 0.960 & 0.959 & 1.915 & 1.942 \\ & 15 & 0.961 & 0.960 & 1.890 & 1.923 \\ & 18 & 0.962 & 0.960 & 1.872 & 1.910\end{array}$

$\begin{array}{rrr}\mathrm{V} & 1 & 0.729 \\ \mathrm{C} & 2 & 0.818 \\ \mathrm{~V} & 3 & 0.897 \\ \mathrm{Q} & 4 & 0.933 \\ \mathrm{X} & 5 & 0.933 \\ \mathrm{~L} & 6 & 0.953 \\ \mathrm{I} & 7 & 0.953 \\ \mathrm{~N} & 8 & 0.954 \\ & 9 & 0.955 \\ & 12 & 0.958 \\ & 15 & 0.960 \\ & 18 & 0.962\end{array}$

0.729

$4.672 \quad 4.677$

$\begin{array}{rrrrrr}\mathrm{C} & 1 & 0.766 & 0.765 & 4.391 & 4.400 \\ \mathrm{O} & 2 & 0.872 & 0.870 & 3.344 & 3.363 \\ \mathrm{R} & 3 & 0.916 & 0.914 & 2.744 & 2.7772 \\ \mathrm{Q} & 4 & 0.943 & 0.941 & 2.269 & 2.305 \\ \mathrm{X} & 5 & 0.954 & 0.952 & 2.051 & 2.098 \\ \mathrm{Q} & 6 & 0.962 & 0.960 & 1.853 & 1.911 \\ \mathrm{U} & 7 & 0.971 & 0.969 & 1.631 & 1.698 \\ \mathrm{~A} & 8 & 0.972 & 0.969 & 1.605 & 1.690 \\ \mathrm{D} & 9 & 0.975 & 0.972 & 1.518 & 1.618 \\ & 10 & 0.977 & 0.973 & 1.449 & 1.567 \\ & 11 & 0.979 & 0.974 & 1.403 & 1.541 \\ & 12 & 0.981 & 0.976 & 1.334 & 1.492 \\ & 15 & 0.985 & 0.978 & 1.179 & 1.410 \\ & 18 & 0.987 & 0.978 & 1.079 & 1.418\end{array}$

$$
\begin{aligned}
& \text { C } \\
& \text { O } \\
& \text { S } \\
& \text { V } \\
& \text { X } \\
& \text { L } \\
& \text { I }
\end{aligned}
$$

$\begin{array}{rrrrrr}\mathrm{C} & 1 & 0.748 & 0.747 & 4.533 & 4.538 \\ \mathrm{O} & 2 & 0.759 & 0.758 & 4.445 & 4.455 \\ \mathrm{~S} & 3 & 0.763 & 0.761 & 4.415 & 4.430 \\ \mathrm{~V} & 4 & 0.905 & 0.904 & 2.900 & 2.913 \\ \mathrm{X} & 5 & 0.930 & 0.929 & 2.517 & 2.531 \\ \mathrm{~L} & 6 & 0.942 & 0.941 & 2.298 & 2.313 \\ \mathrm{~N} & 7 & 0.944 & 0.943 & 2.250 & 2.268 \\ \mathrm{~N} & 8 & 0.944 & 0.943 & 2.248 & 2.269 \\ & 9 & 0.944 & 0.943 & 2.248 & 2.271 \\ & 12 & 0.949 & 0.948 & 2.148 & 2.178 \\ & 15 & 0.951 & 0.949 & 2.112 & 2.148 \\ & 18 & 0.954 & 0.952 & 2.054 & 2.096 \\ \mathrm{C} & 1 & 0.764 & 0.763 & 4.408 & 4.418 \\ \mathrm{O} & 2 & 0.844 & 0.842 & 3.667 & 3.688 \\ \mathrm{~S} & 3 & 0.884 & 0.881 & 3.197 & 3.229 \\ \mathrm{~V} & 4 & 0.954 & 0.952 & 2.050 & 2.083 \\ \mathrm{X} & 5 & 0.964 & 0.963 & 1.805 & 1.847 \\ \mathrm{Q} & 6 & 0.966 & 0.964 & 1.768 & 1.824 \\ \mathrm{U} & 7 & 0.971 & 0.969 & 1.625 & 1.692 \\ \mathrm{~A} & 8 & 0.973 & 0.970 & 1.578 & 1.661 \\ \mathrm{D} & 9 & 0.975 & 0.972 & 1.509 & 1.609 \\ & 12 & 0.981 & 0.976 & 1.325 & 1.481 \\ & 15 & 0.985 & 0.979 & 1.173 & 1.403 \\ & 18 & 0.989 & 0.981 & 0.999 & 1.313\end{array}$

$\begin{array}{lrllll}\mathrm{C} & 1 & 0.751 & 0.750 & 4.508 & 4.513 \\ \mathrm{O} & 2 & 0.807 & 0.806 & 4.036 & 4.045 \\ \mathrm{R} & 3 & 0.807 & 0.806 & 4.031 & 4.045 \\ \mathrm{~V} & 4 & 0.880 & 0.879 & 3.247 & 3.261 \\ \mathrm{X} & 5 & 0.906 & 0.905 & 2.895 & 2.911 \\ \mathrm{~L} & 6 & 0.910 & 0.908 & 2.836 & 2.855 \\ \mathrm{I} & 7 & 0.949 & 0.948 & 2.150 & 2.167 \\ \mathrm{~N} & 8 & 0.958 & 0.957 & 1.957 & 1.975 \\ & 9 & 0.959 & 0.958 & 1.946 & 1.966 \\ & 12 & 0.961 & 0.960 & 1.880 & 1.905 \\ & 15 & 0.962 & 0.961 & 1.863 & 1.895 \\ & 18 & 0.962 & 0.961 & 1.854 & 1.893 \\ \mathrm{C} & 1 & 0.757 & 0.756 & 4.461 & 4.471 \\ \mathrm{O} & 2 & 0.867 & 0.866 & 3.398 & 3.417 \\ \mathrm{R} & 3 & 0.912 & 0.910 & 2.799 & 2.827 \\ \mathrm{~V} & 4 & 0.942 & 0.940 & 2.288 & 2.324 \\ \mathrm{X} & 5 & 0.953 & 0.951 & 2.068 & 2.116 \\ \mathrm{Q} & 6 & 0.962 & 0.959 & 1.872 & 1.931 \\ \mathrm{U} & 7 & 0.971 & 0.968 & 1.635 & 1.703 \\ \mathrm{~A} & 8 & 0.972 & 0.969 & 1.609 & 1.695 \\ \mathrm{D} & 9 & 0.975 & 0.971 & 1.519 & 1.619 \\ & 10 & 0.977 & 0.973 & 1.451 & 1.569 \\ & 11 & 0.979 & 0.975 & 1.388 & 1.525 \\ & 12 & 0.981 & 0.976 & 1.316 & 1.472 \\ & 15 & 0.985 & 0.979 & 1.163 & 1.391 \\ & 18 & 0.988 & 0.980 & 1.046 & 1.375\end{array}$

$$
\begin{array}{lr}
\mathrm{V} & 1 \\
\mathrm{C} & 2 \\
\mathrm{~V} & 3 \\
\mathrm{~V} & 4 \\
\mathrm{X} & 5 \\
\mathrm{~L} & 6 \\
\mathrm{~L} & 7 \\
\mathrm{~N} & 8 \\
& 9 \\
& 12 \\
& 15 \\
& 18
\end{array}
$$

0.722
0.816
0.892
0.932
0.932
0.953
0.953
0.954
0.955
0.958
0.960
0.962
0.724
0.862
0.935
0.960
0.965
0.970
0.972
0.975
0.977
0.979
0.986
0.990

0.722
0.815
0.892
0.931
0.931
0.953
0.953
0.953
0.954
0.956
0.959

$\begin{array}{ll}4.722 & 4.727 \\ 3.943 & 3.952 \\ 3.081 & 3.091 \\ 2.481 & 2.492 \\ 2.476 & 2.490 \\ 2.060 & 2.074 \\ 2.060 & 2.076 \\ 2.056 & 2.075 \\ 2.022 & 2.043 \\ 1.968 & 1.995 \\ 1.902 & 1.934 \\ 1.861 & 1.899 \\ 4.712 & 4.723 \\ 3.465 & 3.485 \\ 2.430 & 2.454 \\ 1.911 & 1.941 \\ 1.778 & 1.819 \\ 1.673 & 1.726 \\ 1.611 & 1.677 \\ 1.515 & 1.595 \\ 1.465 & 1.562 \\ 1.377 & 1.540 \\ 1.148 & 1.372 \\ 0.984 & 1.293\end{array}$

Abbreviations: N: number of principal components. RNA: unadjusted multiple correlation coefficient. RA: adjusted multiple correlation coefficient. SENA: unadjusted standard error of residuals. SEA: adjusted standard error of residuals. COS: cosine-theta matrix. COR: LIN: linear equation. QUAD: nonlinear equation of the second degree.

Table 2. Principal component regression technique. Multiple correlation coefficients and standard errors of residuals. 
weighting method (W) was used in the case of the cosine of the vector angle and an inverse distance-squared weighting function (IDW) (in Davis, 1986) was used for the case of the taxonomic distances. For the case of the squared chord distance, weighting was also performed with the chord similarity measure (CSW) (Prell, 1985). Furthermore, the unweighted average (UW) was also tested for all procedures. In short, a total of 11 procedures were tested: MATCOSIDW, MATCOSUW, etc. The results of these are listed in Table 7.

\section{EVALUATION OF THE TECHNIQUES}

There are, thus, 305 techniques in all. Which is the best? To compare the results of the different techniques tested, we used three types of criteria: the evaluation of the residuals of the calibration data set, the evaluation of the errors of the estimate of a set of samples obtained from the geographical area covered by the calibration data set and the evaluation of a set obtained from another geographical area.

Of the initial calibration set, 450 samples were randomly separated to be used as a provisional calibration data set (experiment 1a); the remaining 155 were to be used as a set of samples of analog conditions (in part; obviously, some must be, to a greater or lesser degree, biological or environmental no-analog). This procedure is intended to simulate the results that would be obtained by the various techniques if, during the time interval covering the downcore samples, the ecological responses of the species were similar to contemporary ones and the environmental and taphonomic conditions were not different from present-day ones in the area of the calibration data set. To simplify matters, this will henceforth be referred to as the analog set (though, strictly speaking, not all the samples are so).

Imbrie and Kipp (1971) included 27 samples from the Atlantic and Western Indian Ocean in their calibration data set. Since, for a particular value of environmental condition, the percentages of the species of planktonic foraminifera vary between oceans and between the hemispheres of an ocean (Cifelli, 1971, with respect to

\begin{tabular}{|c|c|c|c|c|c|c|c|c|c|c|c|c|}
\hline \multirow{3}{*}{$\begin{array}{l}\text { TR.FUNC. } \\
\text { SPR }\end{array}$} & \multicolumn{6}{|c|}{ ANALOG SET } & \multicolumn{6}{|c|}{ NO-ANALOG SET } \\
\hline & SE & MxE & ME & $E>3$ & $E>2$ & V & & MxE & N & $E>3$ & $E>2$ & 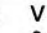 \\
\hline & 1.93 & 8.4 & 1.37 & 18 & 34 & -1 & 2.04 & 3.3 & 1.83 & 3 & 13 & -3 \\
\hline SPRVL1 & 2.23 & 11.6 & 1.53 & 21 & 34 & -6 & 2.23 & 5.2 & 1.82 & 6 & 11 & -9 \\
\hline SPR18LIN & 2.00 & 9.6 & 1.38 & 19 & 36 & -2 & 2.13 & 3.9 & 1.71 & 6 & 9 & -5 \\
\hline SPR18QUAD & 2.66 & 13.5 & 1.73 & 27 & 40 & -10 & 3.80 & 10.6 & 2.67 & 8 & 14 & -10 \\
\hline SPRLOGIT1 & 1.97 & 7.3 & 1.44 & 18 & 35 & 0 & 2.50 & 6.0 & 2.07 & 7 & 11 & -10 \\
\hline SPRLOGIT2 & 1.94 & 7.3 & 1.42 & 17 & 33 & 0 & 2.40 & 5.6 & 1.96 & 7 & 11 & -10 \\
\hline SPRLOGIT3 & 1.92 & 7.3 & 1.41 & 17 & 31 & 0 & 2.34 & 5.2 & 1.90 & 6 & 11 & -10 \\
\hline SPRLOGIT4 & 1.91 & 7.3 & 1.40 & 16 & 30 & 0 & 2.31 & 5.1 & 1.85 & 6 & 11 & -10 \\
\hline SPRLOGIT5 & 1.90 & 7.3 & 1.40 & 16 & 30 & 0 & 2.30 & 5.1 & 1.82 & 7 & 11 & -10 \\
\hline SPRLOGIT6 & 1.89 & 7.3 & 1.39 & 14 & 30 & 3 & 2.29 & 5.0 & 1.80 & 7 & 11 & -10 \\
\hline SPRLOGIT7 & 1.89 & 7.2 & 1.39 & 14 & 30 & 3 & 2.29 & 4.9 & 1.80 & 7 & 12 & -10 \\
\hline SPRLOGIT8 & 1.89 & 7.2 & 1.39 & 15 & 28 & 3 & 2.30 & 4.9 & 1.82 & 6 & 13 & -10 \\
\hline SPRLOGIT9 & 1.88 & 7.2 & 1.39 & 15 & 29 & 3 & 2.31 & 4.8 & 1.84 & 5 & 13 & -10 \\
\hline WAOPT & 3.05 & 7.8 & 2.53 & 22 & 35 & -7 & 3.34 & 5.9 & 2.75 & 7 & 8 & -7 \\
\hline WATOL & 2.85 & 7.3 & 2.36 & 21 & 28 & -5 & 3.12 & 5.9 & 2.48 & 6 & 8 & -7 \\
\hline WAOPTLIN & 2.54 & 7.3 & 1.89 & 14 & 25 & 0 & 1.74 & 3.9 & 1.50 & 3 & 7 & 4 \\
\hline WATOLLIN & 2.49 & 7.1 & 1.87 & 15 & 27 & -2 & 1.77 & 3.9 & 1.42 & 3 & 6 & 3 \\
\hline WAOPTQUAD & 2.44 & 8.0 & 1.78 & 11 & 25 & 1 & 2.05 & 4.1 & 1.86 & 2 & 8 & -1 \\
\hline WATOLQUAD & 2.39 & 7.4 & 1.74 & 11 & 26 & 2 & 2.05 & 4.5 & 1.76 & 2 & 7 & 0 \\
\hline WAOPTPOT & 2.44 & 7.7 & 1.78 & 11 & 24 & 1 & 1.79 & 3.6 & 1.63 & 2 & 8 & 3 \\
\hline WATOLPOT & 2.40 & 7.2 & 1.74 & 12 & 26 & 2 & 1.84 & 3.6 & 1.57 & 1 & 6 & 5 \\
\hline DISC & 2.00 & 10.5 & 1.32 & 11 & 27 & 3 & 4.77 & 14.0 & 3.67 & 12 & 14 & -10 \\
\hline
\end{tabular}

Abbreviations:

Indices and statistics: SE: Standard error of the estimate.- MxE: Maximum of the absolute values of the errors of the estimate.- ME: Mean of the absolute values of the errors of the estimate.- E>2: number of absolute values of the errors of the estimate exceeding $2^{\circ} \mathrm{C}$.- E>3: Idem $3^{\circ} \mathrm{C}$.- V: Evaluation of the errors of the estimate.

Techniques: SPR: Species regression.- WA: Weighted average.- DISC: Discriminant analysis. For the abbreviations of the variants, see text.

Table 3. Experiment 1a: Calibration data set of 450 samples, analog set of 155 samples and no-analog set of 27 samples. Evaluation of the variants of the species regression, weighted average and discriminant analysis techniques.

temperatures), these samples can be used to study the responses of the different techniques when they are applied to downcore samples, if the ecological responses of the species have changed over time. Also for the sake of simplification, this will be termed the no-analog set.

As described above, when the modern analog technique is applied to each sample of the calibration data set, the sample in question is excluded from the set. However, to compare the results of this technique with those of the transfer functions, an analogous procedure was followed; the 155 samples from the analog set and the 27 from the no-analog set were estimated with each of
COSLIN

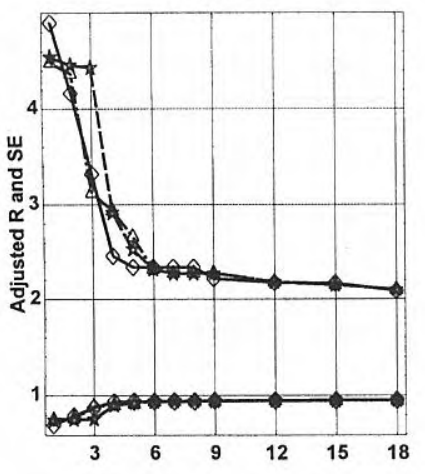

Number of principal components
COSQUAD

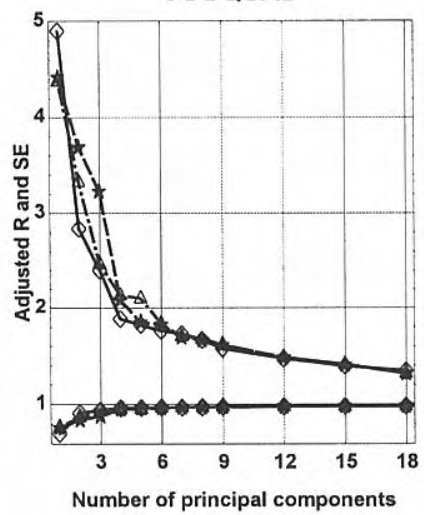

COSLIN

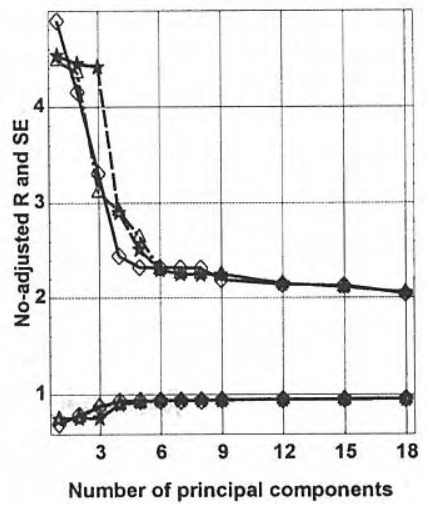

COSQUAD

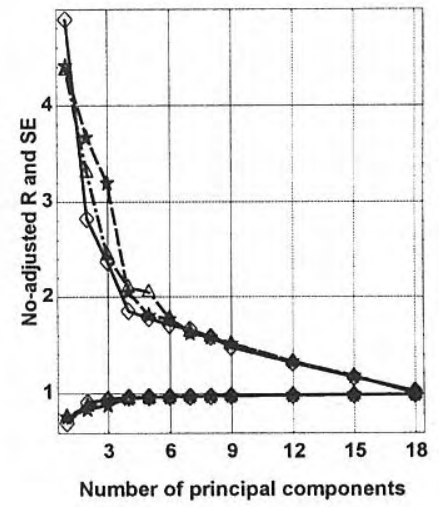

Figure 2. Principal component regression technique. Variation of the values of the multiple correlation coefficient (R) and the standard error of the residuals of the calibration data set (SE) vs. the number of principal components retained in a Q-mode analysis of the cosine-theta matrix with linear regression (COSLIN) and nonlinear equation (COSQUAD). Diamond: without rotation. Triangle: quartimax rotation. Star: varimax rotation. 


\begin{tabular}{|c|c|c|c|c|c|c|c|c|c|c|c|c|c|}
\hline \multirow{2}{*}{\multicolumn{2}{|c|}{$\mathrm{N}$}} & \multicolumn{6}{|c|}{ ANALOG SET } & \multicolumn{6}{|c|}{ NO-ANALOG SET } \\
\hline & & SE & MxE & ME & $E>3$ & $E>2$ & V & SE & MxE & ME & $E>3$ & $E>2$ & V \\
\hline c & 1 & 4.91 & 20.3 & 3.42 & 64 & 84 & -10 & 3.69 & 7.8 & 2.94 & 10 & 15 & -10 \\
\hline 0 & 2 & 4.32 & 13.5 & 3.03 & 53 & 80 & -10 & 4.71 & 13.7 & 3.15 & 9 & 13 & -10 \\
\hline $\mathbf{s}$ & 3 & 3.65 & 9.0 & 2.77 & 62 & 73 & -9 & 3.73 & 8.7 & 2.82 & 12 & 15 & -10 \\
\hline $\mathrm{N}$ & 4 & 2.78 & 10.1 & 2.06 & 37 & 55 & -10 & 2.09 & 5.8 & 1.66 & 5 & 7 & -4 \\
\hline $\mathbf{R}$ & 5 & 2.58 & 10.0 & 1.88 & 30 & 55 & -9 & 2.11 & 5.9 & 1.56 & 4 & 6 & -2 \\
\hline L & 6 & 2.58 & 9.8 & 1.89 & 31 & 56 & -9 & 2.11 & 5.8 & 1.57 & 4 & 6 & -2 \\
\hline 1 & 7 & 2.59 & 9.7 & 1.89 & 32 & 57 & -9 & 2.13 & 5.8 & 1.59 & 5 & 7 & -3 \\
\hline $\mathrm{N}$ & 8 & 2.58 & 9.6 & 1.89 & 32 & 56 & -9 & 2.13 & 5.8 & 1.59 & 5 & 7 & -3 \\
\hline & 9 & 2.44 & 11.3 & 1.75 & 27 & 51 & -9 & 2.02 & 5.6 & 1.44 & 4 & 8 & -1 \\
\hline & 12 & 2.40 & 11.9 & 1.71 & 26 & 47 & -8 & 2.03 & 5.3 & 1.55 & 4 & 8 & -2 \\
\hline & 15 & 2.39 & 11.8 & 1.73 & 26 & 46 & -8 & 2.03 & 5.5 & 1.53 & 4 & 9 & -3 \\
\hline & 18 & 2.32 & 12.1 & 1.61 & 23 & 38 & -7 & 2.14 & 5.3 & 1.77 & 4 & 7 & -3 \\
\hline 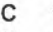 & 1 & 4.91 & 20.4 & 3.42 & 65 & 85 & -10 & 3.65 & 7.6 & 2.92 & 10 & 15 & -10 \\
\hline 0 & 2 & 3.29 & 10.3 & 2.44 & 45 & 78 & -10 & 3.93 & 10.1 & 3.17 & 12 & 18 & -10 \\
\hline S & 3 & 2.84 & 8.6 & 2.14 & 36 & 66 & -8 & 2.70 & 5.3 & 2.4 & 10 & 18 & -10 \\
\hline $\mathrm{N}$ & 4 & 2.34 & 12.7 & 1.68 & 23 & 54 & -8 & 2.10 & 4.4 & 1.82 & 4 & 11 & -8 \\
\hline $\mathbf{R}$ & 5 & 2.32 & 13.7 & 1.61 & 21 & 47 & -7 & 2.02 & 4.1 & 1.72 & 3 & 9 & -2 \\
\hline$Q$ & 6 & 2.26 & 9.7 & 1.64 & 25 & 46 & -8 & 2.37 & 6.7 & 2.09 & 5 & 13 & -10 \\
\hline U & 7 & 2.23 & 10.3 & 1.61 & 24 & 44 & -6 & 2.40 & 6.6 & 2.16 & 6 & 14 & -10 \\
\hline A & 8 & 2.16 & 7.4 & 1.56 & 25 & 41 & -2 & 2.35 & 5.7 & 2.16 & 4 & 16 & -9 \\
\hline D & 9 & 2.23 & 8.1 & 1.53 & 25 & 37 & -3 & 2.41 & 7.5 & 2.05 & 5 & 10 & -9 \\
\hline 1 & 2 & 2.16 & 8.3 & 1.42 & 20 & 38 & -3 & 2.26 & 6.4 & 2.06 & 3 & 11 & -8 \\
\hline 1 & 5 & 2.13 & 9.4 & 1.44 & 16 & 39 & -4 & 2.13 & 5.2 & 1.66 & 4 & 7 & 3 \\
\hline & 182 & 2.73 & 15.1 & 1.78 & 24 & 47 & -10 & 2.59 & 5.9 & 2.28 & & 15 & 70 \\
\hline
\end{tabular}

$\begin{array}{llllllllllllll}\text { C } & 1 & 4.61 & 17.8 & 3.09 & 54 & 75 & -10 & 4.02 & 10.4 & 3.04 & 12 & 14 & -10\end{array}$ $\begin{array}{llllllllllllll}0 & 2 & 4.49 & 14.9 & 3.12 & 56 & 74 & -10 & 4.71 & 13.4 & 3.22 & 10 & 14 & -10\end{array}$ $\begin{array}{llllllllllllll}\mathrm{S} & 3 & 3.46 & 8.4 & 2.61 & 58 & 73 & -8 & 3.17 & 6.6 & 2.41 & 9 & 13 & -10\end{array}$ $\begin{array}{llllllllllllll}\mathrm{Q} & 4 & 3.30 & 9.2 & 2.48 & 49 & 73 & -9 & 2.68 & 6.5 & 2.23 & 7 & 13 & -10\end{array}$ $\begin{array}{llllllllllllll}\mathrm{X} & 5 & 2.91 & 8.0 & 2.16 & 48 & 66 & -7 & 2.30 & 5.5 & 2.04 & 8 & 12 & -10\end{array}$ $\begin{array}{llllllllllllll}\mathrm{L} & 6 & 2.57 & 8.6 & 1.93 & 35 & 61 & -7 & 2.20 & 5.3 & 1.88 & 6 & 9 & -7\end{array}$ $\begin{array}{llllllll}7 & 2.49 & 10.3 & 1.83 & 31 & 51 & -9 & 2.05\end{array}$

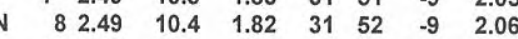
$\begin{array}{llllllll}9 & 2.48 & 10.3 & 1.82 & 31 & 52 & -9 & 2.06\end{array}$ $\begin{array}{llllllll}12 & 2.41 & 12.0 & 1.72 & 27 & 46 & -8 & 2.06\end{array}$ $\begin{array}{llllllll}15 & 2.37 & 11.6 & 1.71 & 24 & 44 & -8 & 2.05\end{array}$ $\begin{array}{llllllll}18 & 2.34 & 11.5 & 1.65 & 23 & 39 & -8 & 2.10\end{array}$

$\begin{array}{lllllllll}\text { C } & 1 & 4.49 & 18.8 & 3.19 & 57 & 80 & -10 & 3.63\end{array}$ $\begin{array}{rrrrrrrrr}\mathrm{O} & 2 & 3.84 & 14.8 & 2.76 & 54 & 75 & -10 & 4.59\end{array}$ $\begin{array}{lllllllll}\mathrm{Q} & 4 & 2.59 & 8.7 & 1.89 & 31 & 57 & -7 & 2.41 \\ \mathrm{X} & 5 & 2.57 & 8.9 & 1.88 & 33 & 56 & -8 & 2.39\end{array}$ $\begin{array}{lllllllll}\mathrm{X} & 5 & 2.57 & 8.9 & 1.88 & 33 & 56 & -8 & 2.39\end{array}$ $\begin{array}{lllllllll}Q & 6 & 2.37 & 10.2 & 1.68 & 27 & 42 & -8 & 2.51\end{array}$ $\begin{array}{lllllllll}\mathrm{U} & 7 & 2.24 & 11.2 & 1.59 & 22 & 44 & -6 & 2.40\end{array}$ $\begin{array}{lllllllll}\text { A } & 8 & 2.22 & 10.4 & 1.54 & 22 & 38 & -6 & 2.50\end{array}$ $\begin{array}{lllllllll}\text { D } & 9 & 2.16 & 9.2 & 1.49 & 19 & 37 & -4 & 2.44\end{array}$ $\begin{array}{llllllll}12 & 2.21 & 7.7 & 1.49 & 20 & 34 & -2 & 2.26\end{array}$ $\begin{array}{llllllll}15 & 2.29 & 10.2 & 1.54 & 20 & 35 & -7 & 2.60\end{array}$ $\begin{array}{llllllll}18 & 2.70 & 14.6 & 1.76 & 22 & 44 & -10 & 2.63\end{array}$

C $\quad \begin{array}{llllllll}1 & 4.66 & 17.4 & 3.12 & 53 & 75 & -10 & 4.28\end{array}$ $\begin{array}{llllllllll}0 & 2 & 4.57 & 14.9 & 3.13 & 56 & 74 & -10 & 4.85 & 13.7\end{array}$ $\begin{array}{llllllll}4 & 3.28 & 9.2 & 2.46 & 48 & 75 & -9 & 2.69\end{array}$ $\begin{array}{lllllllll}\times & 5 & 2.87 & 8.7 & 2.12 & 42 & 59 & -8 & 2.44\end{array}$ $\begin{array}{lllllllll}\mathrm{L} & 6 & 2.56 & 8.7 & 1.92 & 34 & 61 & -7 & 2.19\end{array}$ $\begin{array}{lllllllll}\mathrm{I} & 7 & 2.49 & 10.4 & 1.83 & 31 & 51 & -9 & 2.05 \\ \mathrm{~N} & 8 & 2.48 & 10.5 & 1.82 & 31 & 51 & -9 & 2.05\end{array}$ $\begin{array}{llllllll}9 & 2.48 & 10.4 & 1.82 & 31 & 51 & -9 & 2.05\end{array}$ $\begin{array}{llllllll}12 & 2.41 & 12.0 & 1.72 & 27 & 46 & -8 & 2.05\end{array}$ $\begin{array}{llllllll}15 & 2.37 & 11.6 & 1.70 & 24 & 44 & -8 & 2.06\end{array}$ $\begin{array}{llllllll}18 & 2.34 & 11.5 & 1.65 & 23 & 39 & -8 & 2.10\end{array}$

$\begin{array}{lllllllll}\text { C } & 1 & 4.52 & 18.3 & 3.22 & 59 & 83 & -10 & 3.98\end{array}$ $\begin{array}{lllllllll}0 & 2 & 4.13 & 15.8 & 2.94 & 54 & 72 & -10 & 5.16\end{array}$ $\begin{array}{lllllllll}\mathrm{S} & 3 & 3.56 & 16.7 & 2.47 & 45 & 69 & -10 & 4.31\end{array}$ $\begin{array}{lllllllll}\mathrm{V} & 4 & 2.54 & 8.4 & 1.85 & 32 & 55 & -7 & 2.37\end{array}$ $\begin{array}{lllllllll}X & 5 & 2.43 & 9.7 & 1.76 & 28 & 47 & -8 & 2.44\end{array}$ $\begin{array}{lllllllll}Q & 6 & 2.37 & 10.3 & 1.68 & 26 & 42 & -8 & 2.49\end{array}$ $\begin{array}{lllllllll}\mathrm{U} & 7 & 2.24 & 11.2 & 1.59 & 22 & 43 & -6 & 2.42\end{array}$ $\begin{array}{lllllllll}A & 8 & 2.22 & 10.5 & 1.54 & 21 & 39 & -6 & 2.50\end{array}$ $\begin{array}{lllllll}15 & 9.3 & 1.48 & 19 & 38 & -4 & 2.44\end{array}$ $\begin{array}{llllllll}12 & 2.20 & 7.8 & 1.48 & 20 & 34 & -2 & 2.26\end{array}$ $\begin{array}{llllllll}15 & 2.31 & 10.4 & 1.54 & 20 & 36 & -7 & 2.62\end{array}$ $\begin{array}{llllllll}18 & 2.70 & 14.4 & 1.77 & 23 & 44 & -10 & 2.63\end{array}$ $\begin{array}{lllll}5.6 & 1.52 & 4 & 9 & -2 \\ 5.5 & 1.52 & 4 & 9 & -2\end{array}$

$\begin{array}{lllll}5.6 & 1.52 & 4 & 9 & -2\end{array}$

$\begin{array}{lllll}5.6 & 1.51 & 4 & 9 & -2\end{array}$

$\begin{array}{lllll}5.4 & 1.57 & 4 & 9 & 3\end{array}$

$\begin{array}{lllll}5.4 & 1.62 & 4 & 7 & -1 \\ 5.3 & 1.71 & 4 & 7 & -3\end{array}$

$\begin{array}{lllll}9.0 & 2.78 & 10 & 14 & -10\end{array}$ $\begin{array}{llllll}11.7 & 3.63 & 14 & 17 & -10\end{array}$ $\begin{array}{lllll}6.7 & 2.51 & 10 & 15 & -10\end{array}$ $\begin{array}{lllll}4.6 & 2.24 & 7 & 18 & -10\end{array}$ $\begin{array}{lllll}5.6 & 2.23 & 7 & 15 & -10\end{array}$ $\begin{array}{lllll}6.4 & 2.28 & 6 & 16 & -10\end{array}$ $\begin{array}{lllll}6.8 & 2.16 & 6 & 12 & -10\end{array}$ $\begin{array}{lllll}7.5 & 2.23 & 6 & 11 & -10\end{array}$ $\begin{array}{lllll}6.7 & 2.22 & 6 & 13 & -10\end{array}$ $\begin{array}{lllll}195 & 3 & 11 & -8\end{array}$ $\begin{array}{lll}6 & 12 & -10\end{array}$ $\begin{array}{rrrrr}14.0 & 3.55 & 12 & 17 & -10 \\ 6.5 & 2.24 & 8 & 13 & -10\end{array}$ $\begin{array}{llllll}6.1 & 2.00 & 5 & 11 & -10\end{array}$ $\begin{array}{lllll}5.3 & 1.87 & 7 & 9 & -7\end{array}$ $\begin{array}{lllll}5.5 & 1.52 & 4 & 9 & -2\end{array}$ $\begin{array}{lllll}5.5 & 1.51 & 4 & 9 & -2\end{array}$ $\begin{array}{lllll}5.6 & 1.5 & 4 & 9 & -2\end{array}$ $\begin{array}{lllll}5.4 & 1.56 & 4 & 9 & -3\end{array}$ $\begin{array}{lllll}5.4 & 1.63 & 4 & 7 & -1\end{array}$ $\begin{array}{lllll}5.3 & 1.71 & 4 & 7 & 3\end{array}$

$\begin{array}{lllll}10.1 & 3.04 & 9 & 14 & -10\end{array}$ $\begin{array}{lllll}12.6 & 3.98 & 15 & 18 & -10\end{array}$ $\begin{array}{lllll}1.4 & 3.35 & 11 & 17 & -10\end{array}$ $\begin{array}{lllll}4.4 & 2.21 & 7 & 17 & -10\end{array}$ $\begin{array}{lllll}4.9 & 2.23 & 6 & 16 & -10\end{array}$ $\begin{array}{lllll}6.3 & 2.26 & 5 & 16 & -10\end{array}$ $\begin{array}{lllll}6.9 & 2.18 & 6 & 12 & -10\end{array}$ $\begin{array}{lllll}7.5 & 2.23 & 6 & 12 & -10\end{array}$ $\begin{array}{lllll}6.8 & 2.22 & 7 & 13 & -10\end{array}$ $\begin{array}{lllll}6.1 & 1.96 & 3 & 12 & -8\end{array}$ $\begin{array}{llllll}6.1 & 2.29 & 7 & 11 & -10\end{array}$ $\begin{array}{lllll}6.6 & 2.2 & 6 & 10 & -9\end{array}$
ANALOG SET

NO-ANALOG SET

\section{N SE MXE ME E>3 E>2 V}

MXE ME E>3 E>2

$\begin{array}{rrrrrrrrrrrrrr}\mathrm{R} & 3 & 2.66 & 8.4 & 1.97 & 35 & 61 & -8 & 2.75 & 6.5 & 2.08 & 7 & 13 & -10\end{array}$

$\begin{array}{llllllllllllll}\mathrm{N} & 4 & 2.68 & 8.4 & 1.97 & 35 & 61 & -8 & 2.75 & 6.5 & 2.06 & 9 & 13 & -10\end{array}$

$\begin{array}{llllllllllllll}\mathrm{R} & 5 & 2.47 & 8.2 & 1.81 & 26 & 51 & -6 & 1.93 & 3.8 & 1.88 & 4 & 12 & -5\end{array}$

$\begin{array}{llllllllllllll}\mathrm{L} & 6 & 2.48 & 8.2 & 1.81 & 27 & 49 & -6 & 1.93 & 3.9 & 1.88 & 4 & 12 & -6\end{array}$

$\begin{array}{lllllllllllll}7 & 2.34 & 8.6 & 1.68 & 24 & 41 & -6 & 1.90 & 3.6 & 1.68 & 3 & 11 & -2\end{array}$

$\begin{array}{llllllllllllll}\mathrm{N} & 8 & 2.31 & 8.3 & 1.62 & 22 & 42 & -5 & 1.89 & 3.9 & 1.59 & 1 & 10 & 1\end{array}$ $\begin{array}{lllllllllllll}9 & 2.30 & 8.2 & 1.63 & 22 & 41 & -5 & 1.89 & 3.9 & 1.58 & 1 & 10 & 1\end{array}$ $\begin{array}{rrrrllllllllll}12 & 2.10 & 9.9 & 1.46 & 22 & 40 & -5 & 1.97 & 3.7 & 1.71 & 2 & 10 & -1 \\ 15 & 2.04 & 10.0 & 1.44 & 20 & 36 & 4 & 1.96 & 3.7 & 1.67 & 3 & 9 & -1\end{array}$ $\begin{array}{lllllllllllll}15 & 2.04 & 10.0 & 1.44 & 20 & 36 & -4 & 1.96 & 3.7 & 1.67 & 3 & 9 & -1 \\ 18 & 2.07 & 11.2 & 1.42 & 20 & 35 & -5 & 1.97 & 3.6 & 1.75 & 3 & 9 & -1\end{array}$

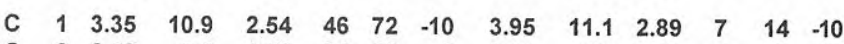
$\begin{array}{llllllllllllll}\mathrm{O} & 2 & 2.58 & 9.2 & 1.94 & 31 & 60 & -8 & 2.64 & 5.9 & 2.34 & 7 & 17 & -10\end{array}$ $\begin{array}{llllllllllllll}\mathrm{R} & 3 & 2.44 & 9.1 & 1.85 & 29 & 53 & -8 & 2.64 & 4.8 & 2.34 & 5 & 19 & -10\end{array}$ $\begin{array}{llllllllllllll}\mathrm{N} & 4 & 2.25 & 8.9 & 1.62 & 25 & 42 & -6 & 2.66 & 5.5 & 2.09 & 6 & 13 & -10\end{array}$ $\begin{array}{llllllllllllll}\mathrm{R} & 5 & 2.09 & 7.8 & 1.50 & 23 & 41 & -2 & 2.39 & 7.0 & 1.78 & 4 & 9 & -7\end{array}$ $\begin{array}{llllllllllllll}\mathrm{Q} & 6 & 1.96 & 8.0 & 1.38 & 19 & 35 & 0 & 2.23 & 6.0 & 1.65 & 4 & 8 & -3\end{array}$ $\begin{array}{llllllllllllll}\mathrm{U} & 7 & 1.89 & 8.7 & 1.26 & 14 & 28 & 3 & 1.89 & 4.1 & 1.53 & 3 & 7 & 2\end{array}$ $\begin{array}{llllllllllllll}\text { A } & 8 & 1.90 & 11.5 & 1.25 & 11 & 27 & 4 & 2.02 & 4.4 & 1.82 & 3 & 8 & -3\end{array}$ $\begin{array}{llllllllllllll}D & 9 & 1.87 & 10.9 & 1.24 & 12 & 26 & 4 & 2.13 & 5.1 & 1.87 & 2 & 12 & -6\end{array}$ $\begin{array}{lllllllllllll}10 & 1.90 & 12.0 & 1.23 & 12 & 25 & 5 & 2.26 & 6.7 & 1.88 & 4 & 11 & -9\end{array}$ $\begin{array}{lllllllllllll}11 & 1.96 & 12.1 & 1.27 & 14 & 28 & 1 & 2.51 & 7.7 & 2.09 & 4 & 13 & -9\end{array}$ $\begin{array}{lllllllllllll}12 & 2.00 & 12.4 & 1.32 & 16 & 29 & -2 & 2.65 & 8.1 & 2.20 & 6 & 14 & -10\end{array}$ $\begin{array}{lllllllllllll}15 & 1.97 & 8.5 & 1.35 & 14 & 31 & 1 & 2.89 & 7.2 & 2.31 & 8 & 13 & -10\end{array}$ $\begin{array}{lllllllllllll}18 & 2.54 & 15.0 & 1.70 & 24 & 47 & -9 & 2.98 & 6.7 & 2.33 & 7 & 14 & -10\end{array}$

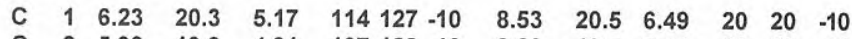
$\begin{array}{llllllllllllll}0 & 2 & 5.93 & 19.3 & 4.91 & 107 & 128 & -10 & 8.29 & 19.5 & 6.44 & 20 & 20 & -10\end{array}$ $\begin{array}{lllllllllllllll}R & 3 & 3.33 & 11.0 & 2.56 & 50 & 81 & -10 & 3.88 & 10.4 & 2.88 & 9 & 15 & -10\end{array}$ $\begin{array}{llllllllllllll}\mathrm{E} & 4 & 3.31 & 11.1 & 2.55 & 49 & 81 & -10 & 3.75 & 9.7 & 2.93 & 11 & 15 & -10\end{array}$ $\begin{array}{llllllllllllll}X & 5 & 3.28 & 9.6 & 2.47 & 51 & 70 & -10 & 3.14 & 7.9 & 2.47 & 9 & 12 & -10\end{array}$ $\begin{array}{llllllllllllll}\mathrm{L} & 6 & 2.91 & 8.0 & 2.07 & 42 & 57 & -7 & 2.04 & 4.1 & 1.89 & 5 & 11 & -7\end{array}$ $\begin{array}{llllllllllllll}\mathrm{I} & 7 & 2.32 & 8.4 & 1.69 & 26 & 46 & -6 & 1.87 & 3.7 & 1.65 & 2 & 10 & 1 \\ \mathrm{~N} & 8 & 2.26 & 8.5 & 1.62 & 23 & 42 & -5 & 1.84 & 3.1 & 1.58 & 2 & 10 & 3\end{array}$ $\begin{array}{lllllllllllll}9 & 2.20 & 9.3 & 1.56 & 21 & 41 & -5 & 1.97 & 4.6 & 1.66 & 2 & 8 & -1\end{array}$ $\begin{array}{lllllllllllll}12 & 2.11 & 9.9 & 1.53 & 19 & 39 & -6 & 1.96 & 4.2 & 1.71 & 1 & 10 & -2\end{array}$ $\begin{array}{lllllllllllll}15 & 1.99 & 8.2 & 1.44 & 18 & 29 & 0 & 1.92 & 3.1 & 1.72 & 2 & 9 & 3\end{array}$ $\begin{array}{lllllllllllll}18 & 1.97 & 7.9 & 1.42 & 18 & 31 & -1 & 1.93 & 3.4 & 1.71 & 2 & 9 & 1\end{array}$

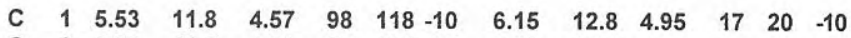
$\begin{array}{llllllllllllll}\mathrm{O} & 2 & 5.06 & 11.2 & 4.21 & 84 & 114 & -10 & 5.83 & 12.4 & 4.84 & 19 & 22 & -10\end{array}$ $\begin{array}{llllllllllllll}R & 3 & 2.67 & 8.0 & 2.05 & 40 & 69 & -7 & 2.84 & 8.0 & 2.29 & 8 & 13 & -10\end{array}$ $\begin{array}{llllllllllllll}\text { E } & 4 & 2.48 & 7.1 & 1.90 & 29 & 53 & -5 & 2.15 & 3.7 & 1.79 & 4 & 10 & -5\end{array}$ $\begin{array}{llllllllllllll}\mathrm{X} & 5 & 2.32 & 8.9 & 1.66 & 24 & 44 & -6 & 2.18 & 4.9 & 1.64 & 5 & 10 & -6\end{array}$ $\begin{array}{llllllllllllll}\mathrm{Q} & 6 & 2.25 & 8.5 & 1.64 & 21 & 50 & -6 & 2.00 & 4.9 & 1.57 & 3 & 10 & -3\end{array}$ $\begin{array}{llllllllllllll}\mathrm{U} & 7 & 2.02 & 9.9 & 1.41 & 18 & 31 & -4 & 1.82 & 4.3 & 1.50 & 2 & 7 & 3\end{array}$ $\begin{array}{llllllllllllll}\mathrm{A} & 8 & 1.98 & 10.3 & 1.33 & 16 & 38 & -3 & 1.97 & 5.8 & 1.47 & 4 & 8 & -1 \\ \mathrm{D} & 9 & 1.92 & 12.1 & 1.24 & 15 & 29 & 0 & 1.98 & 5.8 & 1.46 & 4 & 6 & 0\end{array}$ $\begin{array}{lllllllllllll}12 & 2.20 & 13.3 & 1.44 & 19 & 36 & -5 & 2.03 & 4.5 & 1.56 & 3 & 7 & 0\end{array}$ $\begin{array}{lllllllllllll}15 & 2.48 & 13.7 & 1.59 & 20 & 38 & -8 & 3.40 & 10.6 & 2.48 & 4 & 14 & -9\end{array}$ $\begin{array}{lllllllllllll}18 & 2.92 & 17.5 & 1.81 & 25 & 45 & -10 & 3.48 & 8.8 & 2.58 & 8 & 14 & -10\end{array}$

$\begin{array}{llllllllllllll}\text { C } & 1 & 4.55 & 16.1 & 3.22 & 55 & 77 & -10 & 5.58 & 16.4 & 3.66 & 11 & 15 & -10\end{array}$ $\begin{array}{llllllllllllll}0 & 2 & 3.95 & 16.1 & 2.89 & 56 & 79 & -10 & 5.51 & 16.4 & 3.58 & 10 & 15 & -10\end{array}$ $\begin{array}{llllllllllllll}\mathrm{R} & 3 & 3.93 & 15.8 & 2.90 & 58 & 79 & -10 & 5.43 & 16.1 & 3.50 & 11 & 16 & -10\end{array}$ $\begin{array}{llllllllllllll}\mathrm{Q} & 4 & 3.38 & 8.8 & 2.63 & 48 & 87 & -8 & 3.65 & 8.5 & 2.86 & 11 & 14 & -10\end{array}$ $\begin{array}{llllllllllllll}X & 5 & 3.03 & 7.5 & 2.39 & 55 & 76 & -6 & 2.60 & 5.3 & 2.40 & 10 & 16 & -10\end{array}$ $\begin{array}{llllllllllllll}\mathrm{L} & 6 & 2.94 & 7.2 & 2.33 & 48 & 76 & -6 & 2.55 & 5.1 & 2.34 & 8 & 16 & -10\end{array}$ $\begin{array}{lllllllllllll}7 & 2.23 & 9.2 & 1.68 & 26 & 51 & -6 & 2.44 & 5.1 & 2.11 & 7 & 13 & -10\end{array}$ $\begin{array}{lllllllllllll}8 & 2.19 & 10.6 & 1.54 & 21 & 38 & -6 & 2.21 & 4.4 & 1.92 & 5 & 12 & -9\end{array}$ $\begin{array}{llllllllllllll}9 & 2.18 & 10.7 & 1.52 & 22 & 38 & -6 & 2.22 & 4.3 & 1.92 & 4 & 10 & -7\end{array}$ $\begin{array}{rrrrrrrrrrrrr}12 & 2.10 & 9.9 & 1.49 & 21 & 36 & -5 & 2.25 & 4.5 & 1.92 & 4 & 9 & -7\end{array}$ $\begin{array}{lllllllllllll}18 & 1.95 & 8.0 & 1.40 & 20 & 31 & -1 & 2.22 & 4.9 & 1.85 & 4 & 9 & -6\end{array}$

$\begin{array}{llllllllllllll}\text { C } & 1 & 4.62 & 15.3 & 3.22 & 50 & 75 & -10 & 5.43 & 15.6 & 3.74 & 10 & 17 & -10\end{array}$ $\begin{array}{llllllllllllll}0 & 2 & 3.49 & 13.9 & 2.57 & 52 & 75 & -10 & 4.95 & 14.2 & 3.49 & 11 & 16 & -10\end{array}$ $\begin{array}{llllllllllllll}\mathrm{R} & 3 & 3.07 & 10.3 & 2.27 & 41 & 69 & -10 & 3.68 & 9.1 & 2.80 & 8 & 13 & -10\end{array}$ $\begin{array}{llllllllllllll}Q & 4 & 2.52 & 8.1 & 1.87 & 30 & 60 & -6 & 2.68 & 5.7 & 2.24 & 7 & 13 & -10\end{array}$ $\begin{array}{llllllllllllll}X & 5 & 2.24 & 7.2 & 1.65 & 22 & 42 & -3 & 2.72 & 6.1 & 2.17 & 8 & 12 & -10\end{array}$ $\begin{array}{llllllllllllll}Q & 6 & 2.07 & 6.9 & 1.46 & 18 & 41 & -1 & 2.32 & 6.9 & 1.79 & 4 & 8 & -6\end{array}$ $\begin{array}{llllllllllllll}U & 7 & 1.93 & 10.9 & 1.23 & 12 & 26 & 4 & 2.16 & 5.1 & 1.65 & 5 & 9 & -5\end{array}$

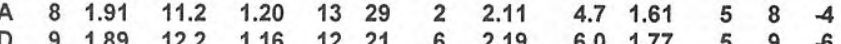
$\begin{array}{lllllllllllll}10 & 2.04 & 12.7 & 1.29 & 13 & 24 & 3 & 2.13 & 5.0 & 1.80 & 4 & 9 & -6\end{array}$ $\begin{array}{lllllllllllll}11 & 2.07 & 13.6 & 1.31 & 15 & 25 & 0 & 2.23 & 4.7 & 1.88 & 4 & 11 & -8\end{array}$ $\begin{array}{lllllllllllll}12 & 2.03 & 11.2 & 1.34 & 16 & 29 & -2 & 2.02 & 4.7 & 1.69 & 3 & 10 & -4\end{array}$ $\begin{array}{lllllllllllll}15 & 2.32 & 10.4 & 1.54 & 22 & 42 & -7 & 2.78 & 7.5 & 2.28 & 6 & 12 & -10\end{array}$ $\begin{array}{lllllllllllll}18 & 2.40 & 13.1 & 1.58 & 25 & 40 & -7 & 3.05 & 10.3 & 2.30 & 5 & 11 & -10\end{array}$ 


\begin{tabular}{|c|c|c|c|c|c|c|c|c|c|c|c|c|c|c|c|c|c|c|c|c|c|c|c|c|c|c|c|}
\hline \multirow[b]{3}{*}{ C } & \multirow[b]{2}{*}{$N$} & \multicolumn{6}{|c|}{ ANALOG SET } & & NO-A & NALO & SET & & & & & & ANALC & OG SE & & & & & NO-AI & NALOC & $\mathrm{SE}$ & & \\
\hline & & SE & MxE & ME & $E>3$ & $E>2$ & V & SE & MxE & ME & $E>3$ & $E>2$ & V & & $\mathrm{N}$ & & MxE & ME & $E>3$ & $E>2$ & V & SE & MxE & ME & $E>3$ & $E>2$ & V \\
\hline & 1 & 4.61 & 16.4 & 3.26 & 55 & 77 & -10 & 5.69 & 16.7 & 3.71 & 11 & 15 & -10 & V & 1 & 4.96 & 17.1 & 3.47 & 54 & 83 & -10 & 6.08 & 17.4 & & 12 & 15 & -10 \\
\hline 0 & 2 & 4.03 & 16.4 & 2.95 & 58 & 80 & -10 & 5.62 & 16.7 & 3.64 & 11 & 15 & -10 & C & 2 & 3.77 & 10.4 & 2.81 & 61 & 75 & -10 & 3.12 & 8.9 & 2.21 & 8 & 11 & -10 \\
\hline $\mathbf{R}$ & 3 & 4.02 & 16.2 & 2.96 & 58 & 81 & -10 & 5.57 & 16.5 & 3.58 & 11 & 16 & -10 & V & 3 & 2.51 & 9.8 & 1.78 & 27 & 48 & -9 & 1.75 & 4.1 & 1.45 & 1 & 8 & 5 \\
\hline V & 4 & 3.45 & 9.1 & 2.67 & 52 & 89 & -9 & 3.66 & 8.5 & 2.89 & 11 & 14 & -10 & E & 4 & 2.53 & 9.8 & 1.82 & 31 & 51 & -9 & 1.81 & 4.4 & 1.55 & 3 & 8 & 0 \\
\hline$x$ & 5 & 3.10 & 7.5 & 2.44 & 56 & 76 & -6 & 2.62 & 5.3 & 2.42 & 10 & 17 & -10 & $x$ & 5 & 2.50 & 12.6 & 1.73 & 25 & 51 & -9 & 3.10 & 12.2 & 2.04 & 5 & 7 & -6 \\
\hline L & 6 & 2.98 & 7.1 & 2.36 & 48 & 76 & -6 & 2.55 & 5.0 & 2.35 & 8 & 16 & -10 & $\mathbf{Q}$ & 6 & & 12.6 & 1.56 & 18 & 44 & -6 & 2.83 & 10.6 & 2.00 & 6 & 8 & -7 \\
\hline 1 & 7 & 2.21 & 9.3 & 1.66 & 26 & 49 & -6 & 2.43 & 5.0 & 2.10 & 7 & 13 & -10 & $\mathrm{U}$ & 7 & & 13.1 & 1.48 & 17 & 38 & -5 & 2.85 & 10.3 & 2.05 & 5 & 10 & -9 \\
\hline $\mathrm{N}$ & 8 & 2.19 & 10.7 & 1.53 & 21 & 38 & -6 & 2.20 & 4.3 & 1.92 & 4 & 12 & -8 & A & 8 & 2.25 & 14.8 & 1.45 & 16 & 36 & -6 & 2.70 & 9.5 & 1.89 & 3 & 7 & -4 \\
\hline & 9 & 2.18 & 10.8 & 1.51 & 20 & 37 & -6 & 2.22 & 4.3 & 1.92 & 4 & 10 & -7 & D & 9 & 2.27 & 14.1 & 1.40 & 15 & 34 & -5 & 2.57 & 8.9 & 1.83 & 3 & 8 & -5 \\
\hline & 12 & 2.08 & 10.5 & 1.49 & 19 & 35 & -5 & 2.02 & 4.1 & 1.7 & 3 & 10 & -4 & & 12 & 2.31 & 11.8 & 1.47 & 15 & 32 & -5 & 2.70 & 7.0 & 1.99 & 6 & 9 & -8 \\
\hline & 15 & 1.99 & 8.9 & 1.43 & 19 & 30 & -3 & 1.97 & 3.8 & 1.7 & 3 & 9 & -1 & & 15 & 2.65 & 19.2 & 1.56 & 14 & 32 & -7 & 2.59 & 5.8 & 1.97 & 6 & 10 & -9 \\
\hline & 18 & 1.98 & 9.4 & 1.42 & 19 & 30 & -3 & 1.97 & 4.1 & 1.70 & 2 & 8 & 0 & & 18 & 3.04 & 24.1 & 1.75 & 25 & 39 & -10 & 3.93 & 9.8 & 2.85 & 8 & 13 & -10 \\
\hline C & 1 & 4.67 & 15.6 & 3.26 & 50 & 75 & -10 & 5.53 & 9 & 3.79 & 11 & 16 & -10 & V & 1 & 4.77 & 1 & 3 & 60 & 78 & -10 & 5.68 & 16.3 & 3.73 & 11 & 15 & -10 \\
\hline 0 & 2 & 3.54 & 14 & 2.58 & 51 & 77 & -10 & 5.02 & 6 & 3. & 10 & 15 & -1 & C & 2 & 4.26 & & & 51 & 71 & -10 & & 7.3 & 2.28 & 8 & 15 & -10 \\
\hline$R$ & 3 & 3.15 & 10.3 & 2.32 & 43 & 70 & -10 & 3.72 & 9.5 & 2.7 & 8 & 12 & -1 & V & 3 & 3.2 & & & 53 & 70 & -7 & 5 & 5.1 & 1.91 & 7 & 12 & -10 \\
\hline V & 4 & 2.55 & 7 & 1.90 & 30 & 61 & -6 & 2.68 & 5.9 & 2. & 7 & 12 & -1 & Q & 4 & 2.78 & & & 29 & 56 & -10 & & 3.5 & 1. & 4 & 7 & 3 \\
\hline$x$ & 5 & 2.27 & & 1.68 & 23 & 44 & -4 & 2.71 & 6.0 & 2. & 8 & 13 & -1 & $\bar{x}$ & 5 & 2.77 & & & 32 & 56 & -10 & & 3.6 & 1. & 3 & 7 & 3 \\
\hline $\mathbf{Q}$ & 6 & 2.10 & & 1.50 & 18 & 42 & -1 & 232 & 7.1 & 1.7 & 4 & 8 & -6 & L & 6 & 2.29 & 1 & & 22 & 42 & -7 & & 3.5 & 1. & 2 & 6 & 7 \\
\hline$U$ & 7 & 1.94 & 10. & 1.25 & 11 & 26 & 4 & 2. & 5.2 & 1.6 & 5 & 8 & -4 & $\bar{I}$ & 7 & 2.29 & 11 & & 22 & 42 & -7 & & 3.5 & & 2 & 6 & 7 \\
\hline A & 8 & 1.9 & & 1.2 & 13 & 29 & 2 & 2.1 & 4.8 & 1.6 & 5 & 8 & -4 & $\mathrm{~N}$ & 8 & 2.28 & 11 & & 23 & 43 & -7 & & 3.8 & & 2 & 6 & 6 \\
\hline D & 9 & 1.89 & 1 & 1.1 & 12 & 23 & 6 & 2. & 6.1 & 1.7 & 5 & 9 & -6 & & 9 & 2.25 & 10 & & 3 & 44 & -7 & & 3.7 & & 2 & 6 & 4 \\
\hline & 10 & 2.0 & 1 & 1.29 & 13 & 26 & 2 & 2 & 5.1 & 1.8 & 4 & 8 & -5 & & 12 & 2.16 & 11 & & 0 & 38 & $-t$ & & 3.5 & 1.56 & 2 & 7 & 4 \\
\hline & 11 & 2.14 & 1 & 1.36 & 14 & 30 & -2 & 2.0 & 4.4 & 1.7 & 2 & 9 & -2 & & 15 & 2.08 & 10 & & 16 & 40 & 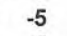 & 2.10 & 3.7 & 1.89 & 2 & 11 & -4 \\
\hline & 12 & 2.20 & 1 & 1.4 & 17 & 31 & -5 & 1.95 & 4.5 & 1.6 & 2 & 8 & 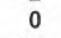 & & 18 & 2.07 & & & 18 & 36 & & & 3.3 & 1.79 & 3 & 11 & -3 \\
\hline & 15 & 2.27 & 10.9 & 1.47 & 20 & 35 & -6 & 3.44 & 11.9 & 2. & 6 & 11 & -1 & & & & & & & & & & & & & & \\
\hline & 18 & 2.54 & 12.7 & 1.60 & 22 & 42 & -8 & 3.44 & 8.9 & 2.50 & 7 & 10 & -8 & & & & & & & & & & & & & & \\
\hline V & 1 & 4.3 & 1 & 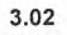 & 50 & 73 & -10 & & 5 & & 7 & 16 & -1 & V & 1 & 4.8 & 1 & 3 & 57 & 81 & -10 & 5.62 & 16.0 & 3.76 & 11 & 15 & -10 \\
\hline C & 2 & 4.1 & 1 & 2 & 49 & 68 & -1 & 2 & 6 & 2. & 7 & 15 & -10 & c & 2 & 3.6 & & 2 & 61 & 77 & -1 & 8 & 8.5 & & 8 & 11 & -10 \\
\hline V & 3 & 2.9 & 9. & 2.2 & 51 & 72 & $-\subseteq$ & 2 & 5 & 2. & 8 & 13 & -10 & V & 3 & 3.68 & & 2 & 61 & 77 & -1 & 8 & 8.5 & 2. & 8 & 11 & -10 \\
\hline $\mathrm{N}$ & 4 & 2.3 & & 1. & 23 & 46 & $-\varepsilon$ & 1 & 3 & 1. & 1 & 0 & 6 & c & 4 & 3.6 & & 2 & 61 & 77 & -10 & 8 & 8.5 & 2 & 8 & 11 & -10 \\
\hline $\mathbf{R}$ & 5 & 2.3 & 10. & 1.6 & 20 & 44 & $-\varepsilon$ & 1.7 & 3 & 1. & 1 & 7 & 9 & 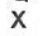 & 5 & 2.32 & & 1 & 22 & 51 & - & 2.82 & 10.6 & 1.93 & 6 & 9 & -8 \\
\hline L & 6 & 2.3 & 1 & 1.6 & 23 & 43 & $-\varepsilon$ & 1.7 & & 1. & 0 & 6 & 9 & ? & 6 & 2.2 & & 1.56 & 20 & 41 & $-\epsilon$ & 2.83 & 10.7 & 2 & 6 & 8 & -7 \\
\hline I & 7 & 2.3 & 1 & 1. & 22 & 44 & $-\varepsilon$ & 1 & 3 & 1. & 1 & 7 & 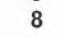 & 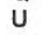 & 7 & 2. & & 1 & 18 & 38 & -2 & 2.84 & 10.3 & 4 & 6 & 11 & -10 \\
\hline $\mathrm{N}$ & 8 & 2.27 & 1 & 1. & 23 & 42 & -7 & 1 & & 1. & 2 & 6 & 7 & $A$ & 8 & 2.2 & & 1.45 & 15 & 36 & -5 & 2.71 & 9.6 & 1.89 & 4 & 7 & -5 \\
\hline & 9 & 2.2 & 10 & 1. & 23 & 42 & -7 & 1. & 3 & 1. & 1 & 7 & 6 & D & 9 & 2.25 & & 1.40 & 15 & 34 & -5 & 2.57 & 8.9 & 1.82 & 3 & 8 & -5 \\
\hline & 12 & 2.1 & 10 & 1. & 20 & 37 & -6 & 1 & 3 & 1. & 2 & 8 & 4 & & 12 & 2.3 & & 1.42 & 15 & 30 & -5 & 2.59 & 8.2 & 1.91 & 4 & 11 & -9 \\
\hline & 15 & 2.10 & 10 & 1. & 19 & 39 & -5 & 2 & 3 & 1.8 & 3 & 11 & 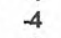 & & 15 & 2.63 & & 1.55 & 14 & 32 & -7 & 2.58 & 5.8 & 1.95 & 6 & 10 & -9 \\
\hline & 18 & 2.05 & 10.3 & 1.41 & 18 & 35 & -4 & 2.02 & 3.5 & 1.80 & 3 & 11 & 3 & & 18 & 3.02 & 23.8 & 1.75 & 25 & 39 & -10 & 3.91 & 9.8 & 2.84 & 8 & 13 & -10 \\
\hline v & 1 & 4.04 & & & 60 & 80 & -1 & & 9 & & 8 & 1 & & $v$ & 1 & & & & 61 & 79 & -1 & 8 & 16.6 & 3.78 & 11 & 14 & -10 \\
\hline C & 2 & 3.2 & 11. & & 42 & 70 & -1 & 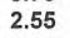 & 7. & 2.0 & 7 & 11 & -1 & C & 2 & 4. & 12 & 2 & 51 & 71 & -10 & 5 & 7.4 & 2.28 & 8 & 15 & -10 \\
\hline V & 3 & 2.47 & 8. & 1 & 29 & 55 & -7 & 2 & 4 & 1.5 & 6 & 12 & . & v & 3 & 3 & & 2. & 56 & 70 & -7 & 2.50 & 5.2 & 1.93 & 8 & 13 & -10 \\
\hline$N$ & 4 & 2.23 & 10. & I & 25 & 45 & - & 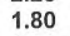 & 3. & 1.5 & 2 & . & & v & 4 & 2. & 1 & 1.98 & 30 & 56 & -10 & 1.85 & 3.5 & 1.59 & 4 & 7 & 3 \\
\hline $\mathbf{R}$ & 5 & 2.24 & 11 & 1 & 23 & 43 & -6 & 2 & 8 & 2. & 6 & 1 & -5 & , & 5 & 2. & 1 & 1.97 & 34 & 57 & -10 & 1.87 & 3.6 & 1.60 & 3 & 7 & 3 \\
\hline $\mathbf{Q}$ & 6 & 2.19 & 12 & 1 & 19 & 42 & - & .76 & 10.2 & 2.1 & 5 & 1 & 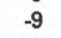 & $\mathrm{L}$ & 6 & 2.2 & 11 & 1.62 & 22 & 42 & -7 & 1.73 & 3.6 & 1.49 & 2 & 6 & 6 \\
\hline $\mathrm{U}$ & 7 & 2.10 & 12 & 1. & 16 & 39 & -5 & 1.7 & 9.9 & 2.0 & 5 & 10 & 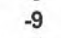 & $\bar{I}$ & 7 & 2.2 & 11 & 1.62 & 22 & 42 & -7 & 1.74 & 3.6 & 1.49 & 2 & 6 & 6 \\
\hline A & 8 & 2.16 & 12 & 1. & 1 & 34 & -5 & 2.6 & 9. & 1.8 & 3 & 7 & 2 & $\mathrm{~N}$ & 8 & 2.29 & 11 & 1.61 & 23 & 43 & -7 & 1.74 & 3.8 & 1.49 & 2 & 6 & 6 \\
\hline D & 9 & 2.14 & 12 & 1. & 1 & 32 & -5 & 2.6 & 9. & 1.8 & 3 & 7 & 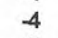 & & 9 & 2. & 10 & 1.61 & 23 & 44 & -7 & 6 & 3.7 & 1.58 & 2 & 6 & 4 \\
\hline & 12 & 2.09 & 11 & 1. & 1 & 26 & -1 & 2.5 & 8.0 & 1. & 4 & 9 & $-i$ & & 12 & 2. & 11 & 1.54 & 20 & 38 & -6 & 36 & 3.6 & 1.57 & 2 & 7 & 4 \\
\hline & 15 & 2.8 & 2 & & 19 & 38 & -9 & 26 & 79 & 1. & 4 & 11 & $-s$ & & 15 & 2.08 & 10 & 1. & 16 & 40 & -5 & 2.10 & 3.7 & 1.89 & 2 & 11 & 4 \\
\hline & 18 & 3.14 & 25.6 & 1.76 & 27 & 39 & -10 & 3.59 & 9.6 & 2.58 & 6 & 10 & -9 & & 18 & 2.07 & 10.5 & 1.43 & 18 & 36 & -5 & 2.02 & 3.4 & 1.79 & 3 & 11 & 3 \\
\hline V & 1 & 4.88 & 10 & & 61 & 83 & -10 & & & & 11 & 15 & & $v$ & 1 & & & & 58 & 82 & -10 & & 16.3 & & 12 & 15 & -10 \\
\hline C & 2 & 4.22 & 12. & & 53 & 71 & -10 & & & & 8 & 15 & -10 & C & 2 & 3. & 10 & 2. & 62 & 76 & -10 & 3.02 & 8.6 & 2.14 & 8 & 11 & -10 \\
\hline V & 3 & 2.77 & 10. & 1.96 & 32 & 53 & -10 & & & & 2 & 10 & - & V & 3 & 2. & 8. & 2.05 & 42 & 69 & -7 & 2.00 & 4.2 & 1.62 & 4 & 8 & -2 \\
\hline$E$ & 4 & 2.78 & 10.8 & 1.96 & 31 & 52 & -10 & & & & 2 & 11 & -5 & V & 4 & 2.2 & 11.5 & 1.62 & 21 & 47 & -7 & 1.60 & 3.6 & 1.27 & 1 & 7 & 8 \\
\hline$x$ & 5 & 2.71 & 12.0 & 1.82 & 27 & 48 & -10 & & & 1. & 2 & 6 & & $x$ & 5 & 2. & 13 & & 22 & 50 & -8 & 2.81 & 10.4 & 1.92 & 6 & 9 & 8 \\
\hline $\mathrm{L}$ & 6 & 2.29 & 11.1 & 1.62 & 22 & 43 & -7 & & & & 2 & 6 & 6 & $Q$ & 6 & 2. & 12 & 1.56 & 18 & 43 & -6 & 2.83 & 10.6 & 2.01 & 6 & 8 & -7 \\
\hline 1 & 7 & 2.30 & 11.2 & 1.62 & 22 & 42 & -7 & 1.7 & & 1. & 2 & 7 & 0 & $\vec{U}$ & 7 & & 13 & 1. & 18 & 38 & -5 & 2.84 & 10.3 & 2.05 & 6 & 10 & -9 \\
\hline $\mathbf{N}$ & 8 & 2.29 & 11.4 & 1.62 & 23 & 43 & -7 & & & & 2 & 6 & 6 & $A$ & 8 & & 14 & 1.45 & 15 & 36 & -5 & 2.70 & 9.5 & 1.89 & 4 & 7 & -5 \\
\hline & 9 & 2.27 & 10.8 & 1.61 & 23 & 44 & -7 & 1.0 & & & 2 & 6 & 4 & D & 9 & & & & 14 & 34 & -4 & 2.57 & 8.9 & 1.82 & 3 & 8 & -5 \\
\hline & 12 & 2.14 & 10.8 & 1.54 & 20 & 38 & -6 & & & 1. & 1 & 11 & 0 & & 12 & 2.32 & 14 & 1.42 & 15 & 30 & -5 & 2.58 & 8.2 & 1.90 & 4 & 10 & -8 \\
\hline & 15 & 2.08 & 10.5 & 1.46 & 16 & 40 & -5 & & & 1.8 & 2 & 11 & -4 & & 15 & & & & 14 & 32 & -7 & 2.58 & 5.8 & 1.96 & 6 & 10 & -9 \\
\hline & 18 & 2.07 & 10.5 & 1.43 & 18 & 36 & -5 & 2.02 & 3.3 & 1.79 & 3 & 11 & -3 & & 18 & 3.02 & 23.8 & 1.75 & 25 & 39 & -10 & 3.91 & 9.8 & 2.84 & 8 & 13 & -10 \\
\hline
\end{tabular}

Abbreviations: as for Tables 2 and 3.

Table 4. Experiment 1a: Calibration data set of 450 samples, analog set of 155 samples and no-analog set of 27 samples. Evaluation of the variants of the principal component regression technique.

the variants of the technique, selecting the ten most similar or least dissimilar samples from the provisional calibration data set of 455 samples.

To evaluate the residuals of the calibration data set for the different variants of the principal component regression technique, we calculated the multiple correlation coefficients and the standard errors of residuals, both unadjusted (RNA, SENA) and adjusted to take into account the degrees of freedom lost (RA, SEA).

To evaluate the errors of the estimates of the analog and no-analog sets, we calculated two statistics, SE and the mean of the absolute values of the errors of the estimate (ME) and three indices: the maximum of the absolute values of the errors of the estimate $(\mathrm{MxE})$ and 
the number of absolute values of the errors of the estimate exceeding $2{ }^{\circ} \mathrm{C}$ and $3{ }^{\circ} \mathrm{C}$, respectively $(\mathrm{E}>2$ and $\mathrm{E}>3$ ).

With these data available, the initial question must be readdressed: which is the best technique? The best technique, according to any of the indices or statistics chosen, is that which provides the minimum value for the index or statistic in question. But such minimum values do not coincide in a single technique. Therefore it is necessary to recur to an evaluation procedure which is applied, independently, to the errors of the estimate of the experimental sets, both analog and no-analog. A score of 2 was assigned to the values of each index or statistic exceeding the minimum value of the index in question by less than $10 \%$; for those exceeding the minimum by 10 to $20 \%$, by 20 to $30 \%$, by 30 to $40 \%$ and by more than $40 \%$, the scores assigned were $1,0,-1$ and -2 , respectively. By adding the scores of each technique when applied to each analog and no-analog set, an evaluation of its response to each case is obtained, with values ranging from 10 (the theoretical maximum, if the technique produces minimum values for all the indices and statistics) to -10 (for technique with bad values for all indices and statistics).

A new round of experiments was now carried out, taking into account only the best transfer functions and modern analog techniques according to the previous evaluation procedure. The calibration data set of 450 samples was divided, also randomly, into three sets of 150 samples (experiments $1 \mathrm{~b}, 1 \mathrm{c}$ and 1d). The errors of the estimate of each of these new sets (and of the noanalog set) were calculated, taking in every case the 455 remaining samples as the calibration data set. The errors of the estimate of the four experiments with analog sets (605 in total) and with no-analogs $(4 \times 27$ in total) were combined, their indices and statistics were calculated and these were submitted to the above-described evaluation procedure.

Subsequently, and only using the two best procedures for the analog set, two other types of possibilities were tested. Firstly (experiment 2) the samples with absolute values of the errors of the estimate that were greater than $2{ }^{\circ} \mathrm{C}$ and $3{ }^{\circ} \mathrm{C}$ were eliminated from the four provisional calibration data sets, and the estimation of temperatures and the indices and statistics calculation were repeated.

Secondly (experiment 3 ), the calibration data set was divided into five groups, using the k-means clustering procedure (in SYSTAT, 1992). The resulting groups are biogeographically coherent and contain 271, 36, 127, 133 and 38 samples, respectively. Each group was randomly divided into three subgroups and then the values of the winter temperatures of each subgroup were estimated with the best transfer function, using the other two subgroups as provisional calibration data set. Given that groups 2 and 5 contain few samples, the transfer functions with a nonlinear equation of the second degree could not be applied. In the case of the modern analog technique, this test has not sense (except in reducing computation times).

\section{RESULTS}

\section{TRANSFER FUNCTIONS \\ Residuals of the calibration data set}

Table 2 show RA, RNA, SEA and SENA for the different variants of the principal component regression technique. As the equamax and quartimax rotations produce very similar results, only those of quartimax are shown. Figure 2 shows the graphics of the Q-mode analysis of the cosine-theta matrix. Certain aspects are worthy of mention:

a) For any association matrix, rotation criterion or regression type, when the number of principal components increases there is an increase in $\mathrm{R}$ and a decrease in SE, marked at first and very slight at the end.

b) When the association matrix, rotation criterion and number of principal components is unchanged, quadratic regression gives better results than linear regression.

c) For any association matrix and regression type, the non rotated matrix gives better results than the rotated ones when few principal components are retained (except in the case of the cosine-theta matrix and just one principal component) but above a variable number of principal components (from 4 to 7 ) the results are virtually identical.

With this criteria for evaluation, the choice of the method would be very simple: variance-covariance matrix, rotation (any of the three), 18 principal components and quadratic regression (RNA $=0.990$, SENA $=0.984^{\circ} \mathrm{C}$ ) although the other methods, using 18 principal components and the nonlinear equation, obtain very similar results.

\section{Errors of the estimate of the analog and no-analog sets}

Tables 3 and 4 lists the SE, ME, MxE, E>2, E>3 and evaluation results (V) of the experiment 1a. Figures 3 to 5 represent the values of some of these indices and statistics for the variants of the principal component regression technique. A brief inspection of the figures or of the tables shows that the results of the evaluation of the different procedures, based on the analysis of the residuals of the calibration data set, cannot be extended, by any means, to the errors of the estimate produced by these procedures when they are applied to samples that are not included in the calibration data set. From this it is concluded that the residuals of the calibration data set are not suitable for evaluating transfer functions.

For the case of the variants of the principal component regression technique (Tab. 4), SE (Fig. 3) also decreases, in the analog set, when the number of principal components in the linear equations increases, attaining similar values for all the procedures above a certain number of principal components, except in CORNR. But in the quadratic equations, the behaviour of SE is more irregular. In general, when the number of principal components increases, the value of SE first shows a considerable decrease, followed by less marked decreases until a minimum is reached, when it begins to increase again; with 18 principal components the SE values are 

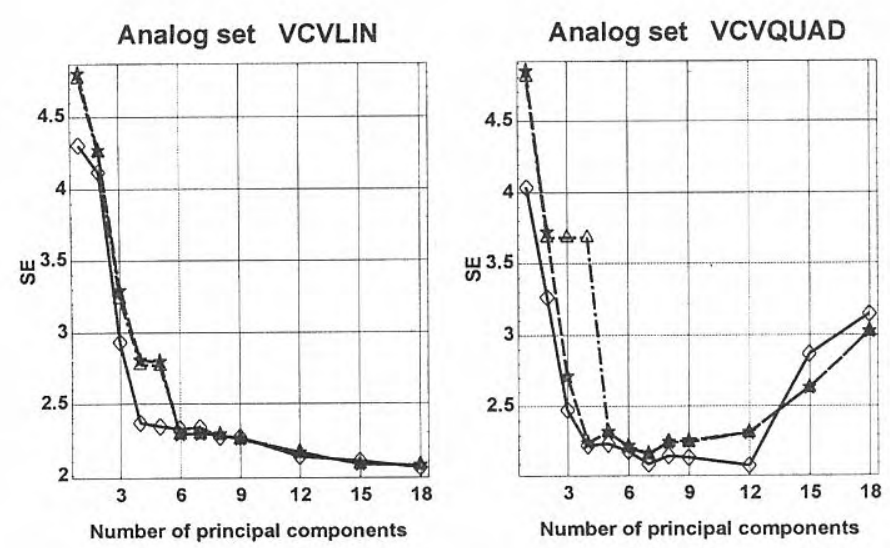

Analog set CosLIN
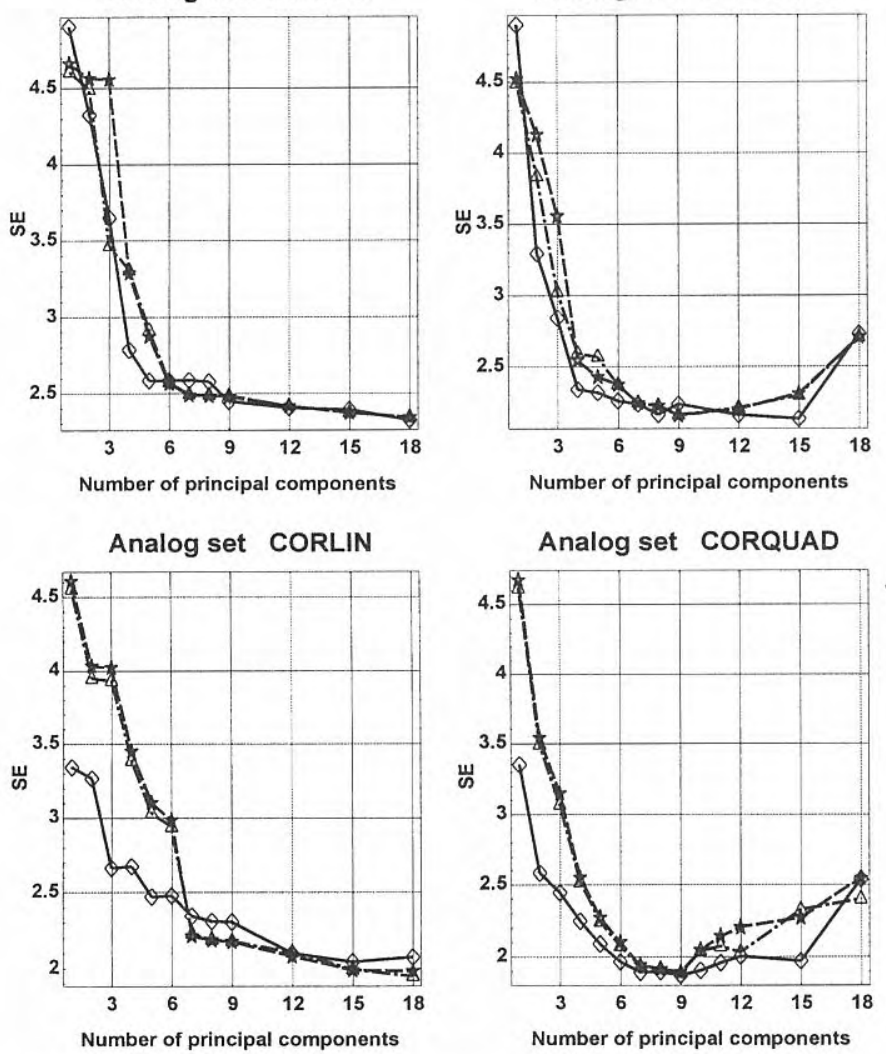

Analog set CORQUAD
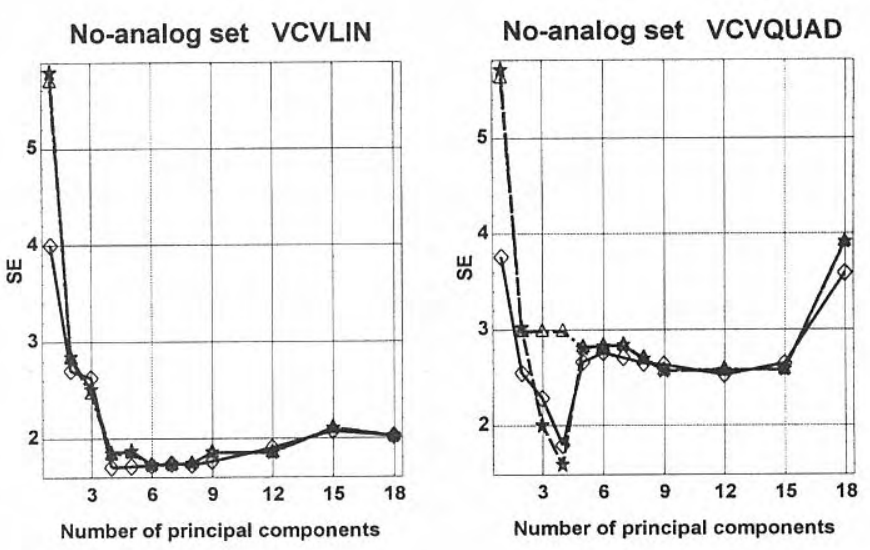

Number of principal components

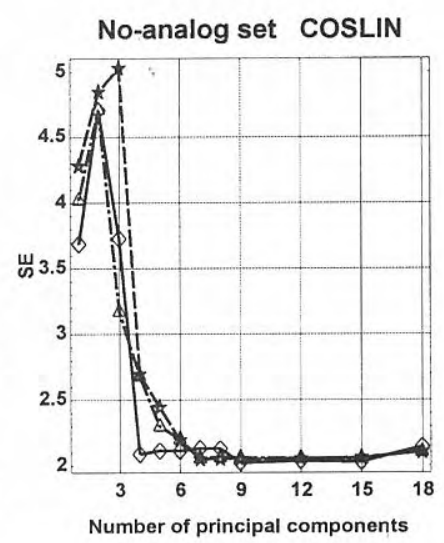

No-analog set COSQUAD

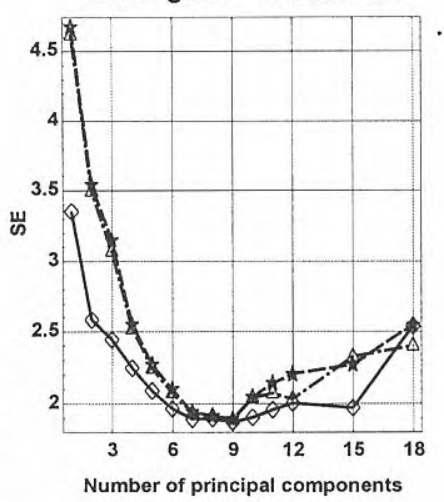

No-analog set CORLIN

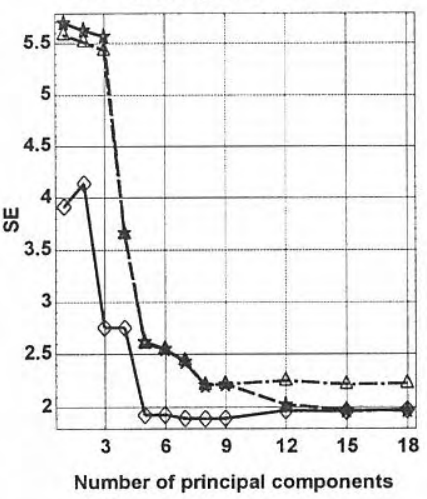

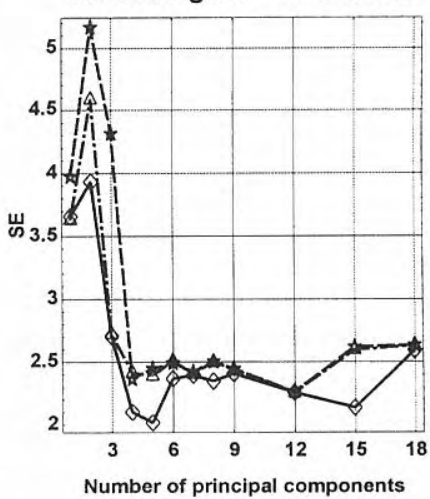

No-analog set CORQUAD

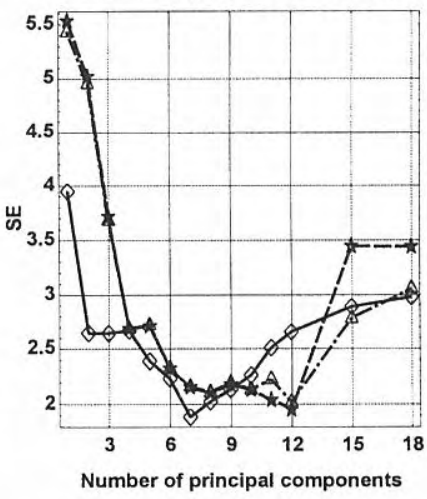

Figure 3. Principal component regression technique. Variation of the values of the standard error of the estimate (SE) in relation to the number of principal components retained. Symbols and abbreviations as for Figure 2 and VCVLIN: R-mode analysis of the variance-covariance matrix with linear regression; VCVQUAD: idem with nonlinear regression; CORLIN: R-mode analysis of the correlation matrix with linear regression; CORQUAD: idem with nonlinear regression.

comparable to those obtained with 2 to 4 principal components. For the no-analog set, the plots usually illustrate local maxima and minima, and the minimum SE values do not correspond to the maximum number of principal components, not even in the linear equations; in CORNRLIN and in all the COS procedures, the highest SE value does not correspond to one, but to 2 or 3 principal components. In some VCVQUAD and COSQUAD procedures, the minima correspond to a low number of principal components, 4 or 5 .

$\mathrm{ME}$ responds in a very similar way to $\mathrm{SE}$, both in the analog and the no-analog sets, and thus it does not appear.
MxE (Fig. 4) is more irregular in the analog set, and various plots show local maxima and minima; in most procedures, QX and VX respond similarly, while NR is somewhat different; the best values correspond to VX or QX, except in COSQUAD. Finally it should be noted that in the case of VCV the best results correspond to 3 principal components. With reference to the no-analog set, the plots for $\mathrm{MxE}$ are relatively similar to those of ME.

To conclude the results of the principal component regression technique, the plots of $E>2$ and $E>3$ for each set, both analog and no-analog, are fairly similar; for that reason only those of E>2 appear (Fig. 5). In the case of 


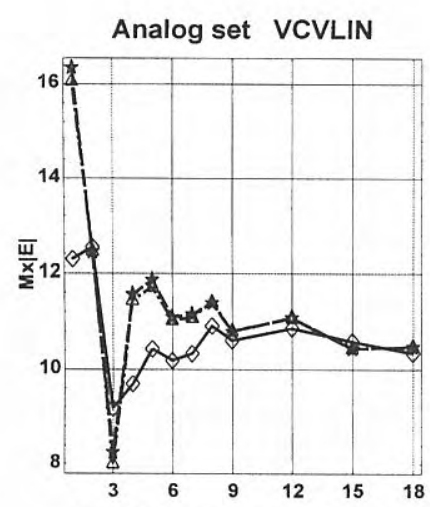

Number of principal components

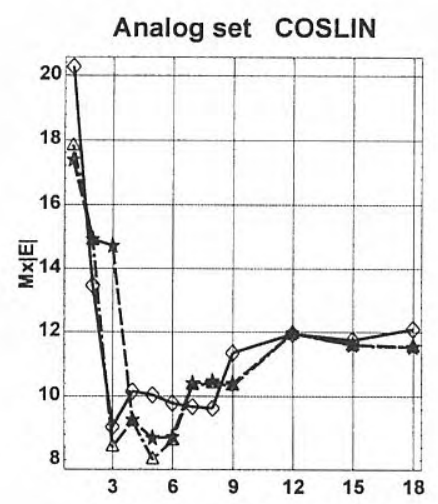

Number of principal components

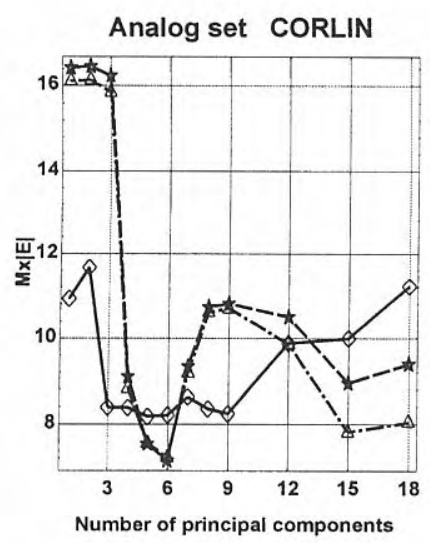

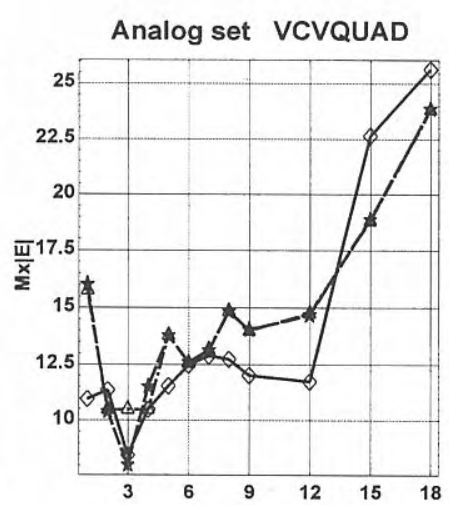

Number of principal components

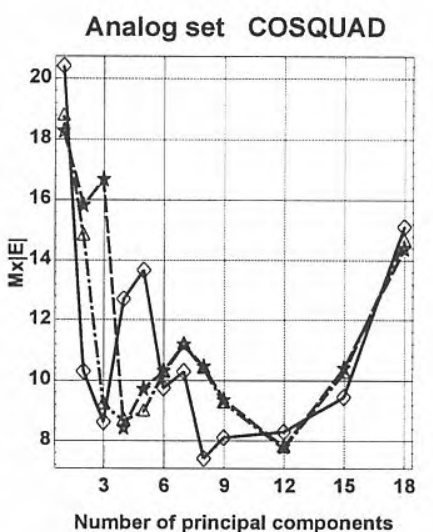

Analog set CORQUAD

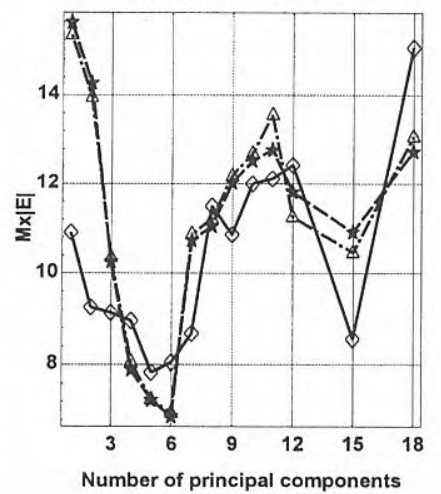

No-analog set VĆVLIN

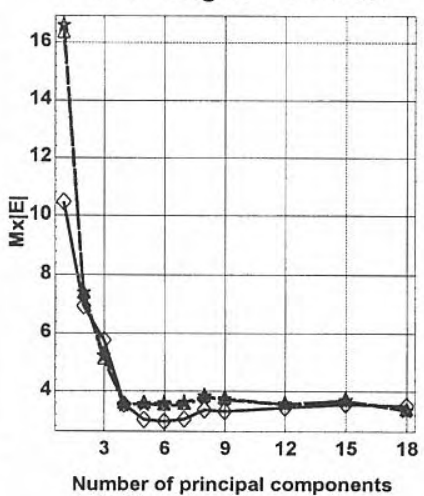

No-analog set COSLIN

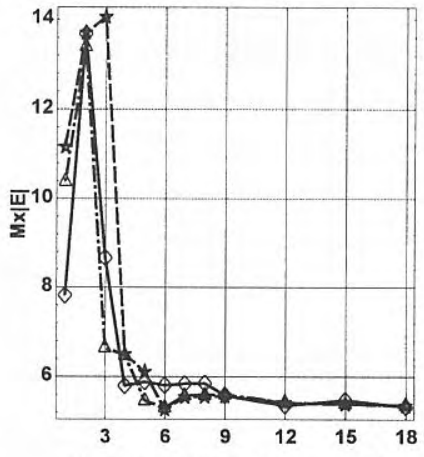

Number of principal components

No-analog set CORLIN

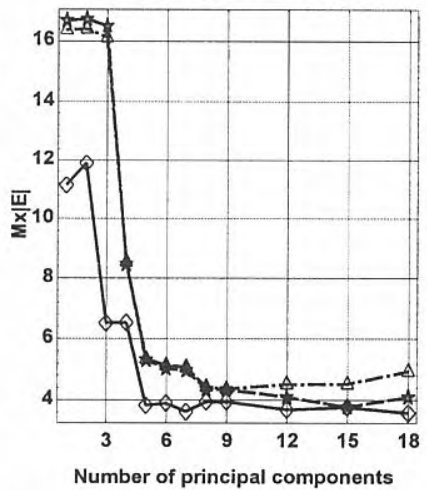

No-analog set VCVQUAD

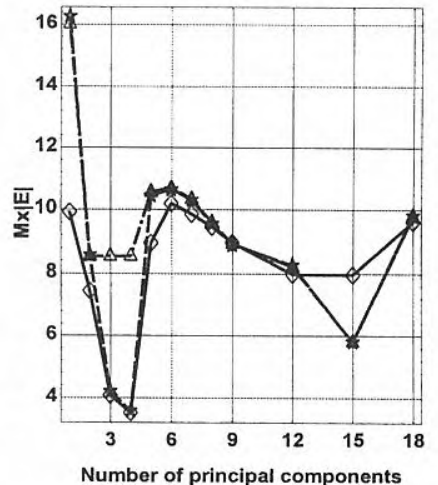

No-analog set COSQUAD

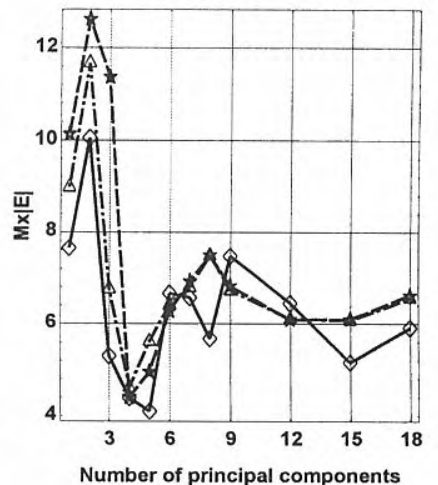

No-analog set CORQUAD

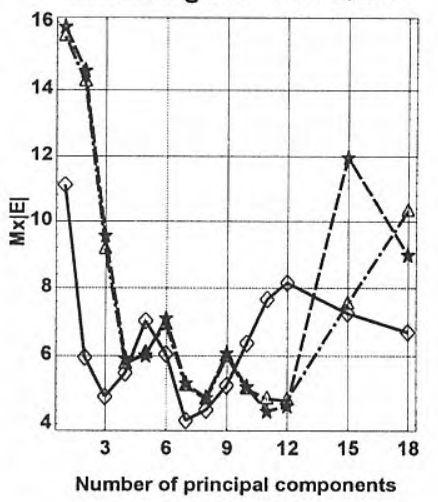

Figure 4. Principal component regression technique. Variation of the maximum of the absolute values of the errors of estimate (MxIEl) in relation to the number of principal components retained. Symbols and abbreviations as for Figure 3.

the analog set, the behaviour is similar to that of ME: in the linear equations (excepting irregularities when a low number of principal components are retained) there is a tendency for the index to decrease as the number of principal components increases. In the quadratic equation, the best results are achieved with 9 to 12 principal components, with the graphs forming $\mathrm{U}$ or $\mathrm{V}$ shapes. For the no-analog set, the graphs are very irregular, particularly in the case of the quadratic equations.

With respect to the technique of species regression, as may be seen in Table 3, some indices and statistics worsen when the number of species is reduced to 18 , while others remain unchanged and one improves. However, on applying an equation of the second degree, the results are very bad. Transforming the relative abundances, such that each sample is a vector of length one, does not improve results, either. On the other hand, in the case of the analog set, some logit transformations achieve better results than the original technique for SE, $\mathrm{MxE}, \mathrm{E}>2$ and $\mathrm{E}>3$. For the no-analog set, the results are, in general, worse.

In the weighted average technique (Tab. 3), the estimates without posterior regression (WAOPT and WATOL) produce worse results for most statistics and indices. When regression is added, the linear equation gives worse results in the analog set than in the quadratic and the potential, except in MxE. On the other hand, in the no-analog set, it gives better results for SE and ME. To sum up, the indices and statistics of the potential are, 

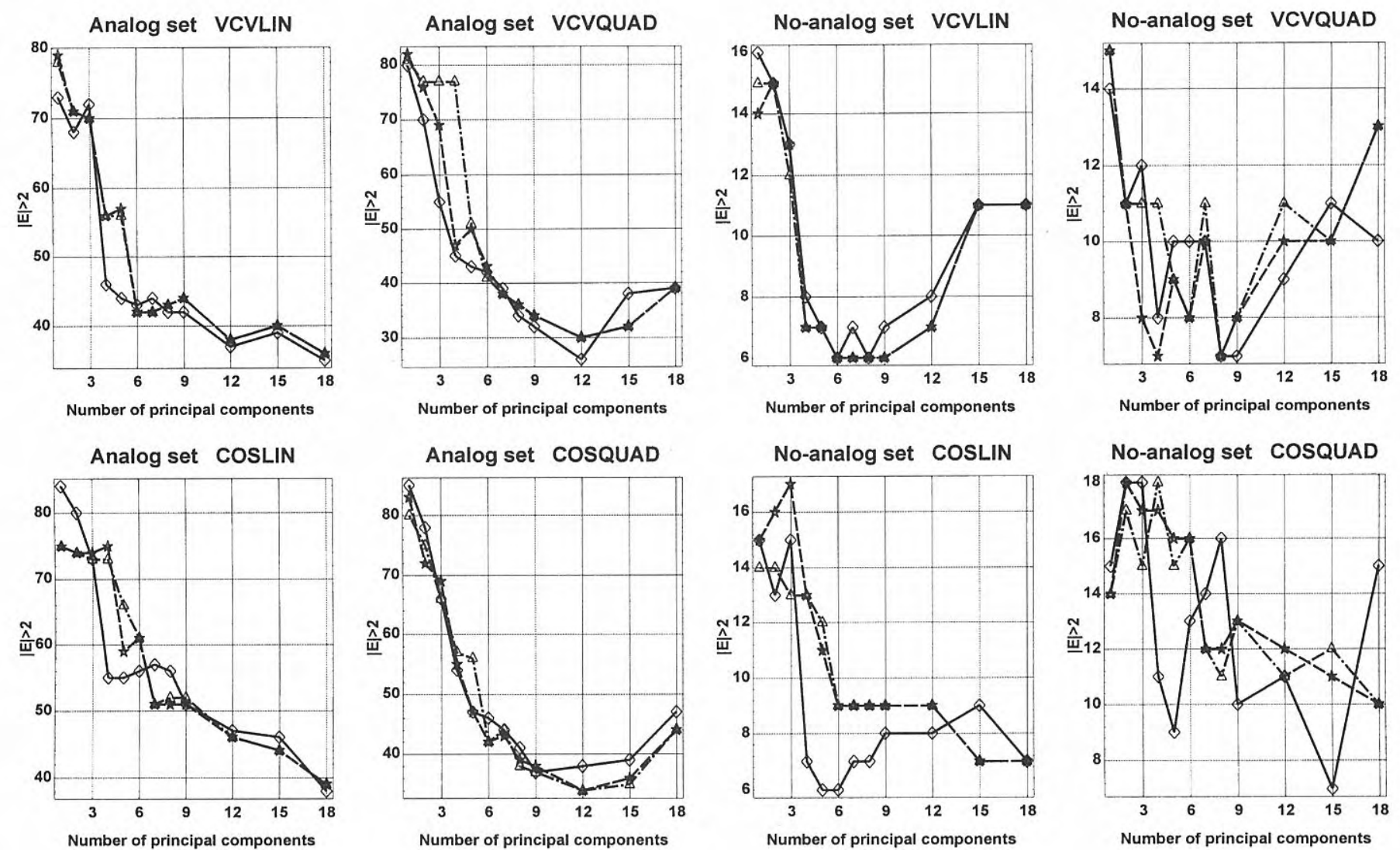

No-analog set COSQUAD
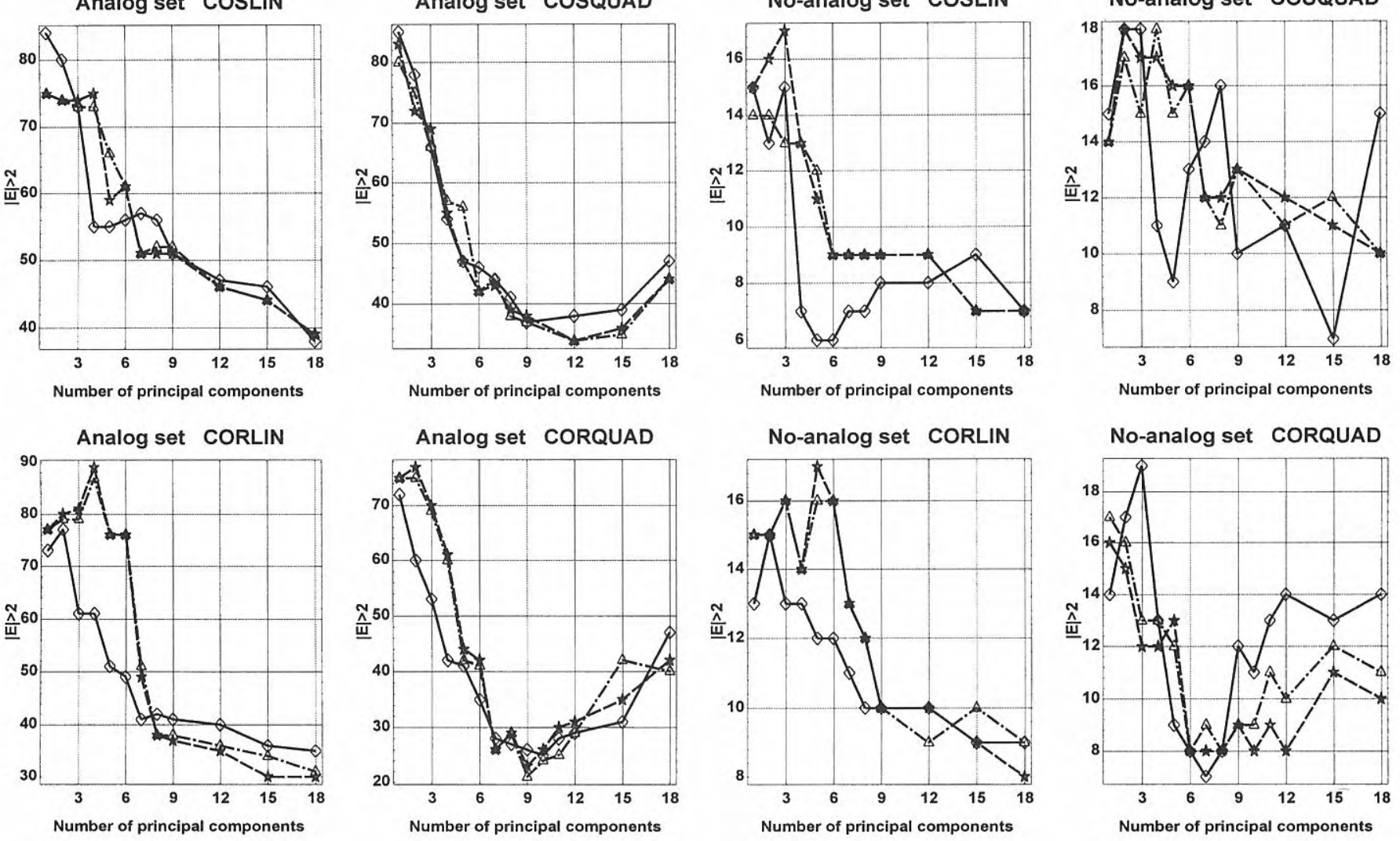

Figure 5. Principal component regression technique. Variation of the number of absolute values of the errors of estimate exceeding $2^{\circ} \mathrm{C}(\mathrm{E}>2)$ in relation to the number of principal components retained. Symbols and abbreviations as for Figure 3.

in general, equal to or better than those of the quadratic.

Finally, discriminant analysis (Tab. 3), even though not performed under the most suitable conditions (as described above) provided acceptable results for the analog set, enabling the expectation of improved results when applied to a more suitable calibration data set.

According to the evaluation procedure above described, the best results of the experiment 1a correspond to some of the variants of the principal component regression technique. These are, for the analog set, CORQX9QUAD and CORVX9QUAD (6 points), CORNR10QUAD (5 points), CORNR8QUAD, CORNR9QUAD, CORQX7QUAD and CORVX7QUAD (4 points); for the no-analog set, VCVNR5LIN and
VCVNR6LIN (9 points), VCVNR7LIN and VCVVX4QUAD (8 points) and VCVNR8LIN, VCVQX6LIN and VCVQX7LIN (7 points).

Then, the experiments $1 \mathrm{~b}, 1 \mathrm{c}$ y $1 \mathrm{~d}$ took place, applying the transfer functions above cited and the indices, statistics and valuations of the errors of estimate of the combined four experiments were calculated (Tab. 5). The best procedures were seen to be CORNR8QUAD and CORNR9QUAD for the analog set and VCVNR6LIN for the no-analog set.

The transfer functions CORNR8QUAD and CORNR9QUAD were used in experiment 2 (Tab. 6). The multiple correlation coefficients and the standard errors of estimate of the calibration data set decreased 
TRANSF.FUNC. SE MxE ME $\quad$ E>3 $\quad$ E $>2 \quad V$

\begin{tabular}{llllllr}
\hline \multicolumn{1}{c}{ ANALOG SET } & & & & & & \\
CORNR8QUAD & 1.72 & 11.5 & 1.20 & 41 & 103 & 9 \\
CORNR9QUAD & 1.75 & 10.9 & 1.22 & 45 & 105 & 10 \\
CORNR10QUAD & 1.75 & 12.0 & 1.22 & 42 & 105 & 8 \\
CORQX7QUAD & 1.82 & 9.9 & 1.31 & 61 & 122 & 5 \\
CORQX9QUAD & 1.82 & 13.1 & 1.22 & 50 & 104 & 5 \\
CORVX7QUAD & 1.86 & 10.7 & 1.32 & 59 & 126 & 4 \\
CORVX9QUAD & 1.85 & 12.9 & 1.25 & 47 & 108 & 6 \\
NO-ANALOG SET & & & & & & \\
VCVNR5LIN & 1.72 & 3.5 & 1.52 & 3 & 13 & 9 \\
VCVNR6LIN & 1.73 & 3.4 & 1.54 & 2 & 27 & 10 \\
VCVNR7LIN & 1.76 & 3.7 & 1.55 & 6 & 30 & 8 \\
VCVNR8LIN & 1.75 & 4.1 & 1.51 & 8 & 28 & 5 \\
VCVQX6LIN & 1.75 & 4.0 & 1.50 & 8 & 27 & 5 \\
VCVQX7LIN & 1.75 & 4.4 & 1.50 & 8 & 27 & 4 \\
VCVVX4QUAD & 1.87 & 4.6 & 1.59 & 15 & 33 & 6 \\
\hline
\end{tabular}

Abbreviations: as for Tables 2 and 3.

Table 5. Evaluation of the best transfer functions giving the results in experiment $1 \mathrm{a}$. Collected errors of the estimate for experiments $1 \mathrm{a}, 1 \mathrm{~b}, 1 \mathrm{c}$, and $1 \mathrm{~d}$.

markedly, as was to be expected, but the changes, in the case of the analog set, were really insignificant, with five of the six procedures producing identical results. These results agree with those of Le (1992), who eliminated the samples with absolute values of the residuals of above 2.3 ${ }^{\circ} \mathrm{C}$ and those with communality below 0.9 ; with this procedure, he obtained similar estimates, applying the new equation to the downcore samples.

With regard to experiment 3 , the transfer function CORNR8QUAD was used. The indices and statistics corresponding to the set of errors of the estimate of the three subgroups available for experiment (Tab. 6, row KMEANS) are not promising. For this reason further experimentation with this possibility, and others of a similar nature, was abandoned.

Figure 6A represents the errors of the estimate of the transfer function CONR9QUAD $<3$ with respect to the observed temperatures and the corresponding regression line. The low value of the correlation coefficient $(r=0.209)$ indicates the slight correlation of the values. The value of the slope of the regression line is very small $(0.055)$ but its corresponding t value (5.256) enables us to reject the null hypothesis that the slope of the line is zero $(\mathrm{p}<0.001)$. The ordinate at the origin $(-0.977)$ also has a $t$ value $(-5.059)$ that refutes the null hypothesis. It must be concluded, therefore, that the function tends to overestimate at low temperatures and to underestimate at high temperatures.

Figure 6B shows, for the CORNR9QUAD function applied to the whole calibration data set, the relation between the absolute values of the error of the estimate and the values of the $\mathrm{T}^{2}$ index for the detection of outliers ( $\mathrm{R}$ mode). A simple inspection of the plots reveals that the greatest errors of the estimate are associated with low $\mathrm{T}^{2}$ values (samples that cannot be considered outliers

\begin{tabular}{lcrccrr}
\hline TRANSF.FUNC. & SE & MXE & ME & E>3 & E>2 & V \\
\hline CORNR8QUAD & 1.72 & 11.5 & 1.20 & 41 & 103 & 8 \\
CORNR8QUAD<2 & 1.74 & 10.9 & 1.21 & 45 & 106 & 8 \\
CORNR8QUAD<3 & 1.75 & 10.2 & 1.21 & 46 & 106 & 8 \\
CORNR9QUAD & 1.75 & 10.9 & 1.22 & 45 & 105 & 8 \\
CORNR9QUAD<2 & 1.75 & 10.0 & 1.20 & 50 & 94 & 8 \\
CORNR9QUAD<3 & 1.76 & 9.7 & 1.19 & 47 & 93 & 9 \\
KMEANS & 2.50 & 15.7 & 1.60 & 69 & 127 & -8
\end{tabular}

Abbreviations: as for Tables 2 and 3.

Table 6. Experiments 2 and 3. Comparison of the results obtained after eliminating from the calibration data sets those samples with absolute value of the error greater than $2^{\circ} \mathrm{C}$ and $3^{\circ} \mathrm{C}$ (experiment 2) and evaluation of CORNR8QUAD applied to groups differentiated by the k-means clustering procedure, KMEANS row (experiment 3 ).

according to the corresponding $\mathrm{F}$ values) while those samples with higher $\mathrm{T}^{2}$ values have absolute errors of the estimate that do not exceed $2.5{ }^{\circ} \mathrm{C}$. As regards regression, the correlation coefficient $(\mathrm{r}=0.021)$ is very low and the $t$ value $(0.522)$ does not enable us to reject the null hypothesis that the slope of the line is zero $(\mathrm{p}=0.602)$.

Turning our attention to the relationships between communalities and errors of the estimate, Figure $6 \mathrm{C}$ shows those corresponding to the COSNR8QUAD (one of the best of all the functions based on the Q-mode). The results are visually comparable to those of Figure $6 \mathrm{~B}$, with the obvious difference that in this case the outliers are the samples with low index values for the communalities. The null hypothesis (i.e. that the slope of the regression line is zero) can be rejected ( $t=-3.868$, $\mathrm{p}<0.001)$. This indicates that as the communality decrease the error increases; in this case there are five outliers (communality less than 0.6) with errors that exceed $2.5^{\circ} \mathrm{C}$. But as in the previous case, the biggest errors also correspond to samples that are not outliers.

\section{MODERN ANALOG TECHNIQUE}

The statistics and indices of the errors of the estimate are given in Tab. 7A. For the analog set, the weighted average usually produces the best results. For the noanalog set, COS, EUC and MANH give better results with the weighted averages while $\mathrm{SCH} 2$ and $\mathrm{CHI} 2$ perform better with unweighted means. After applying the evaluation method used for the transfer functions, the best procedures for the analog set were seen to be MATSCH2IDW, followed by MATSCH2CSW, MATSCH2UW and MATCHI2IDW. For the no-analog set, MATSCH2CSW followed by MATSCH2UW and MATCHI2UW.

The MATSCH2IDW procedure was repeated, after eliminating from the provisional calibration data set those samples that, when this procedure was applied to them, presented absolute values of errors of the estimate exceeding $2{ }^{\circ} \mathrm{C}$ and $3{ }^{\circ} \mathrm{C}$ (experiment 2; MATSCH2 IDW $<2$ and MATSCH2IDW $<3$, Tab. 7A ). As no improvement in the results was observed, research along this line was abandoned. 

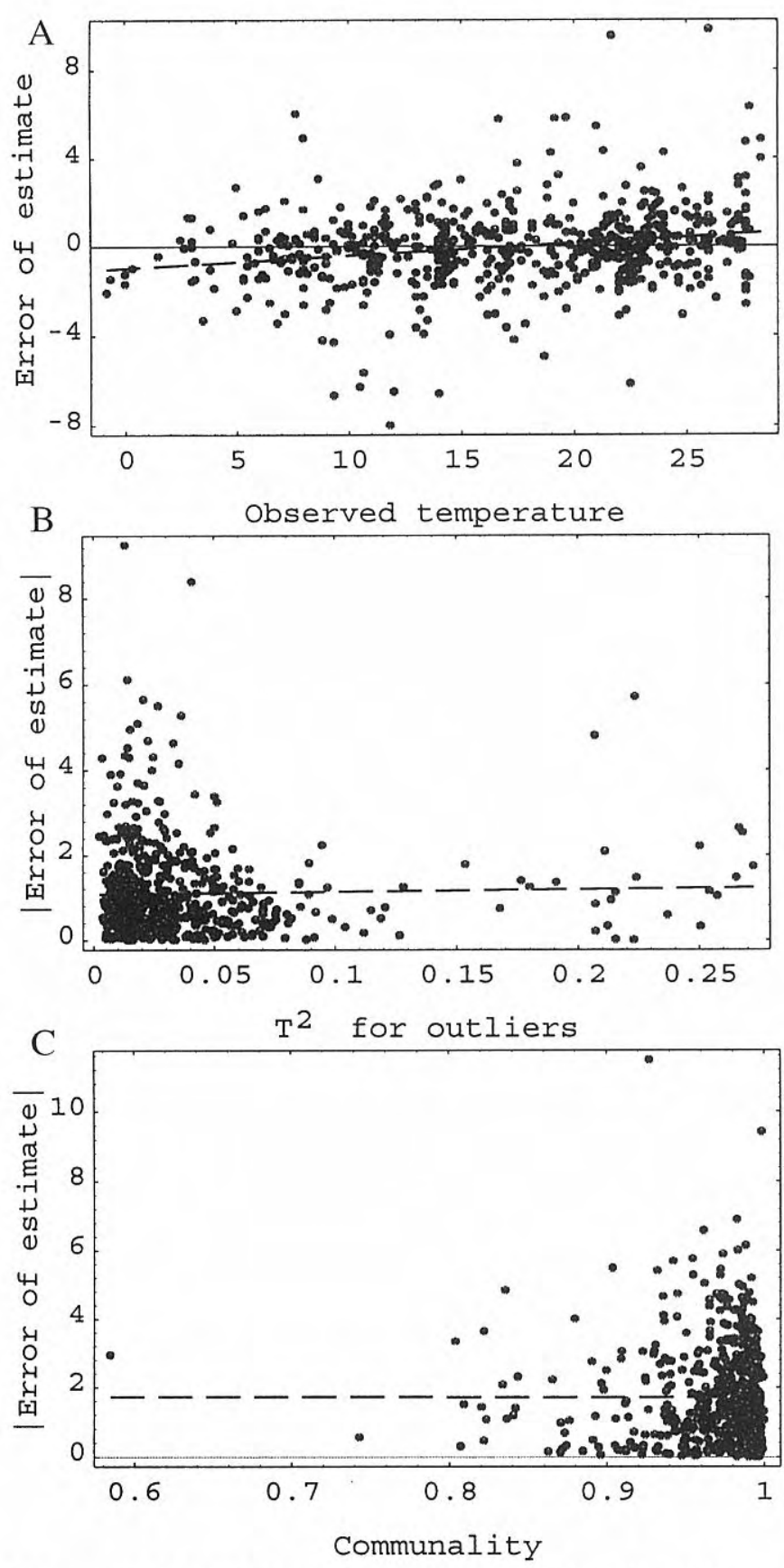

Figure 6. A) CORNR9QUAD $<3$ transfer function. Plot of the error of estimate (EE) vs. observed temperature (OT). $\mathrm{EE}=-0.977+0.5510 \mathrm{OT} ; \mathrm{r}=0.209$; $\mathrm{t}_{\text {constant }}=-5.059, \mathrm{p}<0.001, \mathrm{t}_{\text {slope }}=5.256, \mathrm{p}<0.001$.

B) CORN9QUAD transfer function. Plot of the absolute value of the residual (IRI) vs. $\mathrm{T}^{2}$ value (test for outliers). $|\mathrm{R}|=1.067+0.530 \mathrm{~T}^{2} ; \mathrm{r}=0.021$; $\mathrm{t}_{\text {constant }}=18.204, \mathrm{p}<0.001 ; \mathrm{t}_{\text {slope }}=0.522, \mathrm{p}=0.602$.

C) COSNR8QUAD transfer function. Plot of the absolute value of the residual (|R|) vs. communality $(\mathrm{C}) .|\mathrm{R}|=3.853-2.691 \mathrm{C} ; \mathrm{r}=0.156$; $\mathrm{t}_{\text {constant }}=5.758, \mathrm{p}<0.001 ; \mathrm{t}_{\text {slope }}=-3.868, \mathrm{p}<0.001$.

As the number of processes to repeat is not excessive, CSW, all the IDW and the two best UW procedures, were repeated with the other three provisional calibration data sets. Table 7B shows that MATSCH2IDW is still the best procedure for the analog set and MATSCH2CSW is the best for the no-analog set.

Figure 7A shows the errors of the estimate of MATSCH2IDW with respect to the temperatures observed. As in the case of the CORNR9QUAD $<3$ transfer function, the procedure tends to overestimate at low temperatures and to underestimate at high ones, though somewhat less. Both the slope of the regression line $(0.032)$ and the ordinate at the origin $(-0.518)$ are lesser and also non zero $(\mathrm{p}<0.001$ in both cases).

To discover whether the characteristics of the method itself enable us to estimate the magnitude of the errors of the estimate, the absolute values of these are shown with respect to the averages of dissimilarities with the analog -ten samples- subsets (Fig. 7B), to the minima dissimilarities (Fig. 7C) and to the standard error of the mean of the temperatures of the analog subsets (Fig. 7D).

The plot of the absolute value of the error of the estimate vs. the average of dissimilarities presents a low correlation; the greatest errors of the estimate correspond to small or large averages of dissimilarities (in fact, the greatest error corresponds to an average of dissimilarities that is not very large), while the slope of the regression line $(5.405, \mathrm{t}=6.771, \mathrm{p}<0.001)$ indicates that as the average of dissimilarities increases, so does the error. However, in any case it is clear that a high average of dissimilarities does not indicate necessarily a large error.

The plot of the minimum dissimilarity is comparable and analogous considerations may be made.

The plot of the standard error of the mean of the temperatures is more promising. The correlation coefficient is not much higher $(r=0.391)$, while the slope of the regression line $(0.536, t=10.431, p<0.001)$ also indicates that as the standard error increases so does the error of the estimate; the highest standard errors correspond to errors of the estimate that range from high to almost zero. However, all the samples with a small standard error present a low error of the estimate. Thus, some concrete conclusions may be drawn.

\section{COMPARISON OF THE RESULTS OF THE TRANSFER FUNCTIONS AND THE MODERN ANALOG TECHNIQUE}

The comparison of the results of the best modern analog and transfer function techniques show that the former is, in general, superior. For the analog set, the differences between the best indices and statistics of one and the other are as follows: $\mathrm{SE}_{\mathrm{ft}-\mathrm{ma}}=0.30^{\circ} \mathrm{C}, \mathrm{ME}_{\mathrm{ft}-\mathrm{ma}}=0.33$ ${ }^{\circ} \mathrm{C}, \mathrm{E}>3_{\mathrm{ft}-\mathrm{ma}}=26, \mathrm{E}>2_{\mathrm{ft}-\mathrm{ma}}=41$; only $\mathrm{MxE}_{\mathrm{ft}-\mathrm{ma}}=-0.74{ }^{\circ} \mathrm{C}$ is better in the transfer function. The comparison provides similar results for the no-analog set: $\mathrm{SE}_{\mathrm{ft}-\mathrm{ma}}=0.25^{\circ} \mathrm{C}, \mathrm{ME}_{\mathrm{ft}-}$ ${ }_{\operatorname{ma}}=0.3{ }^{\circ} \mathrm{C}, \mathrm{E}>3_{\mathrm{ft}-\mathrm{ma}}=6$; the transfer function is superior in $\mathrm{MxE}_{\mathrm{ft}-\mathrm{ma}}=-0.32{ }^{\circ} \mathrm{C}$ and in $\mathrm{E}>2_{\mathrm{ft}-\mathrm{ma}}=-5$.

Figure 8 illustrates the errors of the estimate of MATSCH2IDW and CORNRQUAD $<3$. The horizontal and vertical lines limit what, arbitrarily, are termed acceptable estimates: absolute values of the errors of the estimate of less than $2{ }^{\circ} \mathrm{C}$. Apart from the central region (acceptably estimated samples with both techniques) a series of peculiarities should be noted: 


\begin{tabular}{|c|c|c|c|c|c|c|c|c|c|c|c|c|}
\hline & \multicolumn{6}{|c|}{ ANALOG SET } & \multicolumn{6}{|c|}{ NO-ANALOG SET } \\
\hline & SE & MxE & ME & $E>3$ & $E>2$ & V & SE & MxE & ME & $E>3$ & $E>2$ & v \\
\hline \multicolumn{13}{|l|}{ A } \\
\hline MATCOSW & 2.01 & 10.5 & 1.32 & 13 & 28 & -9 & 2.55 & 5.0 & 2.03 & 8 & 10 & -9 \\
\hline MATCOSUW & 2.91 & 12.0 & 2.43 & 48 & 83 & -10 & 3.06 & 7.9 & 2.73 & 12 & 16 & -10 \\
\hline MATCHI2IDW & 1.61 & 10.2 & 0.92 & 6 & 13 & 5 & 1.99 & 4.5 & 1.56 & 2 & 9 & -2 \\
\hline MATCHI2UW & 1.63 & 9.0 & 1.05 & 7 & 17 & 3 & 1.72 & 3.7 & 1.33 & 3 & 7 & 3 \\
\hline MATEUCIDW & 1.98 & 10.2 & 1.30 & 13 & 28 & -9 & 2.51 & 5.0 & 2.12 & 9 & 13 & -10 \\
\hline MATEUCUW & 1.98 & 10.2 & 1.30 & 13 & 28 & -9 & 2.51 & 5.0 & 2.12 & 9 & 13 & -10 \\
\hline MATMANHIDW & 1.79 & 10.9 & 1.00 & 11 & 19 & -5 & 2.35 & 5.0 & 1.82 & 6 & 11 & -10 \\
\hline MATMANHUW & 1.85 & 10.6 & 1.17 & 7 & 26 & -4 & 2.51 & 5.0 & 2.12 & 9 & 13 & -10 \\
\hline MATSCH2IDW & 1.39 & 7.5 & 0.86 & 6 & 10 & 10 & 1.88 & 4.0 & 1.42 & 5 & 8 & -1 \\
\hline MATSCH2CSW & 1.57 & 8.5 & 0.99 & 6 & 11 & 7 & 1.58 & 3.6 & 1.20 & 0 & 2 & 10 \\
\hline MATSCH2UW & 1.56 & 8.2 & 0.98 & 7 & 18 & 5 & 1.58 & 3.6 & 1.20 & 2 & 7 & 5 \\
\hline MATSCH2W $<3$ & 1.54 & 8.0 & 1.09 & 8 & 20 & 2 & 1.77 & 4.2 & 1.40 & 3 & 5 & 3 \\
\hline $\begin{array}{l}\text { MATSCH } 2 \text { W }<2 \\
\text { B }\end{array}$ & \multicolumn{8}{|c|}{ B } & 1.82 & 6 & 11 & -10 \\
\hline MATCOSW & 1.88 & 10.5 & 1.36 & 55 & 128 & -5 & 2.36 & 5.3 & 1.91 & 25 & 43 & -10 \\
\hline MATCHI2IDW & 1.43 & 10.7 & 0.88 & 25 & 53 & 7 & 1.70 & 4.5 & 1.38 & 5 & 27 & 2 \\
\hline MATCHI2UW & 1.50 & 10.3 & 1.02 & 28 & 78 & 1 & 1.57 & 3.8 & 1.24 & 9 & 25 & 4 \\
\hline MATEUCIDW & 1.72 & 10.8 & 1.11 & 46 & 91 & -2 & 2.00 & 5.4 & 1.53 & 13 & 33 & -8 \\
\hline MATMANHIDW & 1.59 & 10.9 & 1.00 & 34 & 84 & 0 & 1.94 & 5.0 & 1.52 & 12 & 28 & -6 \\
\hline MATSCH2IDW & 1.36 & 10.5 & 0.86 & 21 & 52 & 10 & 1.63 & 4.2 & 1.26 & 10 & 25 & 1 \\
\hline MATSCH2CSW & 1.43 & 10.0 & 0.97 & 24 & 75 & 3 & 1.48 & 3.7 & 1.18 & 7 & 21 & 9 \\
\hline MATSCH2UW & 1.64 & 10.6 & 1.57 & 75 & 179 & -4 & 1.47 & 3.8 & 1.17 & 7 & 23 & 8 \\
\hline
\end{tabular}

Abreviations

Indices and statistics: As for Table 3.

Techniques: MATCOS: cosine of the vector angle.- MATCHI2: squared $\chi^{2}$ distance.- MATEUC: Euclidean distance.- MATMANH: average Manhattan distance.- MATSCH2: squared chord distance. UW: unweighted average.- W: simple weighting.- IDW: inverse distance-squared weighting function.- CSW: chord similarity measure weighting.

Table 7. Evaluation of the variant of the modern analog technique. A: experiment 1a, calibration data set of 450 samples, analog set of 155 samples and no-analog set of 27 samples. B: collected errors of the estimate for experiments $1 \mathrm{a}, 1 \mathrm{~b}$, $1 \mathrm{c}$, and $1 \mathrm{~d}$.

a) More samples are acceptably well estimated with MATSCH2IDW and worse estimated with CORNR9 QUAD (63) than vice versa (22). Furthermore, the samples in the latter group do not present excessively large errors of the estimate with MATSCH2IDW.

b) Except for one, all samples that are badly estimated by both procedures (29) present errors of the estimate of the same sign.

c) The worst estimated samples tend to present similar errors of the estimate with the two procedures.

The conclusion is disappointing: agreement of the estimates with the two techniques does not guarantee accuracy. Unless it is not a case of bad estimates but rather one of defects in the calibration data set, as it will be shown below.

These aspects are also reflected in Figures 9A and B, which show the absolute values of the differences between the estimates of the two techniques and the absolute values of their errors of the estimate. Studying these values leads to the striking conclusion that a high difference is associated with an acceptable estimate with MATSCH2IDW, while a small difference, unfortunately, does not guarantee a small error of the estimate. This conclusion may also be derived from Figure 8 .

Regarding the relation between the dissolution of the samples and estimation errors, fifty of the hundred and eighty six samples examined by Kipp (1976) included in the calibration data set are core-tops with moderate to severe dissolution. Table 8 shows that both techniques, when applied to samples without dissolution, produce errors comparable to those of the calibration data set. The exception is CORN9QUAD $<3$, which works better with respect to errors of less than $-2{ }^{\circ} \mathrm{C}$. However, when they are applied to samples with dissolution, both techniques are worse, except, again, CORN9QUAD for errors of less than $-2{ }^{\circ} \mathrm{C}$. In any case, the number of samples with dissolution is clearly insufficient to draw definitive conclusions in this respect.

\section{NATURE OF THE ERRORS}

Figure 10 illustrates the location of the samples of the calibration data set which, after being estimated with the MATSCH2IDW techniques, present errors of more than $2{ }^{\circ} \mathrm{C}$ or less than $-2{ }^{\circ} \mathrm{C}$.

First of all, we should wonder if the incorporation of core-top data from various authors can be a source of anomalous estimates. But with the simplifications introduced in the taxonomic list, we think that errors with this origin are minimum. Firstly, because of the characteristics of the modern analog technique used, rare species in all the core-top samples should not be responsibles of the anomalies. Secondly, some anomalies are in core-top 

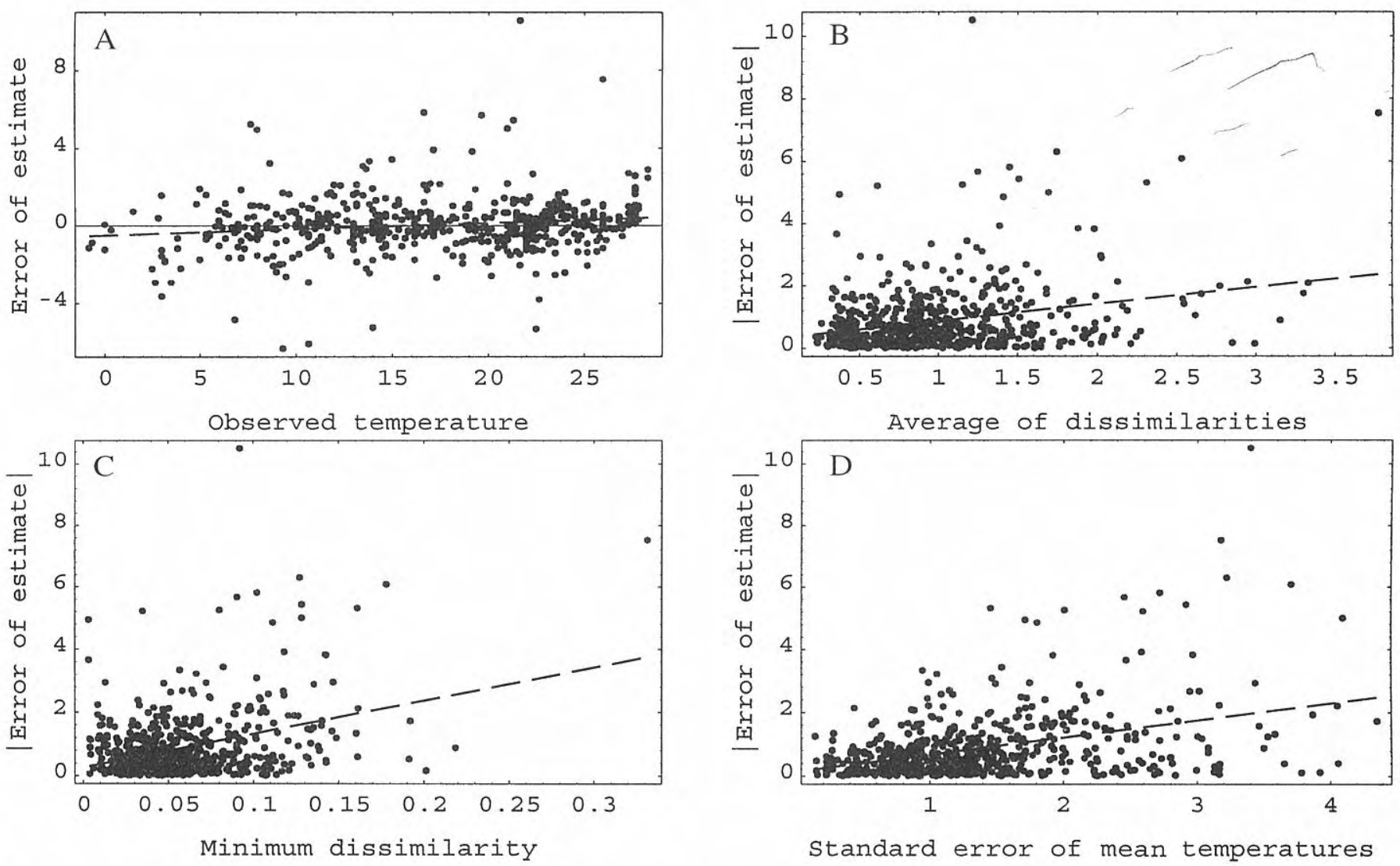

Figure 7. A) MATSCH2IDW modern analog technique. Plot of error of estimate (EE) vs. observed temperature (OT). EE=$0.518+0.1510 \mathrm{OT} ; \mathrm{r}=0.162 ; \mathrm{t}_{\text {constan }}=-3437, \mathrm{p}<0.001 ; \mathrm{t}_{\text {slope }}=4.026, \mathrm{p}<0.001$.

B) MATSCH2IDW modern analog technique. Plot of absolute value of error of estimate (IEEI) vs. average of dissimilarities (AD). $|E E|=0.320+5.405 \mathrm{AD} ; \mathrm{r}=0.266 ; \mathrm{t}_{\text {constant }}=3.567, \mathrm{p}<0.001 ; \mathrm{t}_{\text {slope }}=6.771, \mathrm{p}<0.001$.

C) MATSCH2IDW modern analog technique. Plot of absolute value of error of estimate (IEEI) vs. minimum dissimilarity (MD). $|E E|=0.253+10.559 \mathrm{MD} ; \mathrm{r}=0.364 ; \mathrm{t}_{\text {constant }}=3.384, \mathrm{p}=<0.001 ; \mathrm{t}_{\text {slope }}=9.602, \mathrm{p}<0.001$.

D) MATSCH2IDW modern analog technique. Plot of absolute value of error of estimate (IEEI) vs. standard error of the mean of the temperature of the modern analog subset $(\mathrm{SE}) .|\mathrm{EE}|=0.133+0.536 \mathrm{SE} ; \mathrm{r}=0.391 ; \mathrm{t}_{\text {constann }}=1.668$, $\mathrm{p}=0.096 ; \mathrm{t}_{\text {slope }}=10.431, \mathrm{p}<0.001$.

samples with anomalous percentages (with respect to sea surface temperature) of unmistakable species; as an example, let consider the strip of samples with negative errors mentioned in the next paragraph. Thirdly, anomalies due to different taxonomic conceptions of common species (like Gobigerina bulloides - G. falconesis or Neogloboquadrina pachyderma - N. dutertrei) could be very possible if all the samples of the same author from a region have got the same kind of anomaly (positive or negative), but this is not so. For example, in front of the coast of Africa, between $16^{\circ} \mathrm{N}$ and $25^{\circ} \mathrm{N}$, there are 16 samples, 6 from Kipp and 10 from Pujol; from them, 5 have got anomalies, all positive, 2 from Kipp and 3 from Pujol.

The first point that strikes the attention is a strip of samples with negative errors extending along the North American coastline and continues past Greenland and Iceland as far as Spitzbergen. The reason why the technique estimates, in these cases, higher temperatures than the observed ones does not seem to lie in the slight overestimation at low temperatures noted previously. It is obvious that some species are present in percentages that are higher or lower than those to be expected for the observed temperatures, and seem more appropriate to warmer waters. Thus, between latitudes $38^{\circ} \mathrm{N}$ and $50^{\circ} \mathrm{N}$, the samples with errors of less than $-2{ }^{\circ} \mathrm{C}$ have percentages of Globorotalia inflata and/or Globigerinoides ruber and/or Globorotalia cultrata that are higher than expected. To the $\mathrm{N}$ of parallel $50^{\circ} \mathrm{N}$, the badly estimated samples have low percentages of left-coiling $N$. pachyderma and/or high percentages of right-coiling $N$. pachyderma and/or Globigerinita glutinata. The samples with negative errors that are situated to the $\mathrm{S}$ of parallel $38^{\circ} \mathrm{N}$ do not present any clearly anomalous percentage, but all the species are close to the limits.

A second strip of positive errors, less clearly defined than the former, extends from the Iberian Peninsula to Cape Verde. The cause of the estimation errors is just the opposite to that of the former case: species with optimum temperatures of lower than $15^{\circ}$ (Turborotalita quinqueloba, right-coiling $N$. pachyderma, G. bulloides and $G$. inflata) are present in percentages that may be termed high or very high for the observed temperatures and $G$. ruber, a species which is abundant at above a 


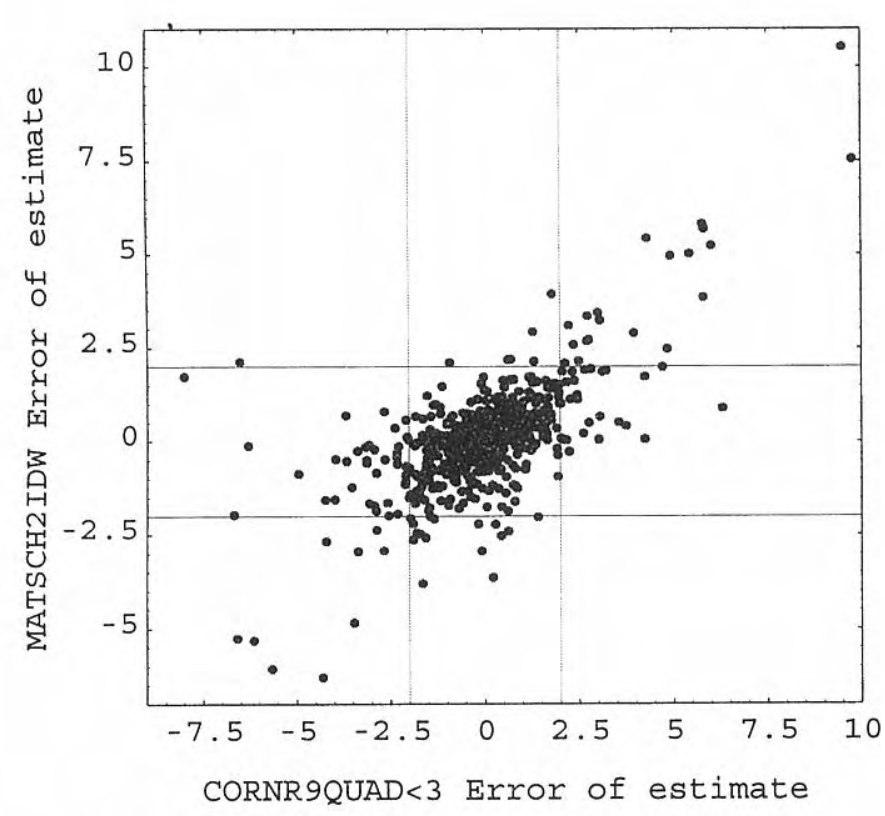

Figure 8. Comparison of errors of estimate of MATSCH2IDW and CORNR9QUAD $<3$.

winter temperature of $15^{\circ}$, has low or very low percentages.

Another group of samples is located to the $\mathrm{S}$ of the above-mentioned ones and is characterized by negative errors. Among these samples, the percentages of $N$. dutertrei and/or G. cultrata and/or Globorotalia tumida and/or Globigerinoides trilobus are high or very high with respect to the normal levels for the observed temperatures. On the other hand, the percentages of $G$. ruber are low or very low in all the samples.

The erroneous estimates are thus justified, but the anomalous percentages remain to be explained. It is always possible to raise the possibility that the core-top sample is a fossil sample, or one with resedimentation, and in some cases a very high level of dissolution might be considered (for example, a sample from the latter group, with $84 \%$ of $G$. tumida ). However, given the

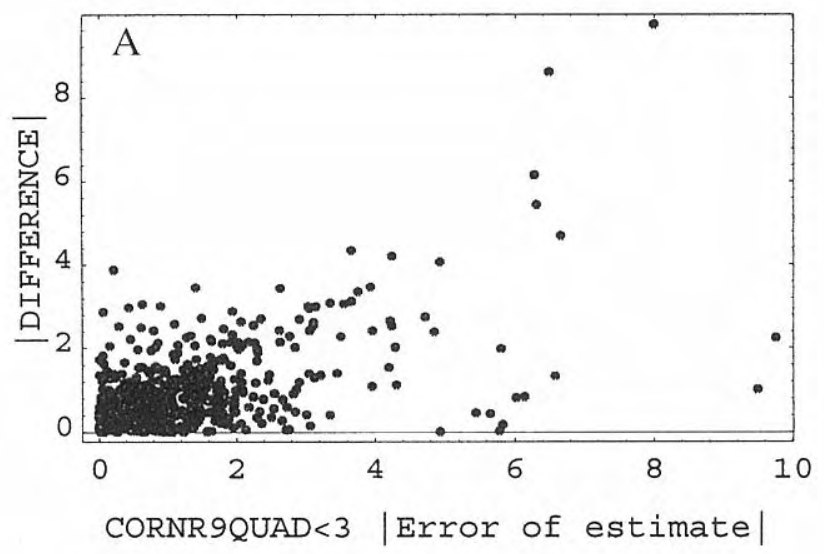

\begin{tabular}{|c|c|c|c|c|c|}
\hline & \multicolumn{3}{|c|}{ MATSCH2IDW } & \multicolumn{2}{|c|}{ CORNRQUAD $9<3$} \\
\hline & Ns & $\mathrm{E}>2^{\circ} \mathrm{C}$ & $E<-2^{\circ} \mathrm{C}$ & $\mathrm{E}>2^{\circ} \mathrm{C}$ & $\mathrm{E}<-2^{\circ} \mathrm{C}$ \\
\hline $\begin{array}{l}\text { Calibration data set } \\
\text { Samples of Kipp (1976 }\end{array}$ & $\begin{array}{l}605 \\
6)\end{array}$ & 0 & 4 & $7.6 \%$ & $7.8 \%$ \\
\hline $\begin{array}{l}\text { without dissolution } \\
\text { with dissolution }\end{array}$ & $\begin{array}{r}136 \\
50\end{array}$ & $\begin{array}{r}3.7 \% \\
10.0 \%\end{array}$ & $\begin{array}{l}4.4 \% \\
6.0 \%\end{array}$ & $\begin{array}{r}7.4 \% \\
14.0 \%\end{array}$ & $\begin{array}{l}3.7 \% \\
2.0 \%\end{array}$ \\
\hline
\end{tabular}

Abbreviations: As for Tables 2 and 7; Ns: number of samples. $\mathrm{E}>2^{\circ} \mathrm{C}$ : error of the estimate exceeding $2^{\circ} \mathrm{C}$. E<-2 ${ }^{\circ} \mathrm{C}$ : error of the estimate less than $2^{\circ} \mathrm{C}$.

Table 8: Relation between dissolution of the samples and errors of the estimate.

geographical distribution of the errors, a global explanation could be sought in the general circulation of the Atlantic waters. Thus, the associations of samples with negative errors from the W Atlantic could have been swollen with relatively warm water fauna carried towards more cool waters by the Gulf - North Atlantic Norwegian current system. The positive errors of the E Atlantic as far as Cape Verde are related to a southerly migration of fauna from relatively cool water, caused by the Azores - Canaries current system (Cifelli and Beniér,1976). Finally, the third group of anomalies could be the result of the Equatorial countercurrent.

Obviously, not all the badly estimated samples can be explained in terms of the general Atlantic circulation. The positive errors of a group of samples located in and to the W of the Gulf of Guinea are the result of having used the seasonal winter instead of the calorific: to the $\mathrm{S}$ of a line from the Grain Coast (Liberia) to the mouth of the Amazon, the temperature of the sea surface is higher in February than in August. The errors of these samples disappear if the observed winter temperatures are substituted by those of the seasonal summer in the region.

Other samples, with cooler estimated temperatures than those observed, could be, in fact, samples of materials deposited during a glacial period. Such might be the case of two samples situated near the Faeroe Islands (marked with the letter $f$ in the map in Fig. 10).

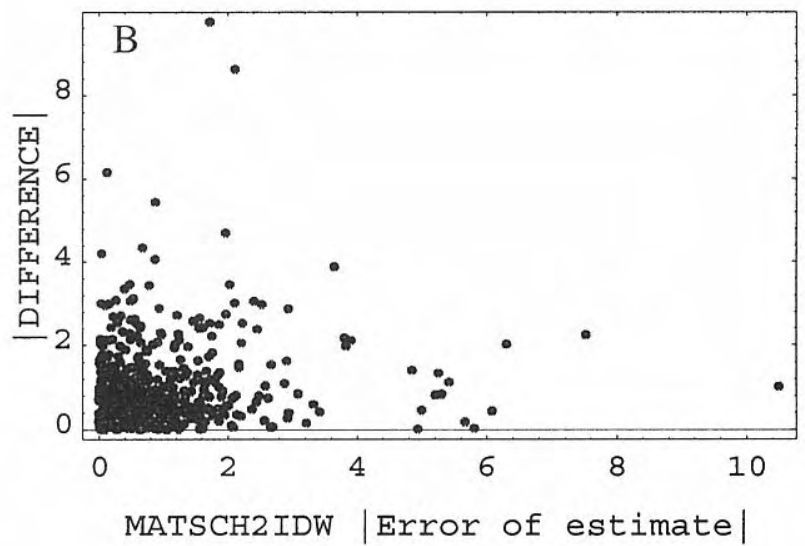

Figure 9. A) Plot of absolute value of the difference between estimate of MATSCH2IDW and CORNR9QUAD $<3$ vs. absolute value of the error of estimate of CORNR9QUAD $<3$.

B) Plot of absolute value of the difference between estimate of MATSCH2IDW and CORNR9QUAD $<3$ vs. absolute value of the error of estimate of MATSCH2IDW. 


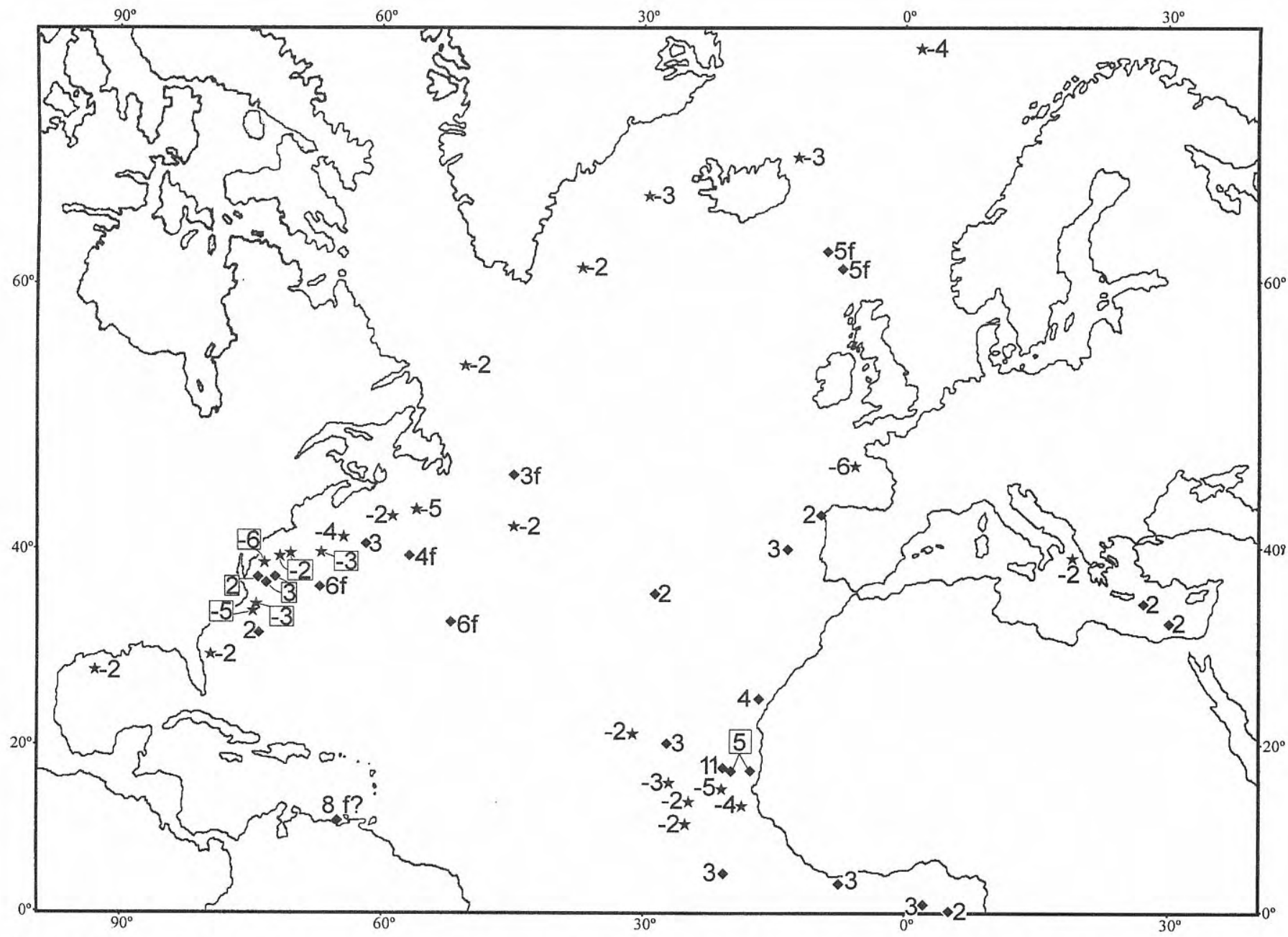

Figure 10. Location of samples with error of estimate $>2$ (diamond) or <-2 (star); f: supposed fossil -glacial- assemblages.

Four samples with positive errors, located off the east coast of North America, grouped around parallel $37^{\circ} \mathrm{N}$, present relatively high percentages of right-coiling $N$. pachyderma and very low ones of $G$. ruber. If these are not also fossil samples then it is necessary to consider an environmental factor other than temperature.

Finally, there exist samples for which there is no clear explanation for the inaccuracy of the estimate. In such cases, the error must be ascribed to the non compliance with one or various of the assumptions implicit in the modern analog technique, and the solution to this could perhaps lie in an improvement of the calibration set. But that is another problem.

\section{CONCLUSIONS}

All the following conclusions have been derived from the calibration data set employed. However, we wish to stress the fact that these may be invalidated, either totally or partially, if the calibration data set is obtained from a different ocean or hemisphere, or from another environmental regime or if a different group of organisms or environmental variable is used.

1. In the case of transfer functions, and especially of those based on a nonlinear equation of the second degree, the multiple correlation coefficient and the standard error of the estimate of the calibration data set, which are normally used to estimate the accuracy of the transfer functions, do not enable the results to be predicted when those transfer functions are applied to samples that are not included in the set.

2. Among the transfer functions analysed, the best results correspond to variants of the principal components regression technique based on R-mode analysis (and not on the normally employed Q-mode analysis). For samples of analog conditions, the best function is that based on the nonlinear equation of the second degree of the first nine non rotated principal components of the correlation matrix (CORNR9QUAD). For samples of no-analog conditions, the best function is that based on the linear equation of the first six non rotated principal components of the variance - covariance matrix (VCVNR6LIN).

3. The transfer functions, recalculated after eliminating from the calibration data set the samples with high errors of the estimate, provide slightly better results for some indices and statistics when applied to analog set.

4. Results are not improved by the division of the calibration data set into a series of subgroups, determined 
by the composition of the assemblages, and working with the transfer function of each subgroup.

5 . The greatest errors of the estimate do not correspond to outliers (low communalities in Q mode, high $\mathrm{T}^{2}$ values in $\mathrm{R}$ mode).

6. The best transfer function tends (very slightly) to overestimate at low temperatures and to underestimate at high temperatures.

7. In the case of the modern analog techniques, the best results correspond to the dissimilarity coefficient of the squared chord distance. For samples of analog conditions, the best results are obtained by applying an inverse distance squared weighting function. For samples of no-analog conditions, weighting with the chord similarity measure produces the best results.

8. If the samples with high errors of the estimate are eliminated from the calibration data set, the results of the modern analog technique are worsened.

9. The best modern analog technique tends (as does the best transfer function, and also to a very slight extent) to overestimate at low temperatures and to underestimate at high temperatures.

10. The values of the dissimilarity coefficient for the subset of the most analogous samples do not enable us to predict the magnitude of the error of the estimate. On the other hand, a low value of the standard error of the mean of the temperatures of the subset of most analogous samples does enable the prediction of a low error of the estimate.

11. For most of the indices and statistics analysed, the best modern analog technique produces better results than the best transfer function.

12. An agreement of the estimates produced by the two techniques is not a guarantee that such estimates are accurate. In the case of large differences between the estimates, that performed by the modern analog technique tends to be better.

13. Most of the errors committed by the modern analog technique correspond to samples with anomalous associations for the temperatures observed. Part of such anomalous associations could be the result of faunal migration caused by the general system of oceanic currents. Others might not really be anomalous associations but rather fossil associations or the result of stratigraphic mixing. Others, too, could derive from local ecological or taphonomic conditions. Finally, the errors observed for some samples, situated to the $S$ of the winter thermal inversion, are the consequence of having used the seasonal winter rather than the calorific.

\section{ACKNOWLEDGEMENTS}

We wish to thank Dr. H.J. Dowsett and the two anonymous referees who examine the manuscript for the useful suggestions and constructive criticism. We also thank Drs. Thunell, Loubere and Brunner, who kindly provided us with the listings of the planktonic foraminifera abundances in the samples mentioned in their respective papers and Glen Harding for translating the original manuscript into English.
This research was carried out under the auspices of project PB90-0797 of the DGCYT.

\section{REFERENCES}

Balsam, W.L. and Flessa, K.W. 1978. Patterns of planktonic foraminiferal abundance and diversity in surface sediments of the western North Atlantic. Marine Micropaleontology, 3, 279-294.

Berger, W.H. 1969. Ecologic patterns of living planktonic foraminifera. Deep-sea Research, 16, 1-24.

Berger, W.H. and Gardner, J.V. 1975. On the determination of Pleistocene temperatures from planktonic foraminifera. Journal of Foraminiferal Research, 5, 102-113.

Birks, H.J.B., Line, J.M., Juggins, S., Stevenson, A.C. and terBraak, C.J.F. 1990. Diatoms and $\mathrm{pH}$ reconstruction. Philosophical Transactions of the Royal Society of London, B 327, 263-278.

Brunner, Ch. A. 1979. Distribution of planktonic foraminifera in surface sediments of the Gulf of Mexico. Micropaleontology, 25, 325-335.

Cifelli, R. 1971. On the temperature relationship of planktonic foraminifera. Journal of Foraminiferal Research, 1, 170-177.

Cifelli, R. and Beniér, C.S. 1976. Planktonic foraminifera from near the West African coast and a consideration of faunal parcelling en the North Atlantic. Journal of Foraminiferal Research, 6, 258-273.

CLIMAP Project Members. 1976. The surface of the IceAge Earth. Science, 191, 131-137.

Davis, J.C. 1986. Statistics and data analysis in Geology. Second Edition. J.Wiley \& Sons, New York, 644 pp.

Dowsett, H.J. 1991. The development of a long-range foraminifer tranfer function and application to Late Pleistocene North Atlantic climatic extremes. Paleoceanography, 6, 259-273.

Dowsett, H.J. and Poore, R.Z. 1990. A new planktic foraminifer transfer function for estimating PlioceneHolocene paleoeceanographic conditions in the North Atlantic. Marine Micropaleontology, 16, 1-23.

Gardner, J.V. and Hays, J.D. 1976. Responses of sea-surface temperature and circulation to global climatic change during the past 200.000 years in the eastern equatorial Atlantic Ocean. In: Investigation of Late Quaternary Paleoceanography and Paleoclimatology (Eds. R.M. Cline \& J.D. Hays). Geological Society of America, Boulder, 221-246.

Gorshkov, S.G. (Ed.). 1978. World Ocean Atlas. Volume 2. Atlantic and Indian Ocean. Pergamon Press, Oxford, pp. 1-305.

Hecht, A.D. 1973. A model for determining Pleistocene paleotemperatures from planktonic foraminiferal assemblages. Micropaleontology, 19, 68-77.

Hutson, W.H. 1977. Transfer functions under no-analog conditions, Experiments with Indian Ocean planktonic foraminifera. Quaternary Research, 8, 355-367.

Hutson, W.H. 1978. Application of transfer functions to Indian Ocean planktonic foraminifera. Quaternary Research, 9, 87-112. 
Hutson, W.H. 1980. The Agulhas Current during the Late Pleistocene, analysis of modern faunal analogs. Science, 207, 64-66.

Hutson, W.H. and Prell, W.L. 1980. A paleoeological transfer function, FI-2, for Indian Ocean planktonic foraminifera. Journal of Paleontology, 54, 381-399.

Imbrie, J. and Kipp, N.G. 1971. A new micropaleontological method for quantitative paleoclimatology, Application to a late Pleistocene Caribbean core. In: The Late Cenozoic Glacial Ages (Ed. K.K. Turekian). Yale University Press, New Haven, 71- 131.

Imbrie, J. and Webb II, T. 1981. Transfer function, calibrating micropaleontological data in climatic tems. In: Climatic variations and variability, facts and theories (Ed. A. Berger). D. Reidel, Dordrecht, 125-134.

Imbrie, J., Donk, J. van and Kipp, N.G. 1973. Paleoclimatic investigation of late Pleistocene Caribbean deep-sea cores, Comparison of isotopic and faunal methods. Quaternary Research, 3, 10-38.

Kellogg, T.B. 1976. Late Quaternary climatic changes, Evidence from deep-sea cores of Norwegian and Greenland Seas. In: Investigation of Late Quaternary Paleoceanography and Paleoclimatology (Eds. R.M. Cline \& J.D. Hays). Geological Society of America, Boulder, 77-110.

Kipp, N.G. 1976. New transfer function for estimating past sea-surface conditions from sea- bed distribution of planktonic foraminifera assemblages in the North Atlantic. In: Investigation of Late Quaternary Paleoceanography and Paleoclimatology (Eds. R.M. Cline \& J.D. Hays). Geological Society of America, Boulder, 3-41.

Klovan, J.E. and Imbrie, J. 1971. An algorithm and FortranIV program for large scale Q-mode factor analysis and calculation of factor scores. Mathematical Geology, 3, 61-67.

Le, J. 1992. Paleotemperature estimation methods, Sensitivity test on two western equatorial Pacific cores. Quaternary Science Review, 11, 801-820.

Le, J. and Thunell, R.C. 1996. Modelling planktic foraminiferal assemblage changes and application to sea surface temperature estimation in the western equatorial Pacific Ocean. Marine Micropaleontology, 28, 211-229.

Loubere, P. 1981. Oceanographic parameters reflected in the seabed distribution of planktonic foraminifera from the North Atlantic and Mediterranean Sea. Journal of Foraminiferal Research, 11, 137-158.

Maslin, M.A., Shackleton, N.J. and Pflaumann, U. 1995. Surface waters temperature, salinity, and density changes in the northeast Atlantic during the last 45,000 years: Heinrich events, deep water formation and climatic rebounds. Paleoceanography, 10, 527-544.

Miao, Q., Thunell, R.C. and Anderson, D.A. 1994. GlacialHolocene carbonate dissolution and sea surface temperatures in the South China and Sulu seas. Paleoceanography, 9, 269-290.

Molina-Cruz, A. and Thiede, J. 1978. The glacial eastern boundary current along the Atlantic Eurafrican continental margin. Deep-Sea Research, 25, 337-356.

Molfino, B., Kipp, N.G. and Morley, J.J. 1982. Comparison of foraminiferal, coccolithophorid, and radiolarian paleotemperature equations, assemblage coherency and estimate concordancy. Quaternary Research, 17, 279313.

Overpeck, J.T., Webb III, T. and Prentice, I.C. 1985. Quantitative interpretation of fossil pollen spectra, dissimilarity coefficients and the method of modern analog. Quaternary Research, 23, 87-108.

Pflaumann, U., Duprat, J., Pujol, C. and Labeyrie, L.D. 1996. SIMMAX, A modern analog technique to deduce Atlantic sea surface temperatures from planktonic foraminifera in deep-sea sediments. Paleoceanography, 11, 15-35.

Prell, W.L. 1985. The stability of low latitude sea surface temperatures, An evaluation of the CLIMAP reconstruction with emphasis on the positive SST anomalies. Technical Report TR025, Department of Energy. Washington D.C, 60 pp.

Pujol, C. 1980. Les foraminiferes planctoniques de l'Atlantique Nord au Quaternaire. Ecologie-Stratigraphie-Environnement. Mémoires de l'Institut de Géologie du Bassin d'Aquitaine, 10, 1-254.

Rohlf, F.J. 1993. NTSYS-pc. Numerical taxonomy and multivariate analysis system. Version 1.80. Exeter Software, New York.

Sachs, H.M., Webb III, T. and Clark, D.R. 1977. Paleoeological transfer functions. Annals Review of Earth and Planetary Sciences, 5, 159-178.

Thompson, P.R. 1976. Planktonic foraminiferal dissolution and the progress towards a Pleistocene equatorial Pacific transfer function. Journal of Foraminiferal Research, 6 , 208-227.

Thompson, P.R. 1981. Planktonic foraminifera in the western North Pacific during the past 150000 years: comparison of modern and fossil assemblages. Palaeogeography, Palaeoclimatology, Palaeoecology, 35, 241-279.

Thunell, R.C. 1978. Distribution of recent planktonic foraminifera in surface sediments of the Mediterranean Sea. Marine Micropaleontology, 3, 147-173.

Thunell, R.C. 1979. Pliocene-Pleistocene paleotemperature and paleosalinity history of the Mediterranean Sea, results from DSDP site 125 and 132. Marine Micropaleontology, 4, 173-187.

Williams, D.F. and Johnson, W.C. 1975. Diversity of Recent planktonic foraminifera in the southern Indian Ocean and Late Pleistocene paleotemperatures. Quaternary Research, 5, 237- 250. 